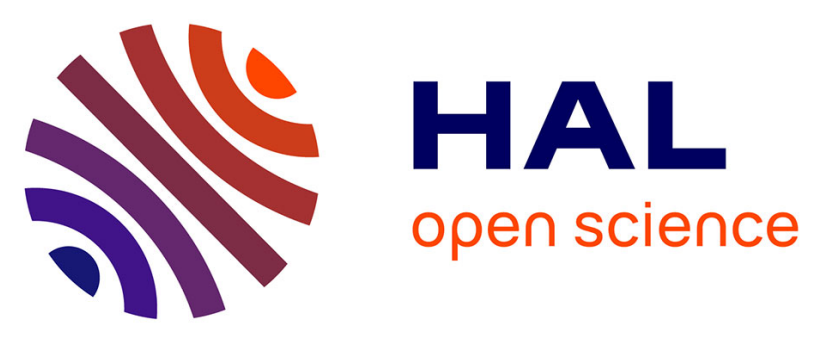

\title{
Importance of explicit smeared lone-pairs in anisotropic polarizable molecular mechanics. Torture track angular tests for exchange-repulsion and charge transfer contributions
}

\author{
Léa El Khoury, Sehr Naseem-Khan, Karolina Kwapien, Zeina El Hobaika, \\ Richard El Maroun, Jean-Philip Piquemal, Nohad Gresh
}

\section{To cite this version:}

Léa El Khoury, Sehr Naseem-Khan, Karolina Kwapien, Zeina El Hobaika, Richard El Maroun, et al.. Importance of explicit smeared lone-pairs in anisotropic polarizable molecular mechanics. Torture track angular tests for exchange-repulsion and charge transfer contributions. Journal of Computational Chemistry, 2017, 121, pp.3997 - 1920. 10.1021/acs.jpcb.7b01836 . hal-01571959

\author{
HAL Id: hal-01571959 \\ https://hal.science/hal-01571959
}

Submitted on 4 Aug 2017

HAL is a multi-disciplinary open access archive for the deposit and dissemination of scientific research documents, whether they are published or not. The documents may come from teaching and research institutions in France or abroad, or from public or private research centers.
L'archive ouverte pluridisciplinaire HAL, est destinée au dépôt et à la diffusion de documents scientifiques de niveau recherche, publiés ou non, émanant des établissements d'enseignement et de recherche français ou étrangers, des laboratoires publics ou privés. 


\section{Importance of explicit smeared lone-pairs in anisotropic polarizable molecular mechanics. Torture track angular tests for exchange-repulsion and charge transfer contributions.}

Léa El Khoury, ${ }^{1,2}$ Sehr Naseem-Khan, ${ }^{1}$ Karolina Kwapien, ${ }^{3,4}$ Zeina Hobaika, ${ }^{2}$ Richard Maroun, ${ }^{2}$ Jean-Philip Piquemal, ${ }^{1,5,6^{*}}$ Nohad Gresh ${ }^{1 *}$

${ }^{1}$ Laboratoire de Chimie Théorique, Sorbonne Universités, UPMC, UMR7616 CNRS, Paris, France

${ }^{2}$ Centre d'Analyses et de Recherche, UR EGFEM, LSIM, Faculté des Sciences, Saint Joseph University of Beirut, BP 11-514, Riad El Solh, Beirut 1116-2050, Lebanon

${ }^{3}$ Chemistry and Biology, Nucleo(s)tides and Immunology for Therapy (CBNIT), UMR 8601 CNRS, UFR Biomédicale, Paris, France

${ }^{4}$ Institut Charles-Gerhardt, UMR 5253, CNRS-UM2-UM1-ENSM, Montpellier, France

${ }^{5}$ Institut Universitaire de France, Paris Cedex 05, 75231, France

${ }^{6}$ Department of Biomedical Engineering, The University of Texas at Austin, Austin, Texas 78712, United States

Contact authors: nohad.gresh@1ct.jussieu.fr (NG), jpp@1ct.jussieu.fr (JPP)

Summary. A correct representation of the short-range contributions such as exchange-repulsion ( $\left.E_{\text {rep}}\right)$ and charge-transfer $\left(E_{c t}\right)$ is essential for the soundness of separable, anisotropic polarizable molecular mechanics potentials. Within the context of the SIBFA procedure, this is aimed at by explicit representations of lone pairs in their expressions. It is necessary to account for their anisotropic behaviors upon performing not only in-plane, but also out-of-plane, variations of a probe molecule or cation interacting with a target molecule or molecular fragment. Thus, $E_{r e p}$ and $E_{c t}$ have to reproduce satisfactorily the corresponding anisotropies of their quantum chemical (QC) counterparts. A significant improvement of the out-of-plane dependencies was enabled when the $\mathrm{sp}^{2}$ and sp localized lone-pairs are, even though to a limited extent, delocalized on both sides of the plane, above and below the atom bearer but at the closely similar angles as the in-plane lone pair. We report calibration and validation tests on a series of monoligated complexes of a probe $\mathrm{Zn}(\mathrm{II})$ cation with several biochemicallyrelevant ligands. Validations are then performed on several polyligated $\mathrm{Zn}$ (II) complexes found in the recognition sites of Zn-metalloproteins. Such calibrations and validations are extended to representative monoand polyligated complexes of $\mathrm{Mg}(\mathrm{II})$ and $\mathrm{Ca}(\mathrm{II})$. It is emphasized that the calibration of all three cations was for each $\Delta \mathrm{E}$ contribution done on a small training set bearing on a limited number of representative $\mathrm{N}-$, $\mathrm{O}-$, and $\mathrm{S}$ mono-ligated complexes. Owing to the separable nature of $\Delta \mathrm{E}$, a secure transferability is enabled to a diversity 
of polyligated complexes. For these the relative errors with respect to the target $\Delta \mathrm{E}(\mathrm{QC})$ values are generally $<$ $3 \%$. Overall the paper proposes a full set of benchmarks that could be useful for force field developers. 


\section{Introduction.}

Anisotropic, polarizable molecular mechanics/dynamics (APMM/APMD) are an appealing alternative to QM/MM calculations for large-scale ligand-macromolecule simulations. Their reliability could be ensured if they enabled to compute the intermolecular interaction energies $(\Delta \mathrm{E})$ in the QM recognition site with an accuracy that would match that of quantum chemistry (QC) on which they are grounded. This can be particularly critical regarding the recognition sites of metalloproteins, ${ }^{[1]}$ in which large polarization and charge-transfer effects come into play. In such sites, furthermore, the binding of the cation(s) to some conjugated ligands such as imidazole, formamide or formate, can occur out of the ligand plane. Out-of-plane binding, with $\phi$ values of up to $45^{\circ}$, has been observed in some metal binding sites, by both X-ray crystallography and QC optimizations. This can be necessary to enable the cation to optimize its simultaneous interactions with all its ligands, since the latter have limited freedom due to their anchoring to the protein main-chain. It is thus necessary to accordingly account for the $\Delta \mathrm{E}$ dependencies upon out-of-plane, and not only in-plane, cation binding.

The present work is along the continued enrichments and refinements of the SIBFA procedure. ${ }^{[2-4]}$ Most of the previous validation studies had resorted to the CEP 4-31G(2d) basis set, ${ }^{[5]}$ the reliability of which could be shown from parallel $\Delta \mathrm{E}$ computations with much more extended basis sets, ${ }^{[4]}$ and Refs. therein. We have subsequently reconstructed a library of fragments with distributed multipoles and polarizabilities derived from QC calculations with the aug-cc-pVTZ(-f) basis set. ${ }^{[6]}$ The procedure was calibrated, ${ }^{[7]}$ using the I-NoLLS ${ }^{[8]}$ procedure and used to study the complexes of the alkali cations $\left(\mathrm{Li}^{+}--\mathrm{Cs}^{+}\right),{ }^{[9]}$ and the intermolecular interactions of the guanine and cytosine bases. ${ }^{[10]}$ Its extensions to divalent cations $\mathrm{Zn}(\mathrm{II}), \mathrm{Mg}(\mathrm{II})$ and $\mathrm{Ca}(\mathrm{II})$ are reported in the present paper. We consider first the monoligated complexes of $\mathrm{Zn}(\mathrm{II})$ with O-, N-, and S-containing ligands. At the optimized cation-ligand distances, we investigate both in- and out-of-plane angular variations. For ligands having localized sp lone-pairs, such as imidazole, or $\mathrm{sp}^{2}$ lone-pairs, such as formamide or formate, out-of-plane variations uncovered a shortcoming in $\mathrm{E}_{\text {rep. }}$ That is, it underwent a regular decrease until the $\phi$ angle came close to $90^{\circ}$, namely upon entering the zone of the $\pi$ lone-pairs. By contrast, the QC exchange-repulsion contribution, $E_{X}$, had limited amplitudes of variations. Thus, even though the overall value of $\Delta \mathrm{E}$ favors in-plane binding, the relative destabilization of out-of-plane binding is not sufficient. This could have adverse consequences in MD simulations, in which the poses are populated as a function of the Boltzmann factor. We have found that a very simple, yet efficient, improvement of $\mathrm{E}_{\text {rep }}$ was obtained upon 'smearing' the $\mathrm{sp}$ and $\mathrm{sp}^{2}$ lone pairs on both sides of the atom-bearer plane (Figure 1). That is, the in-plane occupation number of 2 is reduced to a value, $\alpha$, in the range 1.50-1.68, and two additional, out-of-plane, lone-pairs have each half the (2- $\alpha)$ difference. Owing to the separable nature of the SIBFA intermolecular interaction energy, all comparisons with QC will be done by energy-decomposition analyses (EDA), enabling to compare each SIBFA contribution to its QC counterpart regarding non-isotropy in monoligated complexes and non-additivity in polyligated complexes. Because of the 
proof-of-principle nature of the present study, we focus on results from Reduced Variational Space (RVS) Energy Decomposition Analyses (EDA), ${ }^{[1]}$ limited to the Hartree-Fock level, but enabling an operational resolution of $\Delta \mathrm{E}$ into Coulomb $\left(\mathrm{E}_{\mathrm{C}}\right)$ and exchange-repulsion $\left(\mathrm{E}_{\mathrm{X}}\right)$ in first-order, and polarization $\left(\mathrm{E}_{\mathrm{pol}}\right)$ and charge-transfer $\left(\mathrm{E}_{\mathrm{ct}}\right)$ in second-order. Extensions to correlated QC calculations are underway in the context of the SAPT energy decomposition analysis and will be reported separately.

The organization of the paper is as follows. In the Methods section, we shortly recall the leading formulas of $E_{\text {rep }}$ and $\mathrm{E}_{\mathrm{ct}}$, and the manner the $\mathrm{sp}$ and $\mathrm{sp}^{2}$ lone-pairs are 'smeared' and probed by an incoming dicationic probe. We next investigate in succession the mono- and polyligated complexes of three divalent metals of upmost importance in all chemistry fields: a 'soft' transition metal, $\mathrm{Zn}(\mathrm{II})$, and two hard' alkali-metal cations, $\mathrm{Mg}(\mathrm{II})$ and $\mathrm{Ca}(\mathrm{II})$.

Monoligated complexes. All selected ligands are encountered as side-chains of proteins, and one (hydroxamate) as a metal-binding moiety of metalloprotein inhibitors. Their complexes with all three divalent cations are first investigated regarding the radial dependencies of $\Delta \mathrm{E}$ and its individual contributions. In- and out- of plane dependencies are next investigated for one cation, $\mathrm{Zn}(\mathrm{II})$, and its complexes with conjugated ligands embodying smeared sp or $\mathrm{sp}^{2}$ lone-pairs, namely: formate, formamide, imidazole and hydroxamate. We specify in the Tables which complexes were used for the calibration.

Polyligated complexes. All polyligated complexes were subsequently considered to validate the procedure. The $\mathrm{Zn}$ (II) complexes were considered first, with four up to six identical ligands, then with mixed ligands, in arrangements encountered in $\mathrm{Zn}$-metalloprotein binding sites. For $\mathrm{Mg}(\mathrm{II})$, three same complexes are considered as with $\mathrm{Zn}(\mathrm{II})$, namely those with four and six water molecules, and the one with four imidazoles. This enables to quantify how $\mathrm{Zn}$ (II) 'softness' versus $\mathrm{Mg}$ (II) 'hardness' are translated in terms of the individual $\Delta \mathrm{E}(\mathrm{QC}) / \Delta \mathrm{E}(\mathrm{SIBFA})$ contributions. A bimetallic $\mathrm{Mg}(\mathrm{II})$ binding site is next considered, extracted from the HIV1 integrase. For $\mathrm{Ca}(\mathrm{II})$, which can have coordination numbers in the 6-8 range, three different octahydrate arrangements were considered. This was followed by the study of a $\mathrm{Ca}$ (II) polyligated complex with three formate anions, an extreme case of shielding of the dicationic charge.

Regarding the mono-ligated complexes, each ligand is thus probed in a diversity of in- and out-of-plane positions. Considering extreme cases should enable to unravel possible artefacts of the energy potential away from equilibrium, such as in 'vertical' approaches of the probe to the ligand plane, deliberately shortened theta angles, etc. Regarding the polyligated complexes, a diversity of cases is considered, embodying 'hard' as well as 'soft' ligands, while the total charge of the ligands can range from 0 to -3 . This should also stretch the possibilities of the potential to reveal possible artefacts, notably regarding non-additivity. This has led us to adopt the somewhat unconventional term 'torture track' overall. 


\section{Methods.}

\section{1) SIBFA computations.}

In the SIBFA procedure, ${ }^{[4]}$ the intermolecular interaction energy is computed as the sum of five contributions: electrostatic multipolar $\left(\mathrm{E}_{\mathrm{MTP}}\right)$, short-range repulsion $\left(\mathrm{E}_{\mathrm{rep}}\right)$, polarization $\left(\mathrm{E}_{\mathrm{pol}}\right)$, charge transfer $\left(\mathrm{E}_{\mathrm{ct}}\right)$, and dispersion $\left(\mathrm{E}_{\mathrm{disp}}\right)$

$$
\Delta \mathrm{E}_{\mathrm{TOT}}=\mathrm{E}_{\mathrm{MTP}} *+\mathrm{E}_{\mathrm{rep}}+\mathrm{E}_{\mathrm{pol}}+\mathrm{E}_{\mathrm{ct}}+\mathrm{E}_{\mathrm{disp}}
$$

$\mathrm{E}_{\mathrm{MTP}}$ is computed with distributed multipoles (up to quadrupoles) derived from the QC molecular orbitals precomputed for each individual molecule. They were originally derived from a procedure due to Vigné-Maeder and Claverie ${ }^{[12]}$ and distributed on the atoms and bond barycenters. The anisotropic polarizabilities are distributed on the centroids of the localized orbitals (heteroatom lone pairs and bond barycenters) using a procedure due to Garmer and Stevens. ${ }^{[13]}$ The distributed multipoles are presently derived, for large basis sets, using the Generalized Multipole Analysis (GDMA) method by Stone. ${ }^{[14]} \mathrm{E}_{\mathrm{MTP}}$ is augmented with a penetration term. ${ }^{[15]}$

$E_{\text {rep }}$ and $E_{c t}$, the two short-range repulsions, are computed using representations of the molecular orbitals localized on the chemical bonds and on localized lone-pairs. ${ }^{[2-16]}$ The present work is along continued refinements of the representation of the lone pairs belonging to conjugated atoms which intervene in their expression.

At this stage we wish to recall the starting expressions for the formulation of these two contributions.

Thus $\mathrm{E}_{\mathrm{rep}}$ is expressed as a sum of bond-bond, bond-lone pair, and lone pair-lone pair interactions.

$E_{\text {rep }}=C_{1}\left(\sum_{A B} \sum_{C D} \operatorname{rep}(A B, C D)+\sum_{A B} \sum_{L \gamma} \operatorname{rep}(A B \cdot L \gamma)+\sum_{L a} \sum_{C D} \operatorname{rep}\left(L_{\alpha}, C D\right)+\sum_{L \alpha} \sum_{L \gamma} \operatorname{rep}\left(L_{\alpha}, I_{\gamma}\right)\right)$

$$
\operatorname{rep}(\mathrm{AB}, \mathrm{CD})=N_{\text {occ }}(\mathrm{AB}) N_{\text {occ }}(\mathrm{CD}) \mathrm{S}^{* * 2}(\mathrm{AB}, \mathrm{CD}) /\left(D_{\mathrm{AB}, \mathrm{CD}}\right)^{n}
$$

$\mathrm{AB}$ and $\mathrm{CD}$ denote the chemical bonds belonging to the interacting molecules $\mathrm{M}_{\mathrm{A}}$ and $\mathrm{M}_{\mathrm{B}}$, and $\mathrm{L}_{\alpha}$ and $\mathrm{L}_{\gamma}$ the lone pairs of $M_{A}$ and $M_{B} . N_{o c c}(A B)$ and $N_{o c c}\left(L_{\alpha}\right)$ denote the occupation numbers of bonds $A B$ and $C D$. The $S$ function is computed as sum of exponentials of the distance between the interacting atoms or lone pair bearers, modulated by coefficients taking into account their type of hybridization and an angular factor, depending upon the angle between the lone pair tip and the direction of approach of the interacting atom (see Refs. ${ }^{[16-18]}$ for details). The denominator $\mathrm{D}$ is the distance between the midpoints of the interacting bonds or lone pair bearers 
of MA and those of MB. Each the $\operatorname{rep}(A B, C D), \operatorname{rep}\left(L_{\alpha}, C D\right)$, and $\operatorname{rep}\left(L_{\alpha}, L_{\beta}\right)$ has two components corresponding to $n=1$ and 2 .

$E_{\text {ct }}$ is expressed as:

$E_{\mathrm{ct}}=-2 S_{\mathrm{M}} \sum_{\alpha} N_{\mathrm{occ}}(\alpha)\left(\left(I_{\alpha \mathrm{M}^{*}}\right)^{* * 2} / \Delta E_{\alpha \mathrm{M}^{*}}\right)$

It runs over all lone pairs of electron donating molecules $\mathrm{M}_{\mathrm{A}} . \mathrm{N}_{\mathrm{occ}}(\alpha)$ is the occupation number of lone pair $\mathrm{L}_{\alpha}$ belonging to atom $A, I_{\alpha M^{*}}$ is a function of the overlap between the electron donor, $L_{\alpha}$, and the anti-bonding orbital of the electron acceptor bond HX or metal cation M. It has dependencies upon the hybridization of $\mathrm{L}_{\alpha}$ and the angle centered at $\mathrm{A}$ between its direction and the $\mathrm{AX}, \mathrm{AH}$, or $\mathrm{AM}$ direction. The denominator is the difference between the ionization potential of $\mathrm{L}_{\alpha}$ and the electron affinity of the acceptor. Both $\mathrm{I}_{\alpha \mathrm{M}^{*}}$ and the denominator are modulated by the electrostatic potentials undergone by both the electron donor and the electron acceptor (see ${ }^{[3-4,19]}$ for details).

The actual location of the lone pairs has evolved in the course of the SIBFA refinements. On the one hand, those bearing an ' $\mathrm{s}$ ' character, namely $\mathrm{sp}^{3}, \mathrm{sp}^{2}$ and $\mathrm{sp}$ could be oriented along standard hybridization angles such as: for $\mathrm{sp}^{3}$ lp's, $\theta$ angles close to $109^{\circ} .5$ and $\phi$ angles close to $120^{\circ}$ and $240^{\circ}$; for $\mathrm{sp}^{2} \mathrm{lp}$ 's, $\theta$ angles of $120^{\circ}$ and $\phi$ angles of $0^{\circ}$ and $180^{\circ}$; for sp, a $\theta$ angle corresponding to the external bisector of the bearer. On the other hand, the actual distance to the bearer did evolve. Distances corresponding to those given by the Boys localization algorithm, ${ }^{[20]}$ as listed by the GAMESS software ${ }^{[21]}$ in the context of the Garmer and Stevens procedure were initially adopted. More recently, upon recalibration of the method with aug-cc-pVTZ multipoles and polarizabilities, we resorted to analyses ${ }^{[22-23]}$ given by the Electron Localization Function (ELF) ${ }^{[24-26]}$ giving longer distances of the centroid to the bearer. Thus, for water $\mathrm{O} \mathrm{sp}^{3}$ lone pairs, such a distance amounts to 0.59 $\AA$ instead of $0.295 \AA$ (Boys), etc. The location of the $\pi$ lone pairs on aromatic and conjugated fragments had evolved earlier. The initial implementations had them located at the vertical of the $\pi$ atom bearer and on both sides of the plane, at distances set to $0.5 \AA$. We were subsequently led to 'probe' the vertical of the conjugated planes of formate, formamide, imidazole, etc., with a $\mathrm{Zn}$ (II) cation (Figure 2) approaching each conjugated atom $(\mathrm{C}, \mathrm{N}$, or $\mathrm{O})$ and performing EDA to fit $\mathrm{E}_{\mathrm{rep}}$ in order to reproduce $\mathrm{E}_{\mathrm{X}}$ for a range of distances. A 'bent' representation of the lone pairs, with $\theta$ angles of $60^{\circ}$ and $120^{\circ}$ instead of $90^{\circ}$, such that each $\pi$ lone pair was actually 'shared' between the two atoms of the conjugated bond (Figure 1), enabled a better match to $E_{X}$ than a vertical representation. 's' containing lone pairs had occupation numbers of 2 . The $\pi$ lone pairs had occupation numbers enabling to complete the valencies of their bearers: 0.5 for each lone pair on conjugated C's on each side of the plane, as well as for $\mathrm{N}$ sp and $\mathrm{O} \mathrm{sp}^{2}$ atoms, 1.0 for conjugated $\mathrm{N}$ atoms connected to three bonds, etc.. ${ }^{[27]}$ More recently, we further elaborated on the representation of the $\pi$ lone pairs owing to their heavy 
involvement in stacking interactions, such as between nucleic acid bases. This led us to probe by EDA, using a $\mathrm{Mg}(\mathrm{II})$ cation or a water molecule, the vertical of each heavy atom of cytosine and guanine, and optimize the distance to the bearer, the increment of effective radii for $E_{\text {rep }}$ along the direction of the probed $\pi$ lone pair, as well as some occupation numbers. ${ }^{[10]}$ As mentioned in the Introduction, a shortcoming was identified upon monitoring the $\phi$ dependencies of $\mathrm{E}_{\text {rep }}$ and $\mathrm{E}_{\mathrm{ct}}$. We have thus considered the binding of a dicationic and of a water probe to a $\mathrm{sp}^{2} \mathrm{O}$ atom, such as in formamide or formate, or to a $\mathrm{sp} \mathrm{N}$ atom, such as in imidazole. While the $\theta$, inplane dependencies, of these two contributions matched closely those of their EDA counterparts, a progressive loss of their magnitudes took place upon performing at fixed $\theta$ out-of-plane variations until the probe reached the perpendicular. By contrast, such decreases did not take place in the case of $\mathrm{sp}^{3}$ lone-pairs. Regarding the latter, in an early investigation on the linear water dimer, we found that upon departing from the direction of one electron-donating $\mathrm{sp}^{3}$ lone pair, and upon moving the interacting $\mathrm{HO}$ bond of the electron-accepting water molecule towards the second electron-donating lone pair, the decrease of $E_{\text {rep }} / E_{c t}$ due to reduced overlap with the first was accompanied by a concomitant increase of their intensities due to improved overlap with the second. ${ }^{[2}$, 28]

The 'smearing' of the $\mathrm{sp}$ and $\mathrm{sp}^{2}$ lone pairs was also inspired by the results of ELF analyses. Thus upon decreasing the resolution requested, such lone pairs could be firstly singled out, and then coalesced with the $\pi$ lone pairs, an indication of partial delocalization. SIBFA resorts to discretized sites to compute $\mathrm{E}_{\text {rep }} / \mathrm{E}_{\mathrm{ct}}$. Smearing thus brings this procedure one step closer to the $\mathrm{GEM}^{[29]}$ and $\mathrm{S} / \mathrm{G} 1$ (SIBFA/GEM) ${ }^{[19]}$ procedures, which resort to continuous QC electronic densities to compute both first- and second-order contributions. The computational overhead is not penalizing, being anyway dominated in multimolecular complexes by the iterative computation of $E_{\mathrm{pol}}$. Thus, molecular fragments such as formamide and imidazole total eight and eleven lone pairs respectively. Smearing of the sp imidazole nitrogen and of the $\mathrm{sp}^{2}$ formamide oxygen adds up two additional lone pairs (Figures 1 a,d), whence a total of ten and thirteen lone pairs, respectively. For bond-lone pair interactions, the CPU time is increased by ratios of $10 / 8$ and 13/12, resp. For lone pair-lone pair interactions, of which there are $\mathrm{N}^{*}(\mathrm{~N}-1) / 2$, the increases are obviously larger, namely 1.42 and 1.60 , nevertheless the CPU time remains outweighted by that of $E_{\mathrm{pol}}$. Finally the analytical formulas for the gradients of $\mathrm{E}_{\mathrm{rep}}$ and $\mathrm{E}_{\mathrm{ct}}$ recently coded in Tinker-HP ${ }^{[30]}$ remain unaltered.

Presently, a single-point SIBFA computation on complexes of app. 300 atoms, as encountered in the recognition sites of protein, is, depending upon the size of the basis set, $10^{5}-10^{6}$ times faster than a QC Hartree-Fock or DFT one. The SIBFA and QC computing times increase as $\mathrm{N}^{2}$ and $\mathrm{N}^{4}-\mathrm{N}^{6}$, respectively, $\mathrm{N}$ denoting the number of atoms. This fully motivates our aim for $\triangle \mathrm{E}(\mathrm{SIBFA})$ to reproduce $\Delta \mathrm{E}(\mathrm{QC})$ with relative errors $<2-3 \%$. Nevertheless, the present speed is not sufficient to consider long-duration MD on very large macromolecular complexes. This should be enabled as a next step by Tinker-HP ${ }^{[30]}$, a massively parallel code in which the SIBFA 
potential and its gradients are being ported. This software enables Smooth Particle Mesh Ewald calculations ${ }^{[31]}$ to compute the long-distance parts of $\mathrm{E}_{\mathrm{MTP}}$ and $\mathrm{E}_{\mathrm{pol}}$, together with Truncated Conjugate Gradient calculation of $\mathrm{E}_{\mathrm{pol}}{ }^{[32]}$ enabling considerable speed-ups in its calculation.

We give in the Appendix the input data concerning the lone pairs of formate, formamide, hydroxamate, and imidazole.

Molecular Dynamics (MD). The one nanosecond MD simulation for $\mathrm{Ca}(\mathrm{II})$ in a droplet of 256 waters was done using the Velocity-Verlet algorithm. ${ }^{[33]}$ The temperature was set at $300 \mathrm{~K}$ with the Berendsen algorithm. ${ }^{[34]}$ The $\mathrm{OH}$ bond distances and the $\mathrm{HOH}$ angles were constrained to $0.957 \AA$ and $104.5^{\circ}$ respectively with the SHAKE algorithm. ${ }^{[35]}$ The protocol for the MD simulations of the complexes 5PAH with PMI was detailed in. ${ }^{[36]}$

2) QC computations. The RVS analyses were done with the GAMESS software. ${ }^{[21]}$ The QC calculations were performed at the Hartree-Fock level with the aug-cc-pVTZ(-f) basis set. Effective core potentials were used on $\mathrm{Zn}(\mathrm{II})^{[37]}$ and $\mathrm{Ca}(\mathrm{II}){ }^{[38]}$ Some polyligated complexes were computed at the cc-pVTZ(-f) basis set because of integral storage limitations. Computations on smaller (30 atoms) polyligated Zn(II) complexes with such a basis gave very close $\Delta \mathrm{E}$ values to those with the aug-cc-pVTZ(-f) basis set.

\section{Results and discussion.}

We will denote throughout by $\mathrm{E}_{1}$ the sum of $\mathrm{E}_{\mathrm{C}}$ and $\mathrm{E}_{\mathrm{X}}\left(\mathrm{QC}\right.$ calculations) and of $\mathrm{E}_{\mathrm{MTP}}$ and $\mathrm{E}_{\text {rep }}$ (SIBFA calculations), by $E_{2}$ the sum of $E_{p o l}$ and $E_{c t}$, and by $\Delta E(S I B F A)$ the sum of $E_{1}$ and $E_{2}$. The "torture track" set of tests encompasses usual "radial" distance variations but also angular dependencies along with probe interactions with $\pi$ systems.

The chart given below summarizes the ligands investigated regarding their nature and occurrence in proteins or in metalloprotein-binding drugs.

$\begin{array}{lcll}\text { Ligand } & \text { Net charge } & \text { Nature } & \text { Occurrence } \\ \text { Water } & 0 & \text { hard } & \\ \text { Methanol } & 0 & \text { hard } & \text { Ser, Thr side-chain. } \\ \text { Phenol } & 0 & \text { hard } & \text { Phe side-chain. } \\ \text { Formate } & -1 & \text { hard } & \text { Asp, Glu side-chain. } \\ \text { Formamide } & 0 & \text { hard } & \text { Asn, Gln side-chain, protein main-chain. } \\ \text { Imidazole } & 0 & \text { soft } & \text { His side-chain. } \\ \text { Methanethiolate } & -1 & \text { soft } & \text { Cys side-chain. } \\ \text { Hydroxamate } & -1 & \text { hard } & \text { Zn-metalloprotein inhibitors. }\end{array}$




\section{Monoligated Zn(II) complexes.}

1. Distance variations. The complexes of a $\mathrm{Zn}(\mathrm{II})$ probe with representative $\mathrm{O}-, \mathrm{N}-$, and $\mathrm{S}$-containing ligands were first used to calibrate the procedure. We considered the evolutions of $\Delta \mathrm{E}$ and its contributions for in-plane distance variations of the approach of the cation along a well-defined angle $\theta$. We list in Appendix 1, along with the $\mathrm{Zn}(\mathrm{II})$-specific parameters, the effective atomic radii used in each energy contribution and the two ligandspecific parameters used to screen the polarizing field in $\mathrm{E}_{\mathrm{pol}}$, namely the prefactor of the Gaussian screening factor and its exponent. We then list the internal coordinates used to locate the lone pair centroids with respect to their atom bearer, and the populations and increments of van der Waals effective radii along each lone pair direction. Table Ia reports the comparisons between the QC and SIBFA results at the optimized R distances for O-containing ligands: water, methanol, formamide, phenol, and formate in either in the bridge position or in an external one. These are encountered in the side-chains of the Ser, Thr, Asn, Gln, Tyr, Asp and Glu residues in proteins. Table $\mathrm{Ib}$ reports these comparisons for three N-containing ligands: imidazole, pyridine and trimethylamine, and one S- containing one, methanethiolate. The first and the last are encountered in the sidechains of His and Cy- protein residues respectively. The complete radial dependencies are given as Supporting Informations SI. $\mathrm{a}-\mathrm{i}$. Tables Ia-b show the calibration to enable a close match of $\Delta \mathrm{E}(\mathrm{SIBFA})$ and its contributions to their QC counterparts, which concerns all four contributions to $\triangle \mathrm{E}$. It is notable that $\triangle \mathrm{E}$ (SIBFA) can retain very close values to those of $\Delta \mathrm{E}$ (RVS) concerning the binding of $\mathrm{Zn}$ (II) to formate in either the bidentate or the external monodentate mode; in the latter, the $\mathrm{Zn}-\mathrm{O}$ bond is trans to the bond between the $\mathrm{C}$ atom and the unbound O. In all $\mathrm{Zn}$ (II) complexes with neutral ligands, $\mathrm{E}_{\mathrm{pol}}$ has larger magnitudes than $\mathrm{E}_{1}$, a feature which was already noted in 1995 upon calibrating and testing $\mathrm{Zn}(\mathrm{II})$ in the context of the CEP 4-31G(2d) basis set. ${ }^{[3]}$

2. $\phi$ and $\theta$ dependencies. As a next step, we performed out-of-plane variations of the approach of $\mathrm{Zn}$ (II) to its ligating atoms, as denoted by the $\phi$ angle. For each ligand, we sought to match the evolutions of Ex at the optimized $\mathrm{R}$ and for the same $\theta$ angle, $\theta_{0}$, as for the distance variations, upon performing step-wise variations of the out-of-plane $\phi$ angle. This enabled to optimize the value of $\alpha$, along with the increments of effective radii for $\mathrm{E}_{\mathrm{rep}}$ and $\mathrm{E}_{\mathrm{ct}}$ along the lone-pair directions. The validation of the calibration was then assessed by parallel SIBFA and RVS computations upon resuming the $\phi$ variations for several $\theta$ angles encompassing $\theta_{0}$.

The complete results for $\mathrm{Zn}(\mathrm{II})$ complexes are given under the form of Tables as Supporting Information (SII.ad, SIII a-d, SIV a-d, SV a-d and SVI a-d).

Figures $3 \mathrm{a}-\mathrm{b}$ concern the $\mathrm{Zn}(\mathrm{II})$-formamide complex. They show the evolutions of $\mathrm{E}_{\text {rep }}$, and $\Delta \mathrm{E}$ as a function of $\theta$ at two values of $\phi$, namely $0^{\circ}$ and $90^{\circ}$. The following figures report the corresponding evolutions for $\mathrm{Zn}$ (II)- 
formate in the 'E' complex (4a-b), Zn(II)-hydroxamate bound to either the carbon-bound O atom (5a-d) or the N-bound O (5a-b), and Zn(II)-imidazole (6a-b).

Formamide-Zn(II) (Figures 3a-b). E $\mathrm{E}_{\text {rep }}(\mathrm{SIBFA})$ matches correctly $\mathrm{E}_{X}(\mathrm{RVS})$ upon stepwise increasing $\phi$. This is an essential result for the present study, indicating that upon out-of-plane excursions of the approach of $\mathrm{Zn}$ (II) to an amide ligand, as can occur during MD or MC simulations, there should be no imbalances in $\mathrm{E}_{\text {rep }}$ that could stem from an under-representation of the lone pairs out of the ligand plane and until the perpendicular is reached. If the $\mathrm{sp}^{2}$ lone pairs are not smeared, $\mathrm{E}_{\text {rep }}$ undergoes a strong decrease in magnitude upon increasing $\phi$, until $\phi$ $=90^{\circ}$ is reached, when the cation starts to undergo the $\pi$ lone pair repulsions. On the other hand, for each of the four values of $\phi$, the directionality of $\mathrm{E}_{\mathrm{X}}$ upon varying $\theta$ from $105^{\circ}$ to $150^{\circ}$ is correctly accounted for by $\mathrm{E}_{\mathrm{rep}}$. For both $\phi=0^{\circ}$ and $30^{\circ}$, the two curves run close to one another. They start to diverge, albeit by small amounts, for $\phi=60^{\circ}$ and $90^{\circ}$, which correspond to less favorable $\Delta \mathrm{E}$ values (Supp. Info. SII a-d). For the least favorable $\phi$ value of $90^{\circ}, E_{\text {rep }}$ runs parallel to $E_{X}$, and the offset is small (3 kcal $/ \mathrm{mol}$ ) (Figure 3-b). Overall, and since for each $\phi$ value the evolutions of $E_{M T P} *$ as a function of $\theta$ parallel those of $E_{C}$ (not shown), $E_{1}$ (SIBFA) runs parallel to $E_{1}(R V S)$. The other short-range contribution, $E_{c t}$, has values reasonably close to those of $E_{c t}(R V S)$, as a function of both $\theta$ and $\phi$. The overlap is less than found for the short-range repulsion, but the differences remain small and do not prevent the close agreement between $\Delta \mathrm{E}$ (SIBFA) and $\Delta \mathrm{E}$ (RVS) for all $\phi$ and $\theta$ values investigated.

Formate-Zn(II). (Figures 4a-b). The formate anion is an ubiquitous cation-binding motif, and it is essential to control the anisotropic character of its cation complexes, exemplified here by in- and out-of-plane Zn(II)-binding. $\mathrm{E}_{\text {rep }}(\mathrm{SIBFA})$ has a much lesser $\theta$ dependency than $\mathrm{E}_{\mathrm{X}}$. Thus for $\phi=0^{\circ}$, it decreases by $2 \mathrm{kcal} / \mathrm{mol}$ out of 72 upon increasing $\theta$ from $105^{\circ}$ to $150^{\circ}$, while the corresponding decrease of $E_{X}$ is $16 \mathrm{kcal} / \mathrm{mol}$. The same trends are found for the three other $\phi$ angles. These mismatches are partly absorbed, within $\mathrm{E}_{1}$, by the large magnitudes of $E_{M T P} / E_{C}$, leaving out relative errors of $3 \%$ in terms of $E_{1}$. We have observed that abolishing the smearing by recovering populations of 2 on the in-plane components of the $\mathrm{sp}^{2}$ lone pairs, leaving out zero for the smeared out-of-plane components, restores only a small fraction of the $\theta$ dependencies, but at the cost of a severe loss of $\mathrm{E}_{\text {rep}}$, of up to $17 \mathrm{kcal} / \mathrm{mol}$ upon increasing $\phi$ from $0^{\circ}$ to $60^{\circ}$ (Supp. Info. SIII a-d). On the other hand, resorting to larger decrements of the lone pair radii along the two 'internal' oxygen $\mathrm{sp}^{2}$ lone pairs enabled for a faster decrease of $\mathrm{E}_{\text {rep }}$ than displayed here (unpublished). This would correspond to the fact that the two 'inner' $\mathrm{sp}^{2} \mathrm{O}$ lone pairs would have reduced a radial extension, owing to their mutual Pauli repulsions, than the 'outer' lone pairs. Adopting this would however, require a new cycle of parametrization. It is a clue for further refinements, planned for a subsequent work at the correlated level within the context of SAPT-DFT ${ }^{[39-40]}$ approaches. $\mathrm{E}_{\mathrm{ct}}(\mathrm{SIBFA})$ has a different $\theta$ dependency than $\mathrm{E}_{\mathrm{ct}}(\mathrm{RVS})$. However, the numerical differences are small, and they are compensated for by the polarization energy which is shallow in QC, while it decreases in magnitude upon increasing $\theta$. The agreement between $\triangle \mathrm{E}(\mathrm{SIBFA})$ and $\Delta \mathrm{E}$ (RVS) is to $<3 \%$ in relative errors for all $\phi$ values reported. It is to be 
noted that the present tests are done at the equilibrium $\mathrm{Zn}-\mathrm{O}$ distance of $1.80 \AA$. In polyligated complexes, the Zn-ligand will increase, clearly enabling for improved SIBFA and QC agreements regarding the individual Zn(II) -formate complexes.

Hydroxamate-Zn(II). Hydroxamate is an essential Zn-binding moiety of several high-affinity Zn-metalloenzyme inhibitors, some of which are clinically promising. ${ }^{[41-42]}$ and Refs. therein. Therefore, it could be very important to unravel the in- and out-of-plane angular dependencies of $\Delta \mathrm{E}$ and its contributions, and how well these could be accounted for by PMM. The first parallel QC and PMM study of mono- and polyligated complexes of Zn(II) with hydroxamate was published in $1998,{ }^{[43]}$ but did not probe the potential energy surface at the same detailed level as here. As in Ref. ${ }^{[43]}$ we will focus here on the deprotonated form.

a) Zn(II)-binding to the CO oxygen (Supp. Info. SIV a-d). $\mathrm{E}_{\text {rep }}$ and $\mathrm{E}_{1}$ (SIBFA) have a near-parallelism to their RVS counterparts. $\mathrm{E}_{\mathrm{ct}}(\mathrm{SIBFA})$ presents larger divergences with respect to $\mathrm{E}_{\mathrm{ct}}(\mathrm{RVS})$ for the smaller $\theta$ values, which correspond to less-favored $\Delta \mathrm{E}(\mathrm{RVS})$ values. Such divergences do not appear to compromise the nearparallelism between $\triangle \mathrm{E}(\mathrm{SIBFA})$ and $\triangle \mathrm{E}(\mathrm{RVS})$ found as a function of $\theta$ for all four $\phi$ angles. In fact, the sole exception appears at $\phi=90^{\circ}$, for $\theta$ values of $140^{\circ}-150^{\circ}$, where the two curves actually cross. As shown in the Supp. Info., it is also seen that underestimations of $\mathrm{E}_{\mathrm{ct}}(\mathrm{RVS})$ can to some extent be recovered by corresponding overestimations of $\mathrm{E}_{\mathrm{pol}}(\mathrm{RVS})$ by $\mathrm{E}_{\mathrm{pol}}(\mathrm{SIBFA})$.

b) Zn(II)-binding to the NO oxygen (Figures 5a-b; Supp. Info. SV a-d). The interaction energies are much more favorable than for $\mathrm{Zn}(\mathrm{II})$-binding to the $\mathrm{CO}$ oxygen. Ex is much more sensitive to both $\theta$ and $\phi$ variations, and $E_{\text {rep }}$ has very close values to it throughout, except for $\phi=0^{\circ}$, and in a limited $15^{\circ}$ range, namely for $105^{\circ}<\theta<$ $120^{\circ}$ for which $\Delta \mathrm{E}$ (RVS) and $\Delta \mathrm{E}(\mathrm{SIBFA})$ are themselves much less favorable anyway (Figure. 5-a). Since $\mathrm{E}_{\mathrm{MTP}}$ closely matches $E_{C}$ throughout, $E_{1}(\operatorname{SIBFA})$ parallels $E_{1}(\mathrm{RVS})$, again with the sole exception of $\phi=0^{\circ}$ and $105^{\circ}$ $<\theta<120^{\circ}$ reflecting the corresponding behavior of $\mathrm{E}_{\mathrm{rep}}(\mathrm{SIBFA})$. The angular dependencies of $\mathrm{E}_{\mathrm{ct}}(\mathrm{SIBFA})$ have only slightly lesser parallelism with those of $E_{c t}(R V S)$ than was the case with the short-range repulsion. There are visible exceptions. The first is again for $\phi=0^{\circ}, 105^{\circ}<\theta<120^{\circ}$. The second is for $\phi=90^{\circ}$, where $\mathrm{E}_{\mathrm{ct}}(\mathrm{RVS})$ present a minimum for $\theta=120^{\circ}$, while $\mathrm{E}_{\mathrm{ct}}(\mathrm{SIBFA}$ ) has a smoother behavior (Supp. Info. SV. a-d). The range of $\phi=90^{\circ}$ values nevertheless concerns $\Delta \mathrm{E}$ values that are significantly (app. $50 \mathrm{kcal} / \mathrm{mol}$ ) less stable than for $\phi=$ $0^{\circ}$ and $30^{\circ}$.

For both $\mathrm{Zn}(\mathrm{II})$ binding to the $\mathrm{CO}$ and $\mathrm{NO}$ oxygens, there is a close agreement between $\Delta \mathrm{E}(\mathrm{SIBFA})$ and $\Delta \mathrm{E}(\mathrm{RVS})$ in all relevant energy-wise $\theta$ and $\phi$ values, the relative errors being always $<3 \%$.

Imidazole-Zn(II) (Figures 6a-b). $\mathrm{E}_{\text {rep }}$ reproduces closely $\mathrm{E}_{\mathrm{X}}$ as a function of both $\phi$ and $\theta$. It could not account satisfactorily for the $\phi$ dependency of $E_{X}$ if the N3 sp lone pair were not smeared. Since EMTP* has itself closely 
similar $\phi$ and $\theta$ dependencies as $E_{C}$, the corresponding $E_{1}$ (RVS) dependencies are accordingly closely accounted for by $\mathrm{E}_{1}(\mathrm{SIBFA})$. $\mathrm{E}_{\mathrm{ct}}(\mathrm{SIBFA})$ has a lesser parallelism to its RVS counterpart, but the mismatches appear essentially for the $\Delta \mathrm{E}$ (RVS) values that are the least favored in terms of $\phi$ and $\theta$ (Supp. Info. SVI. a-d). Thus $\Delta \mathrm{E}(\mathrm{SIBFA})$ closely reproduces $\Delta \mathrm{E}(\mathrm{RVS})$ for all $\theta$ and $\phi$ values considered. This has an important implication for the modelling of $\mathrm{Zn}$-binding sites in metalloproteins, in which His residues are recurrent $\mathrm{Zn}$-binding ligands. Zn-binding mostly occurs in the imidazole plane and close to the direction of the external bisector of the coordinating nitrogen. Nevertheless out-of-plane binding, corresponding to $\phi$ values of app. $45^{\circ}$, could also be found by high-resolution X-ray crystallography, possibly due to constraints by the anchoring of the His sidechain to a relatively rigid backbone [see, eg. ${ }^{[44-45]}$ and refs. therein]. The present calculations quantify the $\Delta \mathrm{E}(\mathrm{QC})$ cost incurred by out-of-plane binding, and show that they can be accounted for by anisotropic molecular mechanics.

As a conclusion for the present section, the 'smearing' of the sigma lone pairs ( $\mathrm{sp}^{2}$ for formamide, formate and the $\mathrm{CO}$ oxygen of hydroxamate, sp for the purine-like nitrogen of imidazole) enables $\mathrm{E}_{\text {rep }}$ to closely parallel both in- and out-of-plane dependencies of $\mathrm{E}_{\mathrm{X}}$ in the energy-relevant range. $\mathrm{E}_{\mathrm{MTP}} *$ and $\mathrm{E}_{\mathrm{pol}}(\mathrm{SIBFA})$ also stably reproduce the angular behaviors of their RVS counterparts. Owing to the separability of the SIBFA potential, this results into a close reproduction of $\triangle \mathrm{E}(\mathrm{RVS})$ by $\Delta \mathrm{E}(\mathrm{SIBFA})$. It could also be mentioned that some remaining mismatches of $E_{c t}$ or to $E_{p o l}$ should be absorbed in polyligated complexes, on account of non-additivity due to screening of the cation-exerted field on any $\mathrm{Zn}$-binding ligand by the other ones.

3. Perpendicular Zn(II) binding to imidazole, formamide and phenol. For completeness, we also performed tests which 'probe' the $\pi$ electrons of conjugated or aromatic ligands by $\mathrm{Zn}(\mathrm{II})$ at the vertical of their atoms. Such binding positions are anticipated to be significantly less favorable than $\mathrm{Zn}$ (II)-binding to the $\sigma$ lone-pairs and $a$ priori unlikely to be populated by this cation in the course of MD or MC simulations. They should nevertheless be investigated to ensure that no artificial magnification of $\Delta \mathrm{E}(\mathrm{RVS})$ by $\Delta \mathrm{E}(\mathrm{SIBFA})$ might occur. As reported for the cytosine and guanine bases, ${ }^{[10]}$ a divalent cation acts can be used as a probe for $E_{\text {rep }}$ and $E_{c t}$ involving the $\pi$ lone-pairs: comparison to their RVS counterparts enables to calibrate their radial extension and extent of effective radius increments/decrements of their atom bearer. This is necessary in a more general context, whenever the ligand is involved in even partially stacked interactions with other ligands. Furthermore, a divalent cation enables to evaluate how the GDMA multipolar representation fares above the plane of such ligands. Thus it was reported that for such ligands, GDMA multipoles derived from extended basis sets could be very sensitive to the input parameters used to derive them, ${ }^{[46]}$ namely the effective radii on the $H$ atoms and the value of the switch. A non-optimal choice, while delivering $\mathrm{E}_{\mathrm{MTP}} *$ values close to $\mathrm{E}_{\mathrm{C}}$ in the in-plane position, could severely overestimate it in over-the-plane positions, due to an imbalance of the charge-quadrupole component [unpublished]. The results are reported in Tables IIa-b. Table IIa reports the results at equilibrium distance for 
$\mathrm{Zn}$ (II) bound at the vertical of each of the five atoms of imidazole. Table IIb reports the corresponding results for over the plane binding of $\mathrm{Zn}$ (II) to relevant atoms of two O-containing ligands, phenol and formamide. For completeness, Table III gives the radial dependencies of $\Delta \mathrm{E}(\mathrm{QC})$ and $\Delta \mathrm{E}(\mathrm{SIBFA})$ and their contributions for the $\mathrm{Zn}(\mathrm{II})$-formamide complex, the C-O-Zn(II) angle being $135^{\circ}$.

The results for imidazole show that $\Delta \mathrm{E}(\mathrm{SIBFA})$ retains a close agreement with $\Delta \mathrm{E}(\mathrm{RVS})$, except for binding over C6, which has an error of app. 10\%. This position is nevertheless $50 \mathrm{kcal} / \mathrm{mol}$ less stabilizing for $\mathrm{Zn}$ (II) than in-plane binding to $\mathrm{N} 3$, and $17 \mathrm{kcal} / \mathrm{mol}$ less so than perpendicular binding to N3. For all five binding positions, there is a lesser term-to-term agreement between the individual SIBFA contributions and their RVS counterparts than was the case with in-plane binding to N3. This is due on the on the one hand to EMTP* which as mentioned above tends for conjugated systems to overestimate the charge-quadrupole component. As further refinements we consider resorting to Iterative Stockholder Atom (ISA) partition-derived multipoles ${ }^{[47-48]}$ and GEM-derived multipoles. ${ }^{[49-50]} \mathrm{E}_{\text {rep }}$ accordingly overestimates $\mathrm{E}_{\mathrm{X}}$. It is recalled that the prefactor of $\mathrm{E}_{\text {rep }}$ embodies dependences upon the electronic populations of the pair of interacting atoms, and can thus be sensitive to the stability of the multipolar expansion. The calibration of $E_{\text {rep }}$ will thus be readdressed in conjunction with the derivation of a new set of multipoles. $\mathrm{E}_{\text {pol }}(\mathrm{SIBFA})$ is invariably larger in magnitude than $\mathrm{E}_{\text {pol }}(\mathrm{RVS})$, but this compensates partly the less stabilizing $\mathrm{E}_{1}(\mathrm{SIBFA})$ than $\mathrm{E}_{1}(\mathrm{RVS})$. It is due to a maximal exposure of the bond polarizabilities when a cation binds above the plane at short distances of approach (1.90 $\AA$ in the present case). Such overestimations of $E_{\mathrm{pol}}$ for the vertical positions of approach are not likely to impair future MD simulations, since as mentioned above, in polyligated complexes, the field exerted by the dipositive $\mathrm{Zn}$ (II) charge on any one ligand will be shielded by the fields exerted by the other ligands.

The same observations can be done regarding binding to formamide over the $\mathrm{C}$ atom: the acceptable reproduction of $\Delta \mathrm{E}(\mathrm{RVS})$ by $\Delta \mathrm{E}(\mathrm{SIBFA})$ stems from an overestimated $\mathrm{E}_{\mathrm{pol}}$ (SIBFA) compensated by an overestimated and repulsive $\mathrm{E}_{1}$. In any case the $\Delta \mathrm{E}$ values are app. $80 \mathrm{kcal} / \mathrm{mol}$ less favorable than for in-plane binding to $\mathrm{O}$. For the binding over $\mathrm{N}, \triangle \mathrm{E}(\mathrm{SIBFA})$ has a closer agreement to $\triangle \mathrm{E}(\mathrm{RVS})$ and a better term-to-term match of its contributions to the RVS ones. Here again, $\Delta \mathrm{E}(\mathrm{RVS})$ remains $80 \mathrm{kcal} / \mathrm{mol}$ less favorable than for in-plane binding of $\mathrm{O}$.

We have considered three perpendicular Zn(II) binding positions over phenol: over O, over the O-connected C atom, and over one meta $\mathrm{C}$ atom. $\triangle \mathrm{E}(\mathrm{SIBFA})$ is underestimated by app. $10 \%$ with respect to $\Delta \mathrm{E}(\mathrm{RVS})$. This is mostly due to the underestimation of $\mathrm{E}_{\text {pol }}(\mathrm{RVS})$. As discussed above regarding over the plane Zn-binding to imidazole, a significant reduction of such an error can be anticipated in polyligated complexes, owing to the reduction of the $\mathrm{Zn}$-electrostatic field on any ligand by the fields exerted by the other ligands. The unanticipated preference of over-C2 binding on in-plane binding to $\mathrm{O}$ stems from $\mathrm{E}_{\mathrm{pol}}$ and $\mathrm{E}_{\mathrm{ct}}$. While these features could be accounted for by SIBFA, such a preference could be anticipated not to prevail either in polyligated complexes. 
The improvement brought to $\mathrm{E}_{\text {rep }}$ by smearing the lone pairs is illustrated in Figures 7a-c, for the $\mathrm{Zn}$ (II) complexes with formamide, formate, and imidazole at their equilibrium distances. For formamide and formate, the $\mathrm{CO}-\mathrm{Zn} \theta$ angles are $135^{\circ}$ and $150^{\circ}$. For imidazole, $\mathrm{Zn}(\mathrm{II})$ is along the external bisector of the ligating $\mathrm{N}$ atom. We perform stepwise variations of the $\phi$ angle until the perpendicular to the plane is reached. While for formamide and formate, $\mathrm{E}_{\text {rep }}$ parallels the evolution of EX, $\mathrm{E}_{\text {rep }}$ (without smearing the lone pairs) undergoes 10 $\mathrm{kcal} / \mathrm{mol}$ drops in magnitude past $\phi=60^{\circ}$. With imidazole, $\mathrm{E}_{\text {rep }} *$ undergoes a $10 \mathrm{kcal} / \mathrm{mol}$ drop at $40^{\circ}$ before rising again until $\phi=90^{\circ}$ is reached. Such a drop is in marked contrast with the much smaller decrease of both EX and $\mathrm{E}_{\text {rep }}$ in the $0-60^{\circ}$ range, both contributions increasing again from $60^{\circ}$ to $0^{\circ}$.

Polyligated Zn(II) complexes. We have in several preceding studies ${ }^{[3,27,51-52]}$ addressed the issue of the nonadditivity of $\Delta \mathrm{E}, \delta \mathrm{E}_{\text {nadd, }}$ and its contributions upon passing from mono- to polyligated complexes. The control of $\delta \mathrm{E}_{\text {nadd }}$ is clearly critical in view of reliable $\mathrm{MD}$ simulations of $\mathrm{Zn}$ complexes in a diversity of problems ranging from biological to material science. Our earliest studies were with the CEP 4-31G(2d) basis set. ${ }^{[27]}$ and refs. therein. We have been more recently ${ }^{[7,9]}$ targeting the results from a much more extended basis set, aug ccpVTZ(-f), where second-order effects could have a larger magnitude than with the CEP 4-31G(2d) set. Thus it is all the more necessary to control $\delta \mathrm{E}_{\text {nadd }}$ with this basis, and ensure if the impact of out-of-plane $\mathrm{Zn}$ (II) binding is controlled as well. We have considered the following complexes:

-the oligohydrated $\mathrm{Zn}(\mathrm{II})$ complexes with four and six water molecules, namely $\left[\mathrm{Zn}\left(\mathrm{H}_{2} \mathrm{O}\right)_{4}\right]^{2+}$ in either the square planar alternating or the pyramidal arrangement, and $\left[\mathrm{Zn}\left(\mathrm{H}_{2} \mathrm{O}\right)_{6}\right]^{2+}$ in the octahedral arrangement (Figures 8a-c and Table IVa);

-the complexes of $\mathrm{Zn}$ (II) with three and four imidazole ligands, and with three methanethiolate ligands, denoted as $\left[\mathrm{Zn}(\text { Imidazoles })_{3}\right]^{2+},\left[\mathrm{Zn}(\text { Imidazoles })_{4}\right]^{2+}$, and $\left[\mathrm{Zn}(\text { Methanethiolates })_{3}\right]^{-1}$ respectively (Figures $8 \mathrm{~d}-\mathrm{f}$ and Table $\mathrm{IVb})$;

-three polyligated complexes, with 'mixed' N, S, and O-containing ligands. Each ligand is denoted with one letter, corresponding to the one-letter code for the protein residue of which it is the end side-chain, namely $\mathrm{H}$ for imidazole, $\mathrm{C}$ for methanethiolate, and $\mathrm{E}$ for glutamate. The first complex, $\mathrm{Zn}[\mathrm{HHCC}]$, recurs in several $\mathrm{Zn}$-finger proteins. ${ }^{[53]}$ The second, denoted as $\mathrm{Zn}[\mathrm{HHE}]^{+}$, is found in the Zn-finger motif of the anthrax lethal factor (LT), ${ }^{[54]}$ a target for the design of anthrax inhibitors. ${ }^{[55]}$ The third corresponds to the Zn-binding site of the phosphomannose isomerase (PMI) bacterial enzyme, which catalyzes the reversible interconversion of mannose into glucose, and is a target for the design of antibacterial and antiparasitic diseases. ${ }^{[56]}$

The energy-minimized structures of complexes $\mathrm{Zn}[\mathrm{HHCC}]$ and $\mathrm{Zn}[\mathrm{HHE}]^{+}$are represented in Figures 9a-b, and the interaction energy values are given in Table $\mathrm{V}$. 
$-\left[\mathrm{Zn}\left(\mathrm{H}_{2} \mathrm{O}\right)_{n}\right]^{2+}$ complexes $(n=4,6)$. Table IVa shows that, in line with our previous results, ${ }^{[27]} \Delta \mathrm{E}(\mathrm{RVS})$ and its contributions can be closely reproduced by $\triangle \mathrm{E}(\mathrm{SIBFA})$ and its contributions. For $\mathrm{n}=4$, the preference in favor of the pyramidal arrangement over the planar one (14.7 and $14 \mathrm{kcal} / \mathrm{mol}$ in QC and SIBFA respectively), is mostly due to $E_{\text {pol }}$ by both RVS and SIBFA, and, to a lesser extent, to $E_{1}$ and $E_{c t}$. These conclusions are consistent with those of a study devoted to the tetrahydrates of the alkali cations in the series $\mathrm{Li}^{+}-\mathrm{Cs}^{+}$, although the preference due to $E_{\mathrm{pol}}$ was not dominating. ${ }^{[9]}$ The non-additivities of both $\mathrm{E}_{\mathrm{pol}}$ and $\mathrm{E}_{\mathrm{ct}}$ appear properly controlled. Thus, consistent with our earlier results that resorted to the CEP 4-31G(2d $)^{[3,27,57]}$ basis set, in both QC and SIBFA, $E_{c t}$ increases by only a factor of app. 2 with respect to the monoligated case upon multiplying the number of ligands by 4 or even 6 . Table IVa lists the values of $E_{\text {pol }}$ prior to, and following, iterated calculations on the induced dipoles. The QC values are denoted as $\mathrm{E}_{\mathrm{pol}}(\mathrm{RVS})$ and $\mathrm{E}_{\mathrm{pol}}(\mathrm{VR})$, respectively, and the corresponding SIBFA values by $\mathrm{E}_{\mathrm{pol}} *$ and $\mathrm{E}_{\mathrm{pol}}$ : the latter is $30 \%$ smaller in magnitude than the former, which as previously noted ${ }^{[52]}$ is a signature for anticooperativity.

$\left.-[\text { Zn (imidazole })_{n}\right]^{2+}$ complexes $(n=3,4)$. For completeness, for both $\mathrm{n}=3$ and 4 , we list two sets of distances, as they give rise to closely similar $\Delta \mathrm{E}$ values.

Table IVb shows that for both tri- and tetraligated complexes of imidazoles, $\Delta \mathrm{E}(\mathrm{SIBFA})$ matches $\Delta \mathrm{E}(\mathrm{RVS})$ with relative errors of $2 \%$. There is a slight imbalance between short-range repulsion and charge-transfer, an underestimation of $E_{\text {rep }}(S I B F A)$ being compensated by a corresponding underestimation of $E_{\text {ct }}(S I B F A)$. The close agreements of $\mathrm{E}_{\mathrm{pol}}(\mathrm{SIBFA})$ and $\mathrm{E}_{\mathrm{pol}}(\mathrm{RVS})$ both at non-iterated and iterated levels is noteworthy. The trends in $E_{c t}$ upon passing from $n=3$ to $n=4$ are correctly accounted for. $E_{c t}$ undergoes closely similar and modest increases with both methods, namely -3.5 and $-1.3 \mathrm{kcal} / \mathrm{mol}$. Such increases upon adding up one imidazole ligand are markedly smaller than the corresponding values of $E_{c t}$ in the monoligated $\mathrm{Zn}$ (II)-imidazole complexes for $\mathrm{d}_{\mathrm{N}-\mathrm{Zn}}=2.10 \AA$, namely -17.6 and $-16.3 \mathrm{kcal} / \mathrm{mol}$ : this attests again to the strong anticooperative nature of $\mathrm{E}_{\mathrm{ct}}$ in polyligated $\mathrm{Zn}(\mathrm{II})$ complexes.

The last complex reported in Table IVb is that of $\mathrm{Zn}(\mathrm{II})$ bound to three methanethiolates, $\mathrm{Zn}[\mathrm{CCC}]^{-}$. It represents one extreme test for the procedure and its handling of non-additivity, owing to the presence of three anionic, highly polarizable ligands complexing $\mathrm{Zn}(\mathrm{II})$ in a compact arrangement. $\Delta \mathrm{E}(\mathrm{RVS})$ and $\Delta \mathrm{E}(\mathrm{SIBFA})$ undergo large magnitude increases. The relative error now amounts to $4 \%$, the largest one reported in this study for polyligated complexes. $\mathrm{E}_{1}(\mathrm{SIBFA})$ reproduces $\mathrm{E}_{1}(\mathrm{RVS})$ with a relative error of $1 \%$, but this occurs due to a compensation of errors between $\mathrm{E}_{\mathrm{MTP}} *$ and $\mathrm{E}_{\mathrm{C}}$ on the one hand and $\mathrm{E}_{\mathrm{rep}}$ and $\mathrm{E}_{\mathrm{X}}$ on the other. The main reason for the relative underestimation of $\Delta \mathrm{E}(\mathrm{SIBFA})$ resides in $\mathrm{E}_{\mathrm{ct}}$, which amounts to $-44.8 \mathrm{kcal} / \mathrm{mol}$ in SIBFA and to $-64.2 \mathrm{kcal} / \mathrm{mol}$ with RVS after BSSE correction. 
$-\mathrm{Zn}[\mathrm{HHCC}]$ and $\mathrm{Zn}[\mathrm{HHE}]^{+}$complexes. We next investigate two 'mixed' complexes in which $\mathrm{Zn}$ (II) is ligated by two different kinds of ligands: imidazole and methanethiolate for the first complex, and imidazole and formate for the second (Figure 9 and Table $\mathrm{V}$ ). There is a close agreement between $\triangle \mathrm{E}(\mathrm{SIBFA})$ and $\Delta \mathrm{E}(\mathrm{RVS})$ for the $\mathrm{Zn}[\mathrm{HHCC}]$ complex, with a relative error of $2 \%$. The close match of $\mathrm{E}_{1}(\mathrm{SIBFA})$ to $\mathrm{E}_{1}(\mathrm{RVS})$ is due to a smaller $E_{\text {rep }}$ than $E_{X}$ compensating for a smaller magnitude of $E_{M T P} *$ than $E_{C}$. The $\mathrm{Zn}[H H E]^{+}$complex shows close agreements between $\triangle \mathrm{E}(\mathrm{SIBFA})$ and $\triangle \mathrm{E}(\mathrm{RVS})$ (less than $1 \%$ in relative error) and their individual contributions.

At this stage we can conclude that the $\mathrm{Zn}$ (II) polyligated complexes giving rise to the larger relative errors are those with methanethiolates, the largest one being 4\%. This appears mostly due to $\mathrm{E}_{\mathrm{MTP}} *$ as compared to $\mathrm{E}_{\mathrm{C}}$. It could be due to the derivation of the methanethiolate multipoles using the GDMA procedure. An indication that this could indeed be the case is given by the faster radial decay of $\mathrm{E}_{\mathrm{MTP}} *$ than $\mathrm{E}_{\mathrm{C}}$ in the monoligated complex Zn-methanethiolate complex (Supp. Info SI.i), in contrast to the near-parallel decay of $\mathrm{E}_{\mathrm{MTP}}{ }^{*}$ and $\mathrm{E}_{\mathrm{C}}$ in all the other mono-ligated complexes. This could in turn impact $\mathrm{E}_{\mathrm{rep}}$, which depends upon $\mathrm{E}_{\mathrm{MTP}} *$ by a prefactor which includes the electronic population of the pair of interacting atoms.

The impact of smearing the lone pairs can be also illustrated in Table V. E rep $^{*}$ is $7-12 \mathrm{kcal} / \mathrm{mol} \mathrm{smaller}$ in magnitude than $\mathrm{E}_{\text {rep. }}$. In the extreme case of the $\mathrm{Zn}[\mathrm{HHCC}]$ complex, this can increase to $25-35 \mathrm{kcal} / \mathrm{mol}$ the underestimations of $\mathrm{Ex}_{\mathrm{X}}$. Because of compensations of errors occurring for the $\mathrm{Zn}[\mathrm{HHCC}]$ complex owing to an underestimation of $\mathrm{E}_{\mathrm{X}}$ by $\mathrm{E}_{\mathrm{MTP}} *$, this actually led to an outwardly better agreement of corresponding energy, $\Delta \mathrm{E}^{* *}, \Delta \mathrm{E}^{*}$ than $\Delta \mathrm{E}$ with $\Delta \mathrm{E}(\mathrm{QC})$ for it. But this is not deemed meaningful in the prospect of the planned improvement to $\mathrm{E}_{\mathrm{MTP}} *$ discussed below. In the case of $\mathrm{Zn}[\mathrm{HHE}]^{+}, \Delta \mathrm{E}^{*}$ has a lesser agreement with $\Delta \mathrm{E}(\mathrm{QC})$ than $\Delta \mathrm{E}$, the relative error being $3.5 \%$ compared to $<1 \%$.

-Phosphomannose isomerase (PMI) binding site. PMI is a Zn-dependent metalloenzyme, responsible for several bacterial and parasitic diseases, ${ }^{[58-59]}$ and refs. therein, but to date there are no therapeutically useful PMI inhibitors. Hydroxamate is a recurrent Zn-binding moiety of many Zn-metalloenzyme inhibitors [for a recent review, see]. ${ }^{[41]}$ A submicromolar PMI hydroxamate inhibitor, 5-D-phosphonoarabinohydroxamate (5PAH), was originally designed and synthesized by Hardre et al.. ${ }^{[56]}$ There are no available X-ray crystal structures for complexes of PMI with inhibitors. In a preceding study, ${ }^{[36]}$ we resorted to the X-ray crystal structure of Zn-bound $\mathrm{PMI}^{[60]}$ as a starting point to search for the most-stably bound structures of the complexes of PMI with 5PAH and three dehydroxylated derivatives. This was done by SIBFA Molecular Dynamics (MD) simulations with the hydroxamate ligated to $\mathrm{Zn}$ (II) and the phosphate bound at the entrance of the cavity by a lysine and an arginine residue. ${ }^{[36]}$ Three competing poses for each of the four inhibitors were unraveled by MD, whence a total of twelve complexes. The three poses differed mostly concerning the Zn-hydroxamate binding modes. To lend credence to their computed $\Delta \mathrm{E}$ values and their ranking, we had performed parallel QC (HF and DFT-D3) and SIBFA computations on an enlarged recognition site encompassing up to 265 atoms including 28 waters. Agreements 
between $\triangle \mathrm{E}(\mathrm{QC})$ and $\triangle \mathrm{E}(\mathrm{SIBFA})$ with relative errors $<3 \%$ were obtained. The present comparisons will be limited to the sole $\mathrm{Zn}$ (II)-binding site, each of the seven PMI residues being represented by its end side-chain, and 5PAH being represented by its hydroxamate moiety. These residues are: Asn111, His113, Ly136, Glu138, His285, Tyr287, and Asp300. There is thus a total of nine interacting molecules including hydroxamate and $\mathrm{Zn}(\mathrm{II})$, which is amenable to RVS analyses. Which agreements could still be obtained between QC and SIBFA regarding not only $\Delta \mathrm{E}$, but also their individual contributions? Comparisons with HF and DFT-D3 on an enlarged binding site with the entirety of the inhibitors and 28 structural waters, totaling up to 264 atoms, are reported separately. ${ }^{[36]}$ The three PMI poses, denoted A-C, are represented in Figures 10a-c. In A, the hydroxamate is bidentate bound to $\mathrm{Zn}(\mathrm{II})$, which is also ligated by Asn111, His113 and monodentate bound to Glu138. His 285 has a larger Zn-N distance (3.1 $\AA$ ) than His113 (2.4 $\AA$ ). Tyr287 donates its hydroxyl proton to Asp300 and Lys 136 donates a proton to the second, non-Zn bound anionic oxygen of Glu138. In B, hydroxamate is bound monodentate, through its N-bound $\mathrm{O}$ atom, to $\mathrm{Zn}(\mathrm{II})$, and Tyr287 now partakes into Zn-coordination instead of the C-bound hydroxamate oxygen. The other Zn-ligands are Gln111, His285 instead of His113, which has a Zn$\mathrm{N}$ distance of $2.9 \AA$, and Glu138. As in A, Lys136 and Tyr287 donate a proton to Glu138 and Asp300, respectively. In C, Zn(II) is again bound to hydroxamate monodentate, but no longer by Tyr287. Its other ligands are Asn111, His113, and Glu138: the coordination number is thus 4, and not 5 as in A or B. In addition to the two H-bonded interactions between Lys136 and Glu138 and between Tyr287 and Asp300, an additional H-bond connects another Lys136 proton and the C-bound hydroxamate $\mathrm{O}$ atom. Thus, structures A-C highlight a diversity of $\mathrm{Zn}$-binding motives. The varying coordination numbers will impact differently non-additivity. In addition, according to the structure, Zn-binding can for some ligands occur in out-of-plane positions, as observed in particular for the N-bound hydroxamate oxygen and for the Zn-ligating His 113 nitrogen. Furthermore, some ligand-ligand interactions can themselves occur over the rings. This is observed: -a) between Asn111 and hydroxamate. The amino $\mathrm{H}$ cis to the $\mathrm{CO}$ bond of Asn is at representative $\pi$-H-bond distances to the conjugated ring of hydroxamate: in A, 2.8 and $3.0 \AA$ from the N-bound $\mathrm{O}$ atom and the $\mathrm{N}$ atom, respectively; in $\mathrm{B}, 2.7 \AA$ from the $\mathrm{C}$ and $\mathrm{N}$ atoms; and in $\mathrm{C}, 2.5,2.6,2.9$ and $3.1 \AA$ from the $\mathrm{N}$-bound $\mathrm{O}, \mathrm{N}, \mathrm{C}$, and $\mathrm{C}$-bound $\mathrm{O}$ atoms, respectively; -and b) between His285 and Tyr287 in structures A and B. Such observations underline the need for a dependable representation of anisotropy, which was addressed in the first part of this study. The results are reported in Table VI. $\triangle \mathrm{E}(\mathrm{SIBFA})$ reproduces closely $\triangle \mathrm{E}(\mathrm{QC})$ and its trends along the sequence $\mathrm{C}>\mathrm{A}>\mathrm{B}$, and has the proper balance between $\mathrm{E}_{1}$ and $\mathrm{E}_{2}$. Within $\mathrm{E}_{1}$, there remains some compensation of errors, $\mathrm{E}_{\mathrm{MTP}}$ being larger than $E_{C}$ but $E_{\text {rep }}$ being larger than $E_{X}$ leading to closely similar (within $10 \mathrm{kcal} / \mathrm{mol}$ out of $>550$ ) $E_{1}$ values. Further improvements will resort to alternative, newly-emerging procedures to derive distributed multipoles, such as $\mathrm{GEM}^{[49-50]}$ or the iterative Stockholder method ${ }^{[47-48]}$ and GEM-derived multipoles. ${ }^{[49-50]}$ It will be instructive to evaluate if these could remedy some shortcomings of the GDMA approach regarding conjugated or aromatic ligands which were mentioned in the Introduction. These would in turn impact $\mathrm{E}_{\text {rep, }}$, which has 
prefactors embodying the electronic population of the pair of interacting atoms. Work is in progress along these lines.

Handling of non-additivity effects. At this stage, and in line with a point raised by a Reviewer, it is essential to reevaluate how well the $\mathrm{QC}$ non-additivity, $\delta \mathrm{E}_{\text {nadd, }}$ can be accounted for. We have previously reported comparisons between QC and SIBFA regarding both anti-cooperativity in polyligated complexes of Zn(II) with $\mathrm{N}-, \mathrm{O}-$, and S- containing ligands ${ }^{[51-52]}$ and cooperativity effect in multiply H-bonded complexes. ${ }^{[61-63]}$ These calculations were carried out with the CEP 4-31G(2d) basis set. Which outcome is expectable in the context of the aug-cc-pVTZ(-f) basis, which is more polarizable and has much more diffuse orbitals? We compare in Tables VIIa-c the values of $\delta \mathrm{E}_{\text {nadd }}$ in three representative complexes: the binding site of the anthrax lethal factor, $\mathrm{Zn}[\mathrm{HHE}]^{+}$, with two imidazole and an anionic O ligand (Table VIIa); [Zn(Imidazoles) $\left.)_{4}\right]^{2+}$, with four neutral Nligands (Table VIIb); and [Zn(HHCC)], with two neutral N-ligands and two anionic S-ligands (Table VIIc). $\delta \mathrm{E}_{\text {nadd }}(\mathrm{SIBFA})$ reproduces well its $\mathrm{QC}$ counterpart for all three complexes. There are two cases when the $\delta \mathrm{E}_{\text {nadd }}$ error exceeds $10 \%$, namely for $\mathrm{E}_{\mathrm{pol}}(\mathrm{VR})$ versus $\mathrm{E}_{\mathrm{pol}}$ in the $\mathrm{Zn}[\mathrm{HHE}]^{+}$complex, and for $\mathrm{E}_{\mathrm{pol}}(\mathrm{RVS})$ versus $\mathrm{E}_{\mathrm{pol}}$ * in the $\left[\mathrm{Zn}(\mathrm{Imidazoles})_{4}\right]^{2+}$ complex. Yet in both cases the agreements between $\mathrm{E}_{\mathrm{pol}}(\mathrm{VR})$ and $\mathrm{E}_{\mathrm{pol}}$, and between $E_{\text {pol }}(R V S)$ versus $E_{\text {pol }} *$ respectively are close, with only $2 \%$ relative errors. $\delta E_{\text {nadd }}$ is larger in magnitude for $E_{p o l}(V R)$ and $E_{p o l}$ than for $E_{p o l}(R V S)$ and $E_{p o l} *$. This as earlier mentioned is an additional signature for anticooperativity. $\delta \mathrm{E}_{\text {nadd }}(\mathrm{QC})$ for $\mathrm{E}_{\mathrm{ct}}$ is closely accounted for by $\delta \mathrm{E}_{\text {nadd }}(\mathrm{SIBFA})$. It increases in both approaches by factors of 1.2-1.25 upon passing from $\mathrm{Zn}[\mathrm{HHE}]^{+}$to $\left.[\mathrm{Zn} \text { (Imidazoles) })^{2+}\right]^{2+}$ even though there is no anionic ligand in the latter. It next increases by factors 2.3-2.5 upon passing to [ $\mathrm{Zn}(\mathrm{HHCC})]$ which has two 'soft' anionic ligands. Such agreements regarding $\delta \mathrm{E}_{\text {nadd }}\left(\mathrm{E}_{\mathrm{ct}}\right)$ validate its formulation which introduces dependencies upon the potentials and fields undergone by the interacting partners. ${ }^{[2]}$ While $\mathrm{E}_{\mathrm{C}}$ is strictly additive, $\mathrm{E}_{\mathrm{X}}$ has small $\delta \mathrm{E}_{\text {nadd }}$ magnitude, much smaller than those of the second-order contributions. This is fully consistent with the results from Ref.. ${ }^{[18]}$ It could be accounted for by a three-body overlap formula involving the $\mathrm{Zn}$ (II) cation, and all pairs of ligand heavy atoms. ${ }^{[18]}$ For the present study, it was only included in the three test cases of Table VIIa-c but not at this stage in Tables IV-VI. Refining the calibration of $\delta \mathrm{E}_{\text {nadd }}\left(\mathrm{E}_{\mathrm{rep}}\right)$ and its explicit inclusion within $\Delta \mathrm{E}$ should await prior refinements of $\mathrm{E}_{\mathrm{MTP}}{ }^{*}$ with alternatives to GDMA multipoles, considering the dependencies of $E_{\text {rep }}$ upon the electronic populations of the interacting partners. ${ }^{[2,4,18]}$

Monoligated $\mathbf{M g}$ (II) and $\mathrm{Ca}$ (II) complexes. The very first $\mathrm{PMM}$ calibrations of $\mathrm{Mg}(\mathrm{II})$ and $\mathrm{Ca}$ (II) with an explicit charge-transfer contribution were from 1985. ${ }^{[64]}$ Refinements resorting to the RVS procedure and the CEP 4-31G(2d) basis set were subsequently reported. ${ }^{[57]}$ Upon now resorting to the aug-cc-pVTZ basis set, we performed their calibration as follows. The cation-specific parameters for each contribution were fit in order to reproduce the radial dependency of its QC counterpart in their complexes with water along the water external bisector. The $\mathrm{K}(\mathrm{M}-\mathrm{N})$ and $\mathrm{K}(\mathrm{M}-\mathrm{S})$ constants used for $\mathrm{E}_{\text {rep }}$ were fit in order to match the radial dependency of $\mathrm{E}_{\mathrm{X}}$ 
in the cation complex with imidazole and methanethiolate. Tables VIIIa and VIIIb report the compared SIBFAQC values for the complexes of $\mathrm{Mg}(\mathrm{II})$ with the same O-containing ligands (VIIIa) and $\mathrm{N}$ - and S-containing ligands (VIIIb) as in the corresponding Tables Ia and Ib for Zn(II). Table IX compares the radial dependencies of $\triangle \mathrm{E}(\mathrm{QC})$ and $\triangle \mathrm{E}(\mathrm{SIBFA})$ and their contributions for the monoligated $\mathrm{Mg}(\mathrm{II})$-formamide complex. Tables Xa and $\mathrm{Xb}$ report the results for the same monoligated $\mathrm{Ca}(\mathrm{II})$ complexes as those of Tables VIIIa and VIIIb for $\mathrm{Mg}(\mathrm{II})$. A close reproduction of $\Delta \mathrm{E}(\mathrm{QC})$ and its contributions is found with methanol, phenol, formamide and formate, as well as with pyridine and trimethylamine, which were not used to fit the $\operatorname{Mg}$ (II) and $\mathrm{Ca}$ (II) parameters. Tables $\mathrm{XIa}$ and $\mathrm{XIb}$ report the radial dependencies of $\triangle \mathrm{E}(\mathrm{QC})$ and $\triangle \mathrm{E}(\mathrm{SIBFA})$ and their contributions of the formate-Ca(II) complexes in the external (XIa) and bridge (XIb) complexes. The comparison between $\mathrm{Mg}(\mathrm{II})$ and $\mathrm{Zn}(\mathrm{II})$, which have similar ionic radii, is instructive. At equilibrium distance, for each monoligated complexes, $\mathrm{E}_{1}$ has a significantly larger weight with $\mathrm{Mg}$ (II) than with $\mathrm{Zn}$ (II), while the chargetransfer is much smaller, consistent with the 'harder' character of $\mathrm{Mg}(\mathrm{II}) .{ }^{[65-67]}$ The comparison between $\mathrm{Mg}(\mathrm{II})$ and $\mathrm{Ca}(\mathrm{II})$ shows that even though the equilibrium distance is significantly larger for $\mathrm{Ca}$ (II), by up to $0.5 \AA, \mathrm{E}_{\mathrm{ct}}$ has a much larger magnitude in the monoligated $\mathrm{Ca}(\mathrm{II})$ complex than in the $\mathrm{Mg}(\mathrm{II})$ one. The radial dependencies of $\triangle \mathrm{E}(\mathrm{QC})$ and $\triangle \mathrm{E}(\mathrm{SIBFA})$ and their contributions are given in Supp. Info SVII a-i and SVIII a-h for the monoligated $\mathrm{Mg}(\mathrm{II})$ and $\mathrm{Ca}(\mathrm{II})$ complexes respectively.

\section{Polyligated Mg(II) and Ca(II) complexes.}

$M g(I I)$. We have investigated the tetra- and hexahydrated complexes of $\mathrm{Mg}(\mathrm{II})$ in the same geometries as for $\mathrm{Zn}(\mathrm{II})$. The results are reported in Table XIIa. We also investigated the polyligated complexes in the binding site of the HIV-1 integrase. ${ }^{[68]}$ This complex is represented in Figure 11. The results are reported in Table XIIb. For the $\left[\mathrm{Mg}\left(\mathrm{H}_{2} \mathrm{O}\right)_{4}\right]^{2+}$ and the $\left[\mathrm{Mg}\left(\mathrm{H}_{2} \mathrm{O}\right)_{6}\right]^{2+}$ complexes $\Delta \mathrm{E}(\mathrm{SIBFA})$ and its contributions closely reproduce their RVS counterparts, as was the case for the corresponding $\left[\mathrm{Zn}\left(\mathrm{H}_{2} \mathrm{O}\right)_{4}\right]^{2+}$ complexes. Both $\Delta \mathrm{E}(\mathrm{SIBFA})$ and $\Delta \mathrm{E}(\mathrm{RVS})$ have app. $10 \mathrm{kcal} / \mathrm{mol}$ lesser magnitudes than in the corresponding $\mathrm{Zn}(\mathrm{II})$ complexes. With both procedures, this is due predominantly to $\mathrm{E}_{\mathrm{ct}}$ and, to a lesser extent, to $\mathrm{E}_{\mathrm{pol}}$ as well, which counteract the inverse preferences of $E_{1}$. Within $\mathrm{E}_{1}, \mathrm{E}_{\mathrm{C}} / \mathrm{E}_{\mathrm{MTP}} *$ and $\mathrm{E}_{\mathrm{X}} / \mathrm{E}_{\text {rep }}$ have opposite preferences, the former favoring $\mathrm{Zn}(\mathrm{II})$ due to penetration and the latter favoring $\mathrm{Mg}(\mathrm{II})$ owing to its smaller size, and it is $\mathrm{E}_{X} / \mathrm{E}_{\text {rep }}$ that imposes the preference of $\mathrm{E}_{1}$. This highlights again the need for the separability of the intermolecular potential. The same trends in $\mathrm{Mg}(\mathrm{II})$ versus $\mathrm{Zn}(\mathrm{II})$ are found in their complexes with three and four imidazoles (compare Tables IVb and XIIb). The $[2 \mathrm{Mg}(\mathrm{DDE})]^{+}$is a more challenging case, owing to the presence of two divalent cations and three anionic ligands. Nevertheless, $\Delta \mathrm{E}(\mathrm{SIBFA})$ can still retain a close agreement to $\Delta \mathrm{E}(\mathrm{RVS})$, the relative error being $2 \%$, although some compensations between $\mathrm{E}_{1}$ on the one hand, and $\mathrm{E}_{\mathrm{pol}}$ and $\mathrm{E}_{\mathrm{ct}}$ on the other hand, could again be noted. 
$\mathrm{Ca}(\mathrm{II})$. $\mathrm{Ca}(\mathrm{II})$ in water solution can adopt fluctuating coordination numbers, in the 6-8 range. This was shown in a MD simulation using AMOEBA. ${ }^{[69]}$ In view of long-duration MD simulations using SIBFA and now enabled by the massively parallel Tinker-HP code, ${ }^{[30]}$ it is essential to evaluate how well the values of $\Delta \mathrm{E}(\mathrm{QC})$ and its individual contributions can be matched upon changes of the coordination Figures 12a-c show three structures of $\mathrm{Ca}(\mathrm{II})$ bound by eight water molecules, denoted as: a: $\left[\mathrm{Ca}\left(\mathrm{H}_{2} \mathrm{O}\right)_{6+2}\right]^{2+}, b:\left[\mathrm{Ca}\left(\mathrm{H}_{2} \mathrm{O}\right)_{7+1}\right]^{2+}$, and $c:\left[\mathrm{Ca}\left(\mathrm{H}_{2} \mathrm{O}\right)\right.$ $8]^{2+}$ namely with six and two first- and second-shell molecules, seven first and one second-shell water, and eight first-shell water molecules, respectively. These structures were extracted from a one nanosecond SIBFA MD simulation in a droplet of 512 water molecules. Table XIII compares the SIBFA and QC results in these arrangements. The ordering found by SIBFA is $b:\left[\mathrm{Ca}\left(\mathrm{H}_{2} \mathrm{O}\right)_{7+1}\right]^{2+}>c:\left[\mathrm{Ca}\left(\mathrm{H}_{2} \mathrm{O}\right)_{8}\right]^{2+}>a:\left[\mathrm{Ca}\left(\mathrm{H}_{2} \mathrm{O}\right)_{6+2}\right]^{2+}$. The $b$ versus $a$ preference is dictated by $\mathrm{E}_{1}$ overcoming the inverse preferences of both $\mathrm{E}_{\mathrm{pol}}$ and $\mathrm{E}_{\mathrm{ct}}$ within $\mathrm{E}_{2}$. The preference of $b$ over $c$ is, conversely, now dictated by $\mathrm{E}_{2}$ and goes in par with a small preference of $\mathrm{E}_{1}$ as well. $\mathrm{E}_{\mathrm{pol}}$ has in $b$ values that are intermediate between those found in $c$ and $a$. All these trends, as well as the numerical values and $\Delta \mathrm{E}$ energy differences, are fully consistent with those of $\Delta \mathrm{E}(\mathrm{RVS})$ and its contributions.

Calmodulin $(\mathrm{CaM})$ is a pivotal $\mathrm{Ca}(\mathrm{II})$-binding protein, relaying the role of $\mathrm{Ca}(\mathrm{II})$ as an intracellular messenger [Review in $\left.{ }^{[70-71]}\right]$. It has two $\mathrm{Ca}(\mathrm{II})$-binding loops, denoted I-IV, at each $\mathrm{N}$ - and C-terminal ends. Ca(II)-binding loops III and IV have been previously studied by 2D-NMR spectroscopy and SIBFA energy-minimization. ${ }^{[72]}$ $\mathrm{Ca}$ (II) binding triggers $\mathrm{CaM}$ conformational changes, which it could be very interesting to monitor by longduration MD. We are now given the possibility of validating SIBFA by high-level QC EDA. Thus as a first stage toward such simulations, we have considered Ca(II) binding loop III, having up to four formate anionic ligands and a hydroxyl one (Figure 13). The geometry of the complex was extracted from 1CLL.pdb. ${ }^{[73]}$ There is an excess of two negative charges. Which accuracy could still be expected? Table XIII (last two columns) shows that $\Delta \mathrm{E}(\mathrm{RVS})$ can be reproduced by $\triangle \mathrm{E}(\mathrm{SIBFA})$ with a relative error of $3 \%$. The very significant decrease of $\mathrm{E}_{\mathrm{pol}}(\mathrm{QC})$ and $\mathrm{E}_{\mathrm{pol}}(\mathrm{SIBFA})$ compared of its values in the $\mathrm{Ca}(\mathrm{II})$ polyhydrates is noteworthy. It translates the very strong reduction of the dicationic field by the fields exerted by the four anionic charges.

\section{Conclusions and perspectives.}

The requirement for each contribution of an APMM/APMD potential to reproduce both anisotropy and nonadditivity features of its QC counterpart is critical for transferability. ${ }^{[4]}$ In the context of SIBFA, the anisotropy of the short-range contributions $\mathrm{E}_{\mathrm{rep}}$ and $\mathrm{E}_{\mathrm{ct}}$ is predominantly enabled by the angular features of electron $\mathrm{sp}^{\mathrm{n}}$ and $\pi$ lone pairs. An additional contribution to the anisotropy of $E_{\text {rep }}$ is conferred by its $S^{2} / \mathrm{R}^{\mathrm{n}}$ formulation, ${ }^{[2-16]}$ expressing its dependence upon intermolecular bond-bond, bond-lone pair, and lone pair-lone pair overlaps: the $\mathrm{S}^{2} / \mathrm{R}^{\mathrm{n}}$ bond-bond repulsion should enable to account for anisotropy also in the absence of lone pairs, as in the model case of two hydrogen molecules in linear, parallel, and crossed configurations. ${ }^{[74-75]}$ Of course, results are 
not perfect as other effects in metal cation polyligated complexes such as three-body effects which are sometimes significant. ${ }^{[18]}$ Such additional corrections as mentioned above exist in SIBFA ${ }^{[18]}$ and will upon refinements allow for further corrections in the final incoming set of parameters of the force-field. In the first integration of $E_{c t}$ in the context of SIBFA ${ }^{[2,28]}$ we considered the linear water dimer and monitored its evolution for out-ofplane variations of the electron acceptor as a function of the $\mathrm{HOH}$ (electron donating water) $-\mathrm{H}$ angle. $\mathrm{E}_{\mathrm{ct}}(\mathrm{SIBFA})$ was able to closely parallel the evolution of $\mathrm{E}_{\mathrm{ct}}(\mathrm{QC})$. Its relatively shallow behavior stemmed from mutual compensations, upon augmenting this angle, between the decreased amplitude of $E_{c t}$ contributed by one $\mathrm{sp}^{3}$ lone pair concomitant with the increased amplitude contributed by the other $\mathrm{sp}^{3}$ lone pair. But such a situation does not apply in out-of-plane complexes which involve $\mathrm{sp}^{2}$ or $\mathrm{sp}$ lone pairs in conjugated molecules: if for a fixed $\theta$ angle an incoming H-bond donor or cationic probe is raised progressively above their plane, both $E_{\text {rep }}$ and $E_{c t}$ will undergo a regular decrease in their magnitude due to decreased overlap, until a $\pi$ lone pair is encountered when the probe approaches or reaches the perpendicular. Such decreases are not observed with $E_{X}$ and $E_{c t}(R V S)$, and could thus significantly impair the agreement with these contributions. For conjugated molecules, we found that a simple remedy consisted into smearing the $\mathrm{sp}^{2}$ and $\mathrm{sp}$ lone pairs, by relocating a fraction, $\alpha$, of the initial population, namely two, in a plane perpendicular to the molecule, at a well-defined angle and at equal distances above and below it. For sp lone pairs, as in imidazole, the plane of the two smeared lone pairs cuts the molecular plane along the external bisector of the atom bearer. For $\mathrm{sp}^{2}$ lone pairs, as for carbonyl or carboxylate oxygens, the corresponding plane cuts the molecular plane along the CO bond. We have considered four conjugated fragments: formamide, formate, hydroxamate, and imidazole. For each fragment, and at a given value of the $\theta$ angle for in-plane variations, the values of $\alpha$ and of the out-of-plane elevation $\mathrm{z}$ were fit so that $E_{\text {rep }}$ reproduces the evolution of $E_{X}$ upon $\phi$-dependent out-of-plane evolutions of a probe molecule. Validations were done upon resuming these variations for a range of $\theta$ values encompassing the initial one. Such validations showed that both $\mathrm{E}_{\mathrm{rep}}$ and $\mathrm{E}_{\mathrm{ct}}$ could reproduce closely the in- and out-of plane dependencies of their QC counterparts for such values. Some differences could be observed concerning $E_{c t}$, as in the case of $\mathrm{Zn}$-formate or Zn-hydroxamate, but these either bore on small amounts, or were compensated by $\mathrm{E}_{\mathrm{pol}}$ within $\mathrm{E}_{2}$, and in any case did not impair the agreement between $\Delta \mathrm{E}(\mathrm{SIBFA})$ and $\Delta \mathrm{E}(\mathrm{RVS})$ in the relevant energy-wise geometries.

Along with these refinements, we integrated in the SIBFA library of fragments the polar or anionic moieties of several protein side-chains, constructed with augcc-pVTZ(-f) distributed multipoles and polarizabilities. We retained the general parameters which were previously optimized by the automated INoLLS procedure ${ }^{[7]}$ in this context, and performed limited recalibration of the atom-specific parameters owing to the smearing of the lonepairs. We resorted to $\mathrm{Zn}(\mathrm{II})$ as a probe for $\triangle \mathrm{E}(\mathrm{SIBFA})$ and its contributions to match their $\mathrm{QC}$ counterparts upon varying the $\mathrm{Zn}$-ligand distance at fixed angles. The calibration and validation of the $\mathrm{Mg}(\mathrm{II})$, and $\mathrm{Ca}$ (II) cations were performed subsequently. 
In this context, the most stringent tests and criteria for transferability clearly bear on polyligated complexes of the divalent cations. $\mathrm{Zn}$ (II) plays a prominent role, catalytic as well as structural, in numerous metalloproteins. ${ }^{[1]}$ We focused first on a series of polyligated complexes of $\mathrm{Zn}(\mathrm{II})$ with $\mathrm{O}-, \mathrm{N}-$, and S- containing ligands. We considered first model complexes with four and six water ligands, three and four imidazoles, and three methanethiolates [Tables IVa-b]. Several such complexes had been previously reported by us in the context of the CEP 4-31G(2d) basis set, ${ }^{[27,52]}$ but it could not be granted that close agreements would still hold with the augcc-p-VTZ basis owing to the onset of much larger overlap as well as polarizability effects. We further considered a complex extracted from the X-ray structures of Zn-fingers, $[\mathrm{Zn}(\mathrm{HHCC})]$. A second complex, $[\mathrm{Zn}(\mathrm{HHE})]^{+}$, was extracted from the X-ray structure of the anthrax lethal factor. Close numerical agreements were retained between $\Delta \mathrm{E}(\mathrm{SIBFA})$ and $\triangle \mathrm{E}(\mathrm{RVS})$ in all cases with relative errors in the $1-3 \%$ range, with one exception $[\mathrm{Zn}(\mathrm{CCC})]^{-}$, in which it amounted to $4 \%$. Limited compensations of errors between contributions, however, could be noted in some cases.

The most stringent test of this study related to the complex of hydroxamate with the binding site of phosphomannoseisomerase (PMI). PMI is a Zn-metalloenzyme responsible for bacterial and parasitic diseases ${ }^{[58-}$ ${ }^{59]}$ and refs. therein, and hydroxamate is a recurrent $\mathrm{Zn}$-binding moiety of pharmacological inhibitors. There are no known X-ray structures for inhibitor-bound PMI. Structural insight could be provided by PMD simulations. Thus three candidate structures, denoted A-C, were unraveled by SIBFA MD for the complexes of a hydroxamate-based inhibitor, 5PAH, and three dehydroxylated derivatives. Important, although not exclusive, differences between modes A-C concerned the modes of coordination of hydroxamate to $\mathrm{Zn}(\mathrm{II})$ : bidentate in A, and monodentate in B and C, with five- and four-fold coordinations in A-B and in C, respectively. It was essential to evaluate if the generally close agreements found between $\Delta \mathrm{E}(\mathrm{SIBFA})$ and $\Delta \mathrm{E}(\mathrm{QC})$ for all twelve complexes in enlarged recognition sites with up to 265 atoms obtained as well upon focusing on the sole Zn-binding site encompassing the hydroxamate moiety and seven end side-chain residues, not only regarding $\Delta \mathrm{E}$ but their individual contributions as well. Table VI confirmed this to be the case, with even smaller relative errors $(1 \%)$ than in the other polyligated complexes. Closer consideration of Figures 10a-c showed that Zn-binding to its hydroxamate, formate, formamide and/or imidazole ligands could occur out of the ligand plane, thus not exclusively in the plane; it also showed in some complexes the onset of 'promiscuous' interactions between the $\mathrm{Zn}$-coordinating residues, occurring near, or at, the vertical of the conjugated rings, such as between one formamide $\mathrm{H}$ and the hydroxamate or one imidazole $\mathrm{CH}$ and the $\mathrm{Zn}$-coordinating $\mathrm{N}$ of the other imidazole. These findings, as well as those done recently for the binuclear Zn-binding site of a metallo- $\beta$-lactamase bound to a thiazole-thione inhibitor [Kwapien et al., submitted] stress the need for a correct smearing of the $\mathrm{sp}$ and $\mathrm{sp}^{2}$ lone pairs enabling to account for in- and out-of-plane binding on a balanced level. 
We next considered representative O- and N-polyligated complexes of $\mathrm{Mg}$ (II) in the same geometries as for $\mathrm{Zn}(\mathrm{II})$. This enabled to compare the weights of the energy contributions upon passing from $\mathrm{Zn}$ (II) to $\mathrm{Mg}$ (II). In the context of SIBFA, the preference in favour of the 'softer' cation, $\mathrm{Zn}(\mathrm{II})$, was due to $\mathrm{E}_{\mathrm{ct}}$, while $\mathrm{E}_{1}$ favoured the 'harder' and smaller cation, $\mathrm{Mg}(\mathrm{II})$, due to a lesser $\mathrm{E}_{\text {rep }}$ value within $\mathrm{E}_{1}$, overcoming the more favorable $\mathrm{E}_{\mathrm{MTP}} *$ value for $\mathrm{Zn}(\mathrm{II})$ due to penetration. The results were fully consistent with the RVS ones. $\mathrm{E}_{\mathrm{disp}} / \mathrm{E}_{\text {corr }}$ will further stabilize $\mathrm{Zn}$ (II) over $\mathrm{Mg}(\mathrm{II}) .{ }^{[57,67]}$ These findings reemphasize again the need for separability. A stringent test for polycoordinated $\mathrm{Mg}$ (II) concerned the binding site of the HIV-1 integrase, in which two $\mathrm{Mg}$ (II) cations are chelated by three Asp/Glu end side-chains. This gave rise to very large electrostatic/polarization effects, yet the relative error remained confined to $2 \%$.

The third cation considered is $\mathrm{Ca}(\mathrm{II})$, involved in a wealth of structural and enzymatic processes, and in cellular signaling. $\mathrm{Ca}(\mathrm{II})$ is prone to adopt variable, and possibly fluctuating, coordination numbers. This occurs in water, where $\mathrm{n}$ can vary between 6 and 8. A stringent test for transferability/nonadditivity bore on three competing octahydrated $\mathrm{Ca}(\mathrm{II})$ complexes, extracted as snapshots from $\mathrm{MD}$. We have compared $\Delta \mathrm{E}$ and its contributions in $: a:\left[\mathrm{Ca}\left(\mathrm{H}_{2} \mathrm{O}\right)_{6+2}\right]^{2+}, b:\left[\mathrm{Ca}\left(\mathrm{H}_{2} \mathrm{O}\right)_{7+1}\right]^{2+}$, and $c:\left[\mathrm{Ca}\left(\mathrm{H}_{2} \mathrm{O}\right)_{8}\right]^{2+}$ with six, seven, and eight first-shell water molecules, respectively. $\triangle \mathrm{E}(\mathrm{SIBFA})$ ranked the complexes along the same ranking as $\Delta \mathrm{E}(\mathrm{QC})$, namely $b>c>a$. Its numerical values were close to the $\mathrm{QC}$ ones with relative errors $<1 \%$, and the individual contributions of $\triangle \mathrm{E}(\mathrm{SIBFA})$ closely followed the same trends as their QC counterparts. $\Delta \mathrm{E}(\mathrm{SIBFA})$ also retained a close agreement with $\triangle \mathrm{E}(\mathrm{QC})$, with a relative error $<2 \%$, in a model of a $\mathrm{Ca}(\mathrm{II})$-binding loop in $\mathrm{CaM}$, which encompasses four formate anions and one hydroxyl group, an extreme case of screening of a dipositive charge by up to four anionic charges. The agreements with QC are a strong incentive for extensions of SIBFA to a diversity of $\mathrm{Ca}(\mathrm{II})$-dependent regulatory proteins, as well as to engineered $\mathrm{Ca}(\mathrm{II})$ sensors and transporters [reviewed in $\left.{ }^{[76]}\right]$.

The smeared lone-pair representation has been very recently used to a model bimetallic Zn-binding site of a $\mathrm{Zn}$ dependent metallo- $\beta$-lactamase (MBL). In one monozinc site, a $\mathrm{Zn}$ (II) cation is chelated by three imidazoles and by a cyclic $\mathrm{N}$ atom of thiazole-thione (TZT), the conjugated anionic Zn-binding group of a novel group of MBL inhibitors. In the second site, the other $\mathrm{Zn}$ (II) cation is complexed by two other imidazoles, a formate and the extracyclic $\mathrm{S}$ atom of TZT [Kwapien et al., submitted]. $\triangle \mathrm{E}$ (SIBFA) in the dizinc site as well as in both monozinc sites, whether TZT-ligated or unligated, was found to reproduce $\triangle \mathrm{E}(\mathrm{QC})$ with $<2 \%$ errors, a highly encouraging outcome given the complex interplay of first- and second-order effects and the magnitudes of the interaction energies. Presently, energy-minimizations on the complexes of a series of TZT-based MBL inhibitors are underway. At the present stage, Zn-coordination appears stable and fully consistent with the available data from X-ray crystallography of the complexes of MBL with such TZT inhibitors [Kwapien et al., work in progress]. It remains to be seen how stable such coordinations will remain upon passing to very long duration 
MD. This constitutes the next major step of our developments. It will be undertaken as soon as the integration of the full SIBFA potential and its gradients into the massively parallel Tiker-HP code [Tinker HP_team, TinkerHP, http://www.ip2ct.umpc.fr/tinkerHP, 2016] is completed.

A last note concerns the representation of the localized lone pairs. They are explicitly accounted for in SIBFA in four contributions: along with $E_{r e p}$ and $E_{c t}$, they are represented in $E_{\text {disp }}$ as fictitious atoms [see eg., Ref. ${ }^{[10]}$ ] and, in $\mathrm{E}_{\mathrm{pol}}$, through the dipole polarizabilities on the sigma-type lone-pairs. The importance of lone pairs to improve directionality in H-bonded complexes was demonstrated in the context of classical, non-polarizable force-fields by Lii and Allinger [ ${ }^{[77]}$ and Refs. therein]. Lone-pairs are also represented in another polarizable potential, the classical Drude oscillator model, as centers for virtual sites improving the anisotropy of the polarization response $\mathrm{e}^{[78-79]}$

As a next step of this study, we are extending the construction of the SIBFA library with correlated aug-cc-pVTZ multipoles and polarizabilities. $\triangle \mathrm{E}(\mathrm{SIBFA})$ and its contributions, now integrating correlation effects, as well as $E_{\text {disp, }}$ are being recalibrated on the basis of SAPT EDA's. The present proof-of-principle validations pave the way for those performed at the correlated level. Recent are recently available regarding the stacked and H-bonded complexes of cytosine and guanine bases [Ref. 10] and the channeling of alkali cations across two stacked guanine tetramers [Gresh et al.; submitted]. They showed that upon passing from the HF to correlated levels, resorting to correlated, instead of $\mathrm{HF}$, multipoles and polarizabilities could be sufficient to reproduce correlated $\Delta \mathrm{E}$ results with accuracy. Is this generalizable, and to which extent could correlation impact the parameters (internal coordinates, electron population, increase/decrease of the van der Waals radii) of the in- and smeared out-of plane lone pairs? We are addressing this point for a diversity of ligands upon resorting to Electron Localization Function (ELF) results. ${ }^{[25]}$ We follow a similar strategy as in [Refs. ${ }^{[22-23]}$. The results will be reported in a forthcoming study.

\section{Acknowledgments.}

We wish to thank the Grand Equipement National de Calcul Intensif (GENCI), Institut du Développement et des Ressources en Informatique Scientifique (IDRIS), Centre Informatique de l'Enseignement Supérieur (CINES, France, project No. x2009-075009), and the Centre de Ressources Informatiques de Haute Normandie (CRIHAN, Rouen, France, project 1998053).

We sincerely acknowledge the Research Council of Saint-Joseph University of Beirut, Lebanon (Project FS71), the Lebanese National Council for Scientific Research, CNRS-L (Project FS80), as well as the French InstituteCampus France au Liban and the French-Lebanese program CEDRE (Project FS30) for their financial support 
and, particularly, for funding the PhD thesis of Léa El Khoury. The research by Karolina Kwapien is supported by the ANR 'Anti-MBL'.

Appendix. Internal coordinates of the lone pairs $(\sigma$ and $\pi)$ in formate, formamide, hydroxamate, and imidazole. They are denoted as theta, phi and $r$ (first three columns). The following columns give the occupation numbers of the lone pairs, nocc and the increment of effective radii used for $E_{\text {rep }}$ and $E_{c t}$, denoted as dwlp and twlp, respectively. The last column gives the designation of the atom bearer.

formate

14

\begin{tabular}{rrrrrrl} 
theta & \multicolumn{1}{c}{ phi } & $\mathrm{r}$ & nocc & dwlp & twlp & bearer \\
90.00 & 90.00 & 0.51 & 0.00 & 0.00 & 0.0 & $<=\mathrm{C} 2$ \\
90.00 & -90.00 & 0.51 & 0.00 & 0.00 & 0.0 & $<=\mathrm{C} 2$ \\
115.60 & 00.00 & 0.58 & 1.68 & -0.05 & 0.0 & $<=03$ \\
114.60 & 180.00 & 0.58 & 1.68 & -0.05 & 0.0 & $<=03$ \\
115.00 & 090.00 & 0.82 & 0.32 & 0.20 & 0.0 & $<=03$ \\
115.00 & 270.00 & 0.82 & 0.32 & 0.20 & 0.0 & $<=03$ \\
45.00 & 90.00 & 0.50 & 1.00 & 0.25 & 0.0 & $<=03$ \\
45.00 & -90.00 & 0.50 & 1.00 & 0.25 & 0.0 & $<=03$ \\
115.60 & 000.00 & 0.58 & 1.68 & -0.05 & 0.0 & $<=04$ \\
114.60 & 180.00 & 0.58 & 1.68 & -0.05 & 0.0 & $<=04$ \\
115.00 & 090.00 & 0.82 & 0.32 & 0.20 & 0.0 & $<=04$ \\
115.00 & 270.00 & 0.82 & 0.32 & 0.20 & 0.0 & $<=04$ \\
45.00 & 90.00 & 0.50 & 1.00 & 0.25 & 0.0 & $<=04$ \\
45.00 & -90.00 & 0.50 & 1.00 & 0.25 & 0.0 & $<=04$
\end{tabular}

10

\section{formamide}

$\begin{array}{rrrrrrl}\text { theta } & \text { phi } & \mathrm{r} & \text { nocc } & \text { dwlp } & \text { twlp } & \text { bearer } \\ 60.00 & 90.00 & 0.50 & 0.50 & -0.25 & 0.0 & <=C 2 \\ 60.00 & -90.00 & 0.50 & 0.50 & -0.25 & 0.0 & <=C 2 \\ 113.00 & 00.00 & 0.58 & 1.60 & -0.05 & 0.0 & <=03 \\ 113.00 & 180.00 & 0.58 & 1.60 & -0.05 & 0.0 & <=03 \\ 113.00 & 90.00 & 0.78 & 0.40 & 0.10 & 0.0 & <=03 \\ 113.00 & -90.00 & 0.78 & 0.40 & 0.10 & 0.0 & <=03 \\ 60.00 & 90.00 & 0.50 & 0.50 & 0.25 & 0.0 & <=03 \\ 60.00 & -90.00 & 0.50 & 0.50 & 0.25 & 0.0 & <=03 \\ 60.00 & 90.00 & 0.68 & 1.00 & 0.20 & 0.0 & <=\mathrm{N} 4 \\ 60.00 & -90.00 & 0.68 & 1.00 & 0.20 & 0.0 & <=\mathrm{N} 4\end{array}$


16

\section{hydroxamate}

$\begin{array}{rrrrrrl}\text { theta } & \text { phi } & r & \text { nocc } & \text { dwlp } & \text { twlp } & \text { bearer } \\ 90.00 & 90.00 & 0.50 & 0.50 & 0.00 & 0.0 & <=C 2 \\ 90.00 & -90.00 & 0.50 & 0.50 & 0.00 & 0.0 & <=C 2 \\ 113.00 & 000.00 & 0.58 & 1.75 & 0.00 & 0.0 & <=03 \\ 113.00 & 180.00 & 0.58 & 1.75 & 0.00 & 0.0 & <=03 \\ 113.00 & 090.00 & 0.75 & 0.25 & 0.05 & 0.0 & <=03 \\ 113.00 & -90.00 & 0.75 & 0.25 & 0.05 & 0.0 & <=03 \\ 60.00 & 90.00 & 0.75 & 1.00 & -0.05 & 0.0 & <=03 \\ 60.00 & -90.00 & 0.75 & 1.00 & -0.05 & 0.0 & <=03 \\ 60.00 & 90.00 & 0.50 & 0.50 & 0.00 & 0.0 & <=\mathrm{N} 4 \\ 60.00 & -90.00 & 0.50 & 0.50 & 0.00 & 0.0 & <=\mathrm{N} 4 \\ 105.00 & 000.00 & 0.60 & 1.00 & -0.05 & 0.0 & <=05 \\ 105.00 & 060.00 & 0.60 & 1.00 & -0.05 & 0.0 & <=05 \\ 105.00 & 120.00 & 0.60 & 1.00 & -0.05 & 0.0 & <=05 \\ 105.00 & 180.00 & 0.60 & 1.00 & -0.05 & 0.0 & <=05 \\ 105.00 & 240.00 & 0.60 & 1.00 & -0.05 & 0.0 & <=05 \\ 105.00 & 300.00 & 0.60 & 1.00 & -0.05 & 0.0 & <=05\end{array}$

\section{imidazole}

13

\begin{tabular}{rrrrrrl} 
theta & \multicolumn{1}{c}{ phi } & $\mathrm{r}$ & nocc & dwlp & twlp & bearer \\
110.00 & 131.00 & 0.97 & 0.50 & 0.00 & 0.0 & $<=\mathrm{C} 2$ \\
110.00 & 229.00 & 0.97 & 0.50 & 0.00 & 0.0 & $<=\mathrm{C} 2$ \\
127.54 & 00.00 & 0.72 & 1.50 & -0.10 & 0.0 & $<=\mathrm{N} 3$ \\
120.00 & 43.00 & 1.02 & 0.25 & +0.05 & 0.0 & $<=\mathrm{N} 3$ \\
120.00 & -43.00 & 1.02 & 0.25 & +0.05 & 0.0 & $<=\mathrm{N} 3$ \\
45.00 & 90.00 & 0.85 & 0.50 & 0.00 & 0.0 & $<=\mathrm{N} 3$ \\
45.00 & -90.00 & 0.85 & 0.50 & 0.00 & 0.0 & $<=\mathrm{N} 3$ \\
45.00 & 90.00 & 0.85 & 0.50 & 0.00 & 0.0 & $<=\mathrm{C} 4$ \\
45.00 & -90.00 & 0.85 & 0.50 & 0.00 & 0.0 & $<=\mathrm{C} 4$ \\
45.00 & 90.00 & 0.85 & 1.00 & 0.00 & 0.0 & $<=\mathrm{N} 5$ \\
45.00 & -90.00 & 0.85 & 1.00 & 0.00 & 0.0 & $<=\mathrm{N} 5$ \\
45.00 & 90.00 & 0.85 & 0.50 & 0.00 & 0.0 & $<=\mathrm{C} 6$ \\
45.00 & -90.00 & 0.85 & 0.50 & 0.00 & 0.0 & $<=\mathrm{C} 6$
\end{tabular}




\section{Figure captions.}

Figure 1. Representation of the lone-pair locations in monoligands; a: formamide, b: formate-external, c: hydroxamate and $\mathbf{d}$ : imidazole. $\mathrm{sp}^{2^{*}}$ and $\alpha$ represent the smeared lone-pairs and nocc, respectively.

Figure 2. Representation of the variations undergone by $\mathrm{Zn}$ (II) probe around monoligands; a: $\mathrm{Zn}^{2+}$-formamide, b: $\mathrm{Zn}^{2+}$-formate-external, c: $\mathrm{Zn}^{2+}$-hydroxamate $\left(\mathrm{Zn}^{2+}\right.$ Probing around $\left.\mathrm{O} 3\right)$ and $\mathbf{d}: \mathrm{Zn}^{2+}$-imidazole. Out-of-plane variations of $\varphi$ are represented in different colors; magenta for $\left(\varphi=0^{\circ}\right)$, pink for $\left(\varphi=30^{\circ}\right)$, purple for $\left(\varphi=60^{\circ}\right)$ and iceblue for $\left(\varphi=90^{\circ}\right)$.

Figure 3. $\mathrm{Zn}^{2+}$-formamide complex. Compared evolution of $\Delta \mathrm{E}$ (RVS) and $\Delta \mathrm{E}$ (SIBFA) and of the repulsion contribution on variation of the Zn2+-O $\theta$ angle; a: $\left(\varphi=0^{\circ}\right)$ and b: $\left(\varphi=90^{\circ}\right)$. Zn2+-O distance is $1.90 \dot{\mathrm{A}}$. RVS: Reduced Variational Space (RVS). All energy values are represented in Supp. Info. (Table SII a-d).

Figure 4. $\mathrm{Zn}^{2+}$-formate external complex. Compared evolution of $\triangle \mathrm{E}$ (RVS) and $\triangle \mathrm{E}$ (SIBFA) and of the repulsion contribution on variation of the $\mathrm{Zn}^{2+}{ }_{-} \mathrm{O} \theta$ angle; $\mathbf{a}:\left(\varphi=0^{\circ}\right)$ and $\mathbf{b}:\left(\varphi=90^{\circ}\right) . \mathrm{Zn}^{2+}{ }_{-} \mathrm{O}$ distance is $1.80 \dot{\mathrm{A}}$. RVS: Reduced Variational Space (RVS) analysis. All energy values are represented in Supp. Info. (Table SIII a-d).

Figure 5. $\mathrm{Zn}^{2+}$ - hydroxamate complex. Compared evolution of $\Delta \mathrm{E}$ (RVS) and $\Delta \mathrm{E}$ (SIBFA) and of the repulsion contribution on variation of the $\mathrm{Zn}^{2+}{ }_{-} \mathrm{O} 5 \theta$ angle; $\mathbf{a}:\left(\varphi=0^{\circ}\right)$ and $\mathbf{b}:\left(\varphi=90^{\circ}\right) . \mathrm{Zn}^{2+}-\mathrm{O}$ distance is $1.80 \dot{\mathrm{A}}$. RVS: Reduced Variational Space (RVS) analysis. All energy values are represented in Supp. Info. (Table SIV a-d).

Figure 6. $\mathrm{Zn}^{2+}$ - imidazole complex. Compared evolution of $\Delta \mathrm{E}$ (RVS) and $\Delta \mathrm{E}$ (SIBFA) and of the repulsion contribution on variation of the $\mathrm{Zn}^{2+}-\mathrm{O} \theta$ angle; $\mathbf{a}:\left(\varphi=0^{\circ}\right)$ and $\mathbf{b}:\left(\varphi=90^{\circ}\right)$. $\mathrm{Zn}^{2+}-\mathrm{O}$ distance is $1.90 \dot{\mathrm{A}}$. RVS: Reduced Variational Space (RVS) analysis. All energy values are represented in Supp. Info. (Table SV a-d).

Figure 7. a. $\mathrm{Zn}^{2+}$-formamide complex. Compared evolution of the repulsion contribution on variation of the $\mathrm{Zn}^{2+}-\mathrm{O} \varphi$ angle with $\left(\theta=135^{\circ}\right) ; \mathrm{Zn}^{2+}-\mathrm{O}$ distance is $1.90 \dot{\mathrm{A}}$. b. $\mathrm{Zn}^{2+}$-formate external complex. Compared evolution of the repulsion contribution on variation of the $\mathrm{Zn}^{2+}-\mathrm{O} \varphi$ angle with $\left(\theta=150^{\circ}\right)$; $\mathrm{Zn}^{2+}-\mathrm{O}$ distance is 1.80 A. c. $\mathrm{Zn}^{2+}$-imidazole complex. Compared evolution of the repulsion contribution on variation of the $\mathrm{Zn}^{2+}$ $\mathrm{O} \varphi$ angle with $\left(\theta=127^{\circ}\right) ; \mathrm{Zn}^{2+}$-O distance is $1.90 \dot{\mathrm{A}}$. RVS: Reduced Variational Space (RVS) analysis. $(*)$ Energy values when lone-pairs are not smeared.

Figure 8. Polycoordinated complex of $\mathrm{Zn}$ (II) with: a) four planar water molecules, b) four pyramidal water molecules, c) six octahedral water molecules, d) three methanethiolates, e) three imidazoles and f) four imidazoles.

Figure 9. Polycoordinated complex of $\mathrm{Zn}$ (II) with: a) two imidazoles and two methanethiolates [HHCC], and b) two imidazoles and one formate (Anthrax lethal factor active site [HHE]).

Figure 10. Polycoordinated complex of $\mathrm{Zn}(\mathrm{II})$ with phosphomannose isomerase (PMI). Three structures provided by SIBFA MD are represented in $\mathrm{a}, \mathrm{b}$ and $\mathrm{c}$.

Figure 11. Polycoordinated complex of $\mathrm{Mg}(\mathrm{II})$ with three formate in the integrase catalytic site (Catalytic triad [DDE]). 
Figure 12. Polycoordinated complex of $\mathrm{Ca}(\mathrm{II})$ with 8 water molecules. a) $\left[\mathrm{Ca}(\mathrm{H} 2 \mathrm{O})_{8}\right]^{2+}$, b) $\left[\mathrm{Ca}(\mathrm{H} 2 \mathrm{O})_{7+1}\right]^{2+}$ and c) $\left[\mathrm{Ca}(\mathrm{H} 2 \mathrm{O})_{6+2}\right]^{2+}$.

Figure 13. Polycoordinated complex of $\mathrm{Ca}(\mathrm{II})$ with four formate and one methanol in the calmoduline active site [DDDTE].

\section{Table captions.}

Table I. Complexes of Zn(II) with: Ia : -Oxgen ligands: water, methanol, formamide, phenol, formate E, formate B; Ib: -Nitrogen and Sulfur ligands: imidazole, pyridine, trimethylamine, methanethiolate.

Table II. Complexes of $\mathrm{Zn}(\mathrm{II})$ with: IIa: imidazole over C2, N3, C4, N5, C6 at equilibrium distances. IIb: Formamide over $\mathrm{C}$ and $\mathrm{N}$ phenol over C2, C3, O30.

Table III. Monoligated $\mathrm{Zn}(\mathrm{II})$ complexes: Formamide. Distance variations of $\Delta \mathrm{E}(\mathrm{QC}), \Delta \mathrm{E}(\mathrm{SIBFA})$ and their contributions.

Table IV. Polyligated $\mathrm{Zn}(\mathrm{II})$ complexes with IV. a: pyramidal $\left[\mathrm{Zn}\left(\mathrm{H}_{2} \mathrm{O}\right)_{4}{ }^{2+}\right.$, planar $\left[\mathrm{Zn}\left(\mathrm{H}_{2} \mathrm{O}\right)_{4}\right]^{2+}$, $\left[\mathrm{Zn}\left(\mathrm{H}_{2} \mathrm{O}\right)_{6}\right]^{2+}$; IV.b: $\left[\mathrm{Zn}(\text { Imidazoles })_{3}\right]^{2+},\left[\mathrm{Zn}(\operatorname{Imidazoles})_{4}\right]^{2+},\left[\mathrm{Zn}(\text { Methanethiolates })_{3}\right]^{2+}$

Table V. Polyligated Zn(II) complexes: $[\mathrm{Zn}(\mathrm{HHCC})]$ and $[\mathrm{Zn}(\mathrm{HHE})]^{+}$.

Table VI. PMI- Zn(II) complexes.

Table VII.a-c Nonadditivity values of VII.a: [Zn(HHE) $]^{+}$; VIIb: [Zn(Imidazoles) $)_{4}^{2+}$; VIIc: [Zn(HHCC)].

Table VIII. Complexes of $\mathrm{Mg}(\mathrm{II})$ with: VIIIa: -O-ligands: water, methanol, formamide, phenol, formate B, formate E; VIIIb: -N and S ligands: imidazole, pyridine, trimethylamine, methanethiolate.

Table IX. Monoligated Mg(II) complexes: Formamide. Distance variations of $\Delta \mathrm{E}(\mathrm{QC}), \Delta \mathrm{E}(\mathrm{SIBFA})$ and their contributions.

Table X. Complexes of Ca(II) with: Xa : -O-ligands: water, methanol, formamide, phenol, formate B, formate $\mathrm{E} ; \mathrm{Xb}$ : $-\mathrm{N}$ and $\mathrm{S}$ ligands: imidazole, pyridine, trimethylamine, methanethiolate.

Table XI. Monoligated Ca(II) complexes with XIa. formate external; XIb. Formate bridge. Distance variations of $\triangle \mathrm{E}(\mathrm{QC}), \Delta \mathrm{E}(\mathrm{SIBFA})$ and their contributions.

Table XII. Polyligated complexes of $\mathrm{Mg}(\mathrm{II})$ with XIIa: pyramidal $\left[\mathrm{Mg}(\mathrm{H} 2 \mathrm{O})_{4}\right]^{2+}$, planar $\left[\mathrm{Mg}(\mathrm{H} 2 \mathrm{O})_{4}\right]^{2+}$, $\left[\mathrm{Mg}(\mathrm{H} 2 \mathrm{O})_{6}\right]^{2-}:\left[\mathrm{Mg}(\text { Imidazoles })_{3}\right]^{2+},\left[\mathrm{Mg}(\text { Imidazoles })_{4}\right]^{2+},[2 \mathrm{Mg}(\mathrm{DDE})]^{+}$.

Table XIII. Polyligated complexes of $\mathrm{Ca}(\mathrm{II}):\left[\mathrm{Ca}\left(\mathrm{H}_{2} \mathrm{O}\right)_{6+2}\right]^{2+},\left[\mathrm{Ca}\left(\mathrm{H}_{2} \mathrm{O}\right)_{7+1}\right]^{2+},\left[\mathrm{Ca}\left(\mathrm{H}_{2} \mathrm{O}\right)_{8}\right]^{2+},[\mathrm{Ca}(\mathrm{DDDTE})]^{2-}$. 


\section{Supporting Information.}

Table S.I.a. Monoligated $\mathrm{Zn}(\mathrm{II})$ complexes: $\mathrm{H}_{2} \mathrm{O}$.

Table S.I.b. Monoligated Zn(II) complexes: Methanol.

Table S.I.c. Monoligated Zn(II) complexes: Formate external.

Table S.I.d. Monoligated Zn(II) complexes: Formate bridge.

Table S.I.e. Monoligated Zn(II) complexes: Phenol.

Table S.I.f. Monoligated Zn(II) complexes: Imidazole.

Table S.I.g. Monoligated Zn(II) complexes: Pyridine.

Table S.I.h. Monoligated Zn(II) complexes: Trimethylamine.

Table S.I.i. Monoligated Zn(II) complexes: Methanethiolate.

Table S.II.a. Monoligated Zn(II) complexes: Formamide. Variation of the $\mathrm{Zn}(\mathrm{II})-\mathrm{O} \theta$ angle; $\Phi=0^{\circ} ; \mathrm{d}=1.90 \AA$

Table S.II.b. Monoligated Zn(II) complexes: Formamide. Variation of the $\mathrm{Zn}(\mathrm{II})-\mathrm{O} \theta$ angle; $\Phi=30^{\circ} ; \mathrm{d}=1.90 \AA$

Table S.II.c. Monoligated $\mathrm{Zn}(\mathrm{II})$ complexes: Formamide. Variation of the $\mathrm{Zn}(\mathrm{II})-\mathrm{O} \theta$ angle; $\Phi=60^{\circ}$; $\mathrm{d}=1.90 \AA$

Table S.II.d. Monoligated Zn(II) complexes: Formamide. Variation of the $\mathrm{Zn}(\mathrm{II})-\mathrm{O} \theta$ angle; $\Phi=90^{\circ} ; \mathrm{d}=1.90 \AA$

Table S.III.a. Monoligated $\mathrm{Zn}(\mathrm{II})$ complexes: Formate. Variation of the $\mathrm{Zn}(\mathrm{II})-\mathrm{O} \theta$ angle; $\Phi=0^{\circ} \mathrm{d}=1.80 \AA$

Table S.III.b. Monoligated $\mathrm{Zn}(\mathrm{II})$ complexes: Formate. Variation of the $\mathrm{Zn}(\mathrm{II})-\mathrm{O} \theta$ angle; $\Phi=30^{\circ} \mathrm{d}=1.80 \AA$

Table S.III.c. Monoligated Zn(II) complexes: Formate. Variation of the $\mathrm{Zn}(\mathrm{II})-\mathrm{O} \theta$ angle; $\Phi=60^{\circ} \mathrm{d}=1.80 \AA$

Table S.III.d. Monoligated $\mathrm{Zn}(\mathrm{II})$ complexes: Formate. Variation of the $\mathrm{Zn}(\mathrm{II})-\mathrm{O} \theta$ angle; $\Phi=90^{\circ} \mathrm{d}=1.80 \AA$

Table S.IV.a. Monoligated Zn(II) complexes: Hydroxamate. Variation of the $\mathrm{Zn}(\mathrm{II})-\mathrm{O} 3 \mathrm{\theta}$ angle; $\Phi=0^{\circ} \mathrm{d}=1.80 \AA$

Table S.IV.b. Monoligated Zn(II) complexes: Hydroxamate. Variation of the $\mathrm{Zn}(\mathrm{II})-\mathrm{O} 3 \mathrm{\theta}$ angle; $\Phi=30^{\circ} \mathrm{d}=1.80 \AA$

Table S.IV.c. Monoligated $\mathrm{Zn}(\mathrm{II})$ complexes: Hydroxamate. Variation of the $\mathrm{Zn}(\mathrm{II})-\mathrm{O} 3 \theta$ angle; $\Phi=60^{\circ} \mathrm{d}=180 \AA$

Table S.IV.d. Monoligated $\mathrm{Zn}(\mathrm{II})$ complexes: Hydroxamate. Variation of the $\mathrm{Zn}(\mathrm{II})-\mathrm{O} 3 \mathrm{\theta}$ angle; $\Phi=90^{\circ} \mathrm{d}=1.80$ $\AA$

Table S.V.a. Monoligated $\mathrm{Zn}(\mathrm{II})$ complexes: Hydroxamate. Variation of the $\mathrm{Zn}(\mathrm{II})-\mathrm{O} 5 \theta$ angle; $\Phi=0^{\circ} \mathrm{d}=1.80 \AA$

Table S.V.b. Monoligated Zn(II) complexes: Hydroxamate. Variation of the $\mathrm{Zn}(\mathrm{II})-\mathrm{O} 5 \mathrm{\theta}$ angle; $\Phi=30^{\circ} \mathrm{d}=1.80 \AA$

Table S.V.c. Monoligated Zn(II) complexes: Hydroxamate. Variation of the $\mathrm{Zn}(\mathrm{II})-\mathrm{O} 5 \mathrm{\theta}$ angle; $\Phi=60^{\circ} \mathrm{d}=1.80 \AA$ 
Table S.V.d. Monoligated $\mathrm{Zn}(\mathrm{II})$ complexes: Hydroxamate. Variation of the $\mathrm{Zn}(\mathrm{II})-\mathrm{O} 5 \mathrm{\theta}$ angle; $\Phi=90^{\circ} \mathrm{d}=1.80$ $\AA$

Table S.VI.a. Monoligated Zn(II) complexes: Imidazole. Variation of the $\mathrm{Zn}(\mathrm{II})-\mathrm{O} \theta$ angle; $\Phi=0^{\circ} \mathrm{d}=1.90 \AA$

Table S.VI.b. Monoligated $\mathrm{Zn}(\mathrm{II})$ complexes: Imidazole. Variation of the $\mathrm{Zn}(\mathrm{II})-\mathrm{O} \theta$ angle; $\Phi=30^{\circ} \mathrm{d}=1.90 \AA$

Table S.VI.c. Monoligated Zn(II) complexes: Imidazole. Variation of the $\mathrm{Zn}(\mathrm{II})-\mathrm{O} \theta$ angle; $\Phi=60^{\circ} \mathrm{d}=1.90 \AA$

Table S.VI.d. Monoligated Zn(II) complexes: Imidazole. Variation of the $\mathrm{Zn}(\mathrm{II})-\mathrm{O} \theta$ angle; $\Phi=90^{\circ} \mathrm{d}=1.90 \AA$

Table S.VII.a. Monoligated $\mathrm{Mg}(\mathrm{II})$ complexes: $\mathrm{H}_{2} \mathrm{O}$.

Table S.VII.b. Monoligated Mg(II) complexes: Methanol.

Table S.VII.c. Monoligated $\mathrm{Mg}(\mathrm{II})$ complexes: Formate external.

Table S.VII.d. Monoligated Mg(II) complexes: Formate bridge.

Table S.VII.e. Monoligated Mg(II) complexes: Phenol.

Table S.VII.f. Monoligated $\mathrm{Mg}(\mathrm{II})$ complexes: Imidazole.

Table S.VII.g. Monoligated $\operatorname{Mg}(\mathrm{II})$ complexes: Pyridine.

Table S.VII.h. Monoligated Mg(II) complexes: Trimethylamine.

Table S.VII.i. Monoligated Mg(II) complexes: Methanethiolate.

Table S.VIII.a. Monoligated $\mathrm{Ca}(\mathrm{II})$ complexes: $\mathrm{H}_{2} \mathrm{O}$.

Table S.VIII.b. Monoligated Ca(II) complexes: Methanol.

Table S.VIII.c. Monoligated Ca(II) complexes: Formamide.

Table S.VIII.d. Monoligated Ca(II) complexes: Phenol.

Table S.VIII.e. Monoligated Ca(II) complexes: Imidazole.

Table S.VIII.f. Monoligated Ca(II) complexes: Pyridine.

Table S.VIII.g. Monoligated Ca(II) complexes: Trimethylamine.

Table S.VIII.h. Monoligated Ca(II) complexes: Methanethiolate. 


\section{References.}

[1] F. E. Jacobsen, J. A. Lewis, S. M. Cohen, ChemMedChem 2007, 2, 152-171.

[2] N. Gresh, P. Claverie, A. Pullman, Int. J. Quantum Chem. 1986, 29, 101-118.

[3] N. Gresh, J. Comput. Chem. 1995, 16, 856-882.

[4] N. Gresh, G. A. Cisneros, T. A. Darden, J.-P. Piquemal, J. Chem. Theory Comput. 2007, 3, 1960-1986.

[5] W. J. Stevens, H. Basch, M. Krauss, J. Chem. Phys. 1984, 81, 6026-6033.

[6] T. H. Dunning Jr, J. Chem. Phys. 1989, 90, 1007-1023.

[7] M. Devereux, N. Gresh, J. P. Piquemal, M. Meuwly, J. Comput. Chem. 2014, 35, 1577-1591.

[8] M. M. Law, J. M. Hutson, Comput. Phys. Commun. 1997, 102, 252-268.

[9] T. Dudev, M. Devereux, M. Meuwly, C. Lim, J. P. Piquemal, N. Gresh, J. Comput. Chem. 2015, 36, 285-302.

[10] N. Gresh, J. E. Sponer, M. Devereux, K. Gkionis, B. de Courcy, J.-P. Piquemal, J. Sponer, J. Phys. Chem. B 2015, $119,9477-9495$.

[11] W. J. Stevens, W. H. Fink, Chem. Phys. Lett. 1987, 139, 15-22.

[12] F. Vigné-Maeder, P. Claverie, J. Chem. Phys. 1988, 88, 4934-4948.

[13] D. R. Garmer, W. J. Stevens, J. Phys. Chem. 1989, 93, 8263-8270.

[14] A. J. Stone, J. Phys. Chem. A 2011, 115, 7017-7027.

[15] J. P. Piquemal, N. Gresh, C. Giessner-Prettre, J. Phys. Chem. A 2003, 107, 10353-10359.

[16] J. P. Piquemal, H. Chevreau, N. Gresh, J. Chem. Theory Comput. 2007, 3, 824-837.

[17] N. Gresh, J. Phys. Chem. A 1997, 101, 8680-8694.

[18] R. Chaudret, N. Gresh, O. Parisel, J. P. Piquemal, J. Comput. Chem. 2011, 32, 2949-2957.

[19] R. Chaudret, N. Gresh, C. Narth, L. Lagardère, T. A. Darden, G. A. s. Cisneros, J.-P. Piquemal, J. Phys. Chem. A 2014, 118, 7598-7612.

[20] J. Foster, S. Boys, Rev. Mod. Phys. 1960, 32, 300.

[21] M. W. Schmidt, K. K. Baldridge, J. A. Boatz, S. T. Elbert, M. S. Gordon, J. H. Jensen, S. Koseki, N. Matsunaga, K. A. Nguyen, S. Su, J. Comput. Chem. 1993, 14, 1347-1363.

[22] R. Chaudret, N. Gresh, G. A. Cisneros, A. Scemama, J.-P. Piquemal, Can. J. Chem. 2013, 91, 804-810.

[23] E. Goldwaser, B. de Courcy, L. Demange, C. Garbay, F. Raynaud, R. Hadj-Slimane, J.-P. Piquemal, N. Gresh, J. Mol. Model. 2014, 20, 1-24.

[24] A. D. Becke, K. E. Edgecombe, J. Chem. Phys. 1990, 92, 5397-5403.

[25] B. Silvi, A. Savin, Nature 1994, 371, 683-686.

[26] J. P. Piquemal, J. Pilmé, O. Parisel, H. Gérard, I. Fourré, J. Berges, C. Gourlaouen, A. De La Lande, M. C. Van Severen, B. Silvi, Int. J. Quantum Chem. 2008, 108, 1951-1969.

[27] N. Gresh, J. P. Piquemal, M. Krauss, J. Comput. Chem. 2005, 26, 1113-1130.

[28] N. Gresh, P. Claverie, A. Pullman, Int. J. Quantum Chem. 1982, 22, 199-215.

[29] J.-P. Piquemal, G. A. Cisneros, P. Reinhardt, N. Gresh, T. A. Darden, The Journal of chemical physics 2006, 124, 104101.

[30] L. Lagardère, F. Lipparini, B. Stamm, E. Polack, L. H. Jolly, C. Narth, E. Kratz, G. A. Cisneros, M. Schnieders, T. A. Darden, N. Gresh, Y. Maday, J. W. Ponder, P. Y. Ren, J. P. Piquemal, UPMC, Sorbonne Universités, Paris, 2016. U. Essmann, L. Perera, M. L. Berkowitz, T. Darden, H. Lee, L. G. Pedersen, J. Chem. Phys. 1995, 103, 8577-8593. F. Aviat, A. Levitt, B. Stamm, Y. Maday, P. Ren, J. Ponder, L. Lagardère, L. J. P. Piquemal, J. Chem. Theory Comput. 2017, 13, 180-190.

[34] H. J. C. Berendsen, J. P. M. Potsma, W. F. van Gunsteren, A. DiNola, J. R. Haak, J. Chem. Phys. 1984, 81, 36843960.

[35] J. P. Ryckaert, G. Cicotti, H. J. Berendsen, J. Comput. Phys. 1977, 23, 327-341.

[36] N. Gresh, D. Perahia, B. de Courcy, J. Foret, C. Roux, L. El-Khoury, J. P. Piquemal, L. Salmon, J. Comput. Chem. 2016, 37, 2770-2782

[37] D. Figgen, G. Rauhut, M. Dolg, H. Stoll, Chem. Phys. 2005, 311, 227-244.

[38] A. Bergner, M. Dolg, W. Küchle, H. Stoll, H. Preuß, Mol. Phys. 1993, 80, 1431-1441.

[39] A. J. Misquitta, K. Szalewicz, J. Chem. Phys. 2005, 122, 214109. 
[40] A. Heßelmann, G. Jansen, Chem. Phys. Lett. 2002, 362, 319-325.

[41] Y. Hai, D. W. Christianson, Nat. Chem. Biol. 2016, 12, 741-747.

[42] N. Moitessier, J. Pottel, E. Therrien, P. Englebienne, Z. Liu, A. Tomberg, C. R. Corbeil, Acc. Chem. Res. 2016, 49, 1646-1657.

[43] D. R. Garmer, N. Gresh, B. P. Roques, Proteins: Structure, Function, and Bioinformatics 1998, 31, 42-60.

[44] M. A. Hough, S. S. Hasnain, Structure 2003, 11, 937-946.

[45] C. Bebrone, P. Lassaux, L. Vercheval, J.-S. Sohier, A. Jehaes, E. Sauvage, M. Galleni, Drugs 2010, 70, 651-679.

[46] A. J. Stone, J. Chem. Theory Comput. 2005, 1, 1128-1132.

[47] A. J. Misquitta, A. J. Stone, F. Fazeli, J. Chem. Theory Comput. 2014, 10, 5405-5418.

[48] T. C. Lillestolen, R. J. Wheatley, J. Chem. Phys. 2009, 131, 144101.

[49] D. M. Elking, G. A. Cisneros, J.-P. Piquemal, T. A. Darden, L. G. Pedersen, J. Chem. Theory Comput. 2009, 6, 190202.

[50] G. A. s. Cisneros, J. Chem. Theory Comput. 2012, 8, 5072-5080.

[51] G. Tiraboschi, B. P. Roques, N. Gresh, J. Comput. Chem. 1999, 20, 1379-1390.

[52] G. Tiraboschi, N. Gresh, C. Giessner-Prettre, L. G. Pedersen, D. W. Deerfield, J. Comput. Chem. 2000, 21, 10111039.

[53] J. H. Laity, B. M. Lee, P. E. Wright, Curr. Opin. Struct. Biol. 2001, 11, 39-46.

[54] M. Forino, S. Johnson, T. Y. Wong, D. V. Rozanov, A. Y. Savinov, W. Li, R. Fattorusso, B. Becattini, A. J. Orry, D. Jung, Proc. Natl. Acad. Sci. U. S. A. 2005, 102, 9499-9504.

[55] R. G. Panchal, A. R. Hermone, T. L. Nguyen, T. Y. Wong, R. Schwarzenbacher, J. Schmidt, D. Lane, C. McGrath, B. E. Turk, J. Burnett, Nat. Struct. Mol. Biol. 2004, 11, 67-72.

[56] R. Hardré, C. Bonnette, L. Salmon, A. Gaudemer, Bioorg. Med. Chem. Lett. 1998, 8, 3435-3438.

[57] N. Gresh, D. R. Garmer, J. Comput. Chem. 1996, 17, 1481-1495.

[58] A. Garami, T. Ilg, J. Biol. Chem. 2001, 276, 6566-6575.

[59] E. A. Wills, I. S. Roberts, M. Del Poeta, J. Rivera, A. Casadevall, G. M. Cox, J. R. Perfect, Mol. Microbiol. 2001, 40, 610-620.

[60] A. Cleasby, A. Wonacott, T. Skarzynski, R. E. Hubbard, G. J. Davies, A. E. Proudfoot, A. R. Bernard, M. A. Payton, T. N. Wells, Nat. Struct. Mol. Biol. 1996, 3, 470-479.

[61] N. Gresh, The Journal of Physical Chemistry A 1997, 101, 8680-8694.

[62] M. Masella, N. Gresh, J.-P. Flament, J. Chem. Soc. Faraday Trans. 1998, 94, 2745

[63] H. Guo, N. Gresh, B. P. Roques, D. R. Salahub, J. Phys. Chem. B 2000,104, 9746-9754.

[64] N. Gresh, A. Pullman, P. Claverie, Int. J. Quantum Chem. 1985, 28, 757-771.

[65] R. G. Parr, R. G. Pearson, J. Am. Chem. Soc. 1983, 105, 7512-7516.

[66] R. G. Pearson, J. Am. Chem. Soc. 1988, 110, 7684-7690.

[67] D. R. Garmer, N. Gresh, J. Am. Chem. Soc. 1994, 116, 3556-3567.

[68] X. Li, L. Krishnan, P. Cherepanov, A. Engelman, Virology 2011, 411, 194-205.

[69] J. P. Piquemal, L. Perera, G. A. Cisneros, P. Ren, L. G. Pedersen, T. A. Darden, J. Chem. Phys. 2006, 125, 054511.

[70] K. Dunlap, J. Gen. Physiol. 2007, 129, 379-383.

[71] M. R. Tadross, I. E. Dick, D. T. Yue, Cell 2008, 133, 1228-1240.

[72] N. Gresh, E. Guittet, J.-Y. Lallemand, J. Biomol. Struct. Dyn. 1990, 7, 1003-1018.

[73] R. Chattopadhyaya, W.E. Meador, A. R. Means, F. A. Quiocho, J. Mol. Biol. 1992, 228, 1177-1192.

[74] L. Salem, in Proceedings of the Royal Society of London A: Mathematical, Physical and Engineering Sciences, Vol. A264, 1961, 379-391.

[75] P. Claverie, Inter Molecular Interactions from Diatomic to Biopolymers, J. Wiley \& Sons Ltd. 1978, 69-305.

[76] C. Grienberger, A. Konnerth, Neuron 2012, 73, 862-885.

[77] J. H. Lii, Allinger, N. L., J. Phys. Chem. A 2008, 112, 11903-11913.

[78] J. A. Lemkul, A.D. Mackerell Jr, J. Phys. Chem. B 2016, 120, 11436-11448.

[79] E. Harder, V.M. Anisimov, I.V. Vorobyov, P.E. Lopes, S.Y. Noskov, A.D. MacKerell, B. Roux, J. Chem. Theory Comput. 2006, 2, 1587-1597. 
a

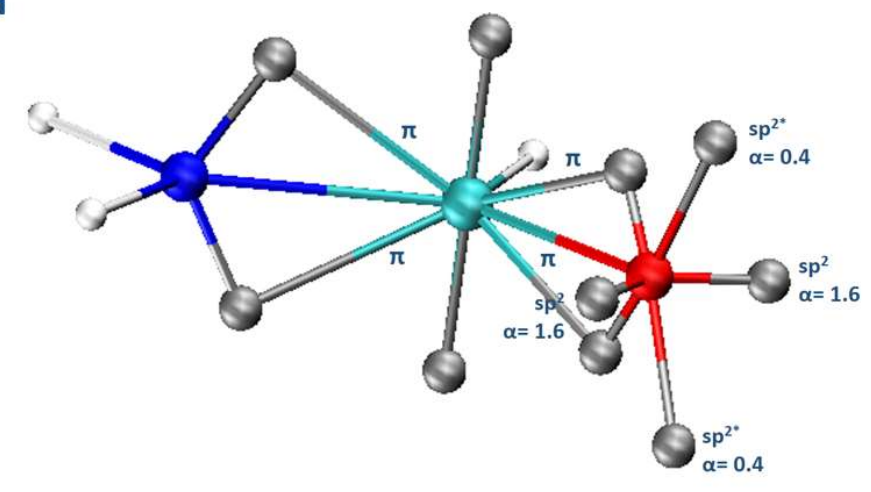

C

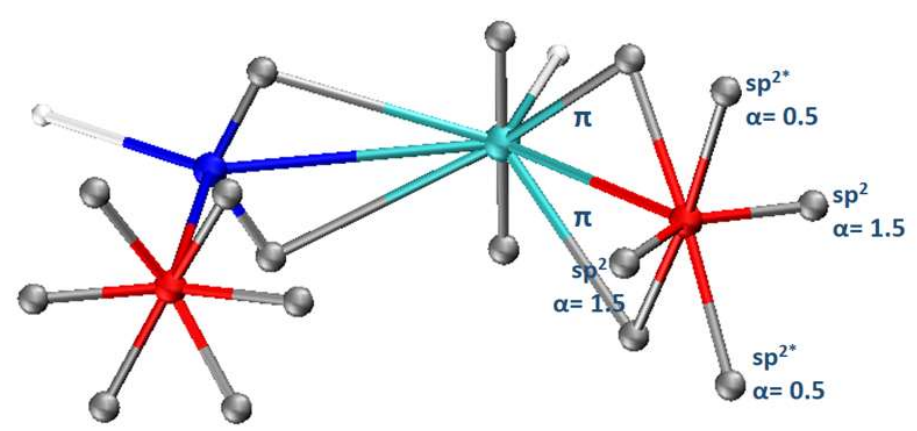

b
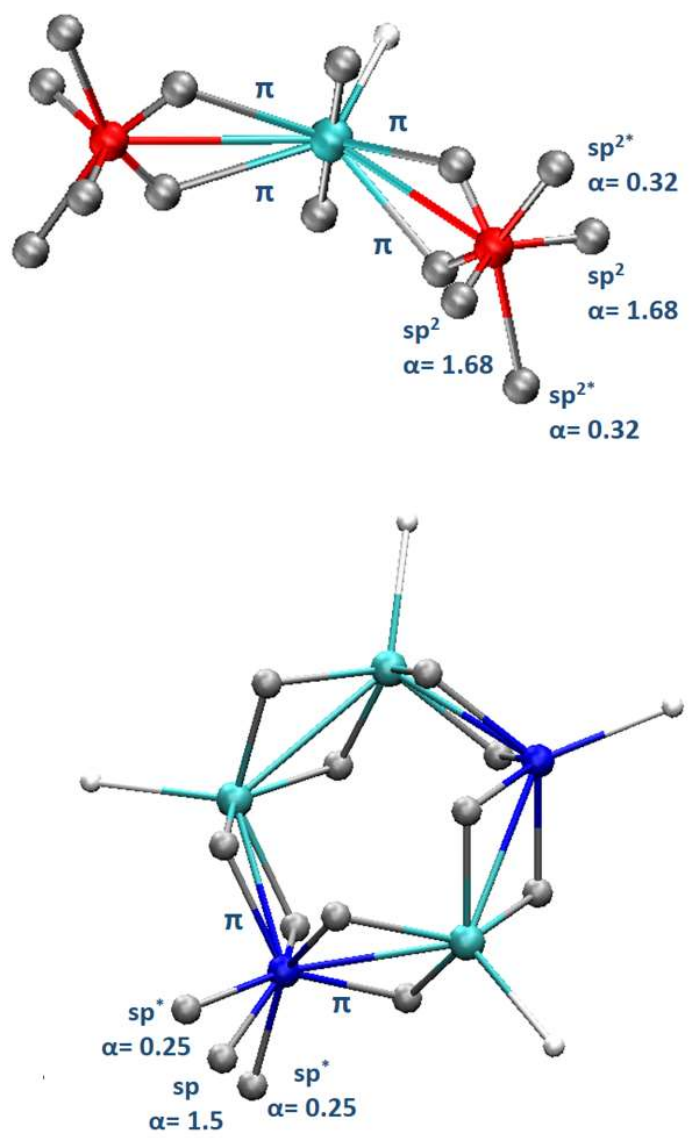

Figure 1. Representation of the lone-pair locations in monoligands; a: formamide, b: formate-external, c: hydroxamate and $\mathbf{d}$ : imidazole. $\mathrm{sp}^{2^{*}}$ and $\alpha$ represent the smeared lone-pairs and nocc, respectively.
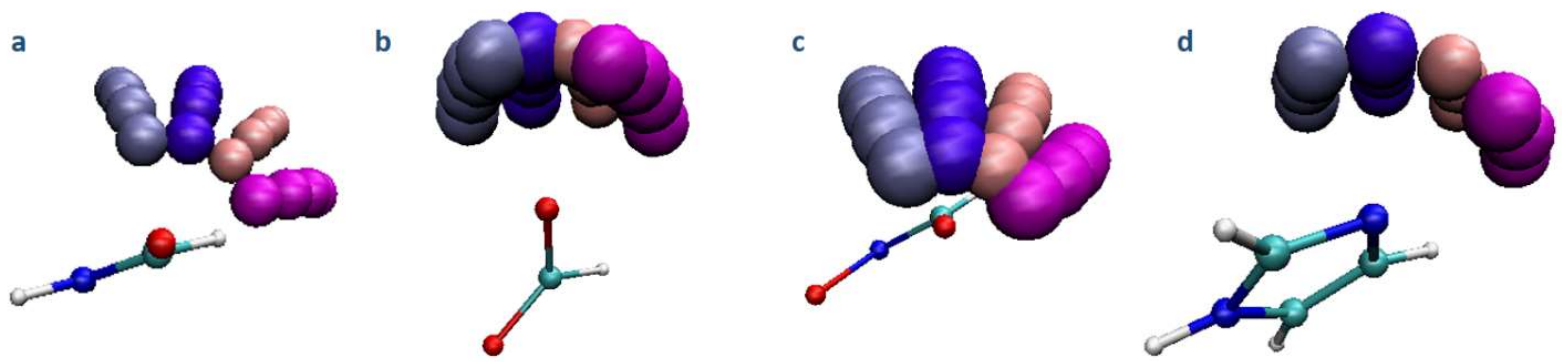

Figure 2. Representation of the variations undergone by $\mathrm{Zn}$ (II) probe around monoligands; a: $\mathrm{Zn}^{2+}-$ formamide, b: $\mathrm{Zn}^{2+}$ formate-external, c: $\mathrm{Zn}^{2+}$-hydroxamate $\left(\mathrm{Zn}^{2+}\right.$ Probing aroundO3) and $\mathbf{d}: \mathrm{Zn}^{2+}$-imidazole. Out-of-plane variations of phi are represented in different colors; magenta for $\left(\phi=0^{\circ}\right)$, pink for $\left(\phi=30^{\circ}\right)$, purple for $\left(\phi=60^{\circ}\right)$ and iceblue for $\left(\phi=90^{\circ}\right)$. 

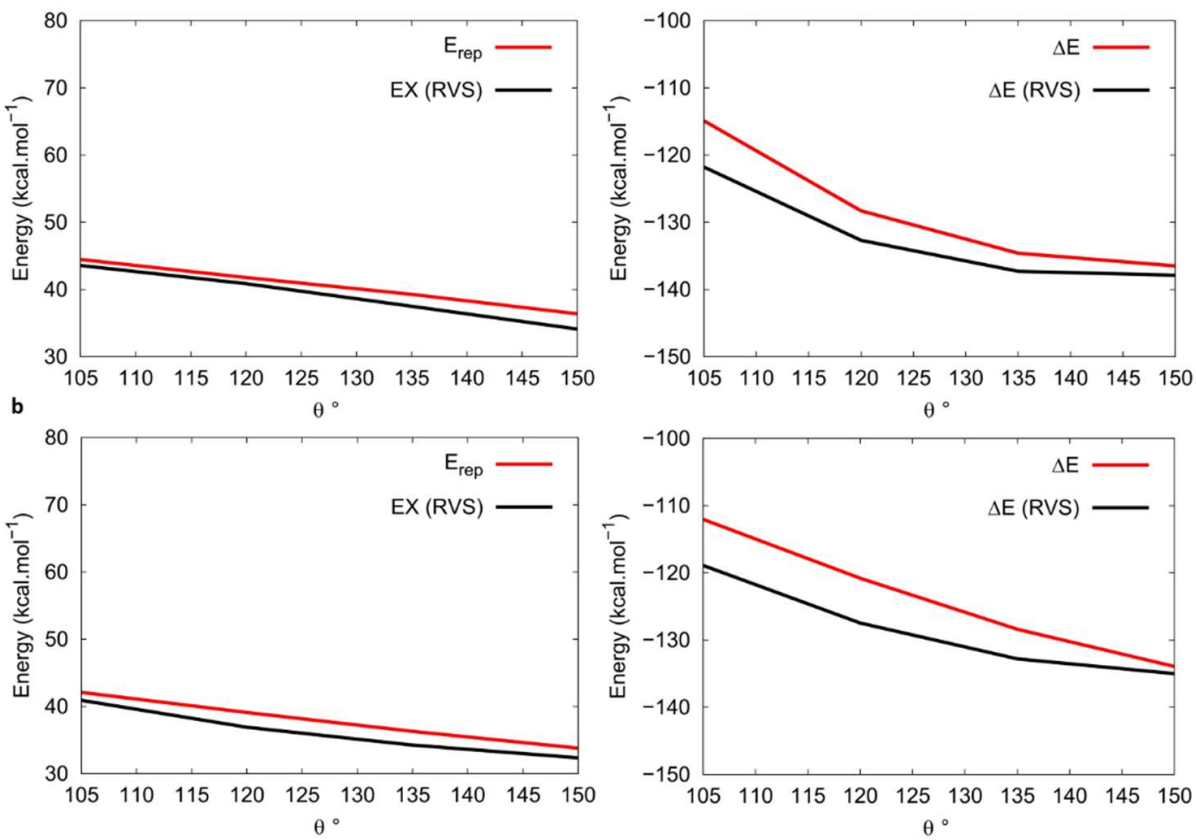

Figure 3. $\mathrm{Zn}^{2+}$-formamide complex. Compared evolution of $\triangle E$ (RVS) and $\triangle E$ (SIBFA) and of the repulsion contribution on variation of the $\mathrm{Zn2}+-\mathrm{O} \theta$ angle; a: $\left(\phi=0^{\circ}\right)$ and $\mathrm{b}:\left(\phi=90^{\circ}\right)$. $\mathrm{Zn2+-O}$ distance is $1.90 \dot{\mathrm{A}}$. RVS: Reduced Variational Space (RVS) analysis, All energy values are represented in Supp. Info. (Table SII a-d).
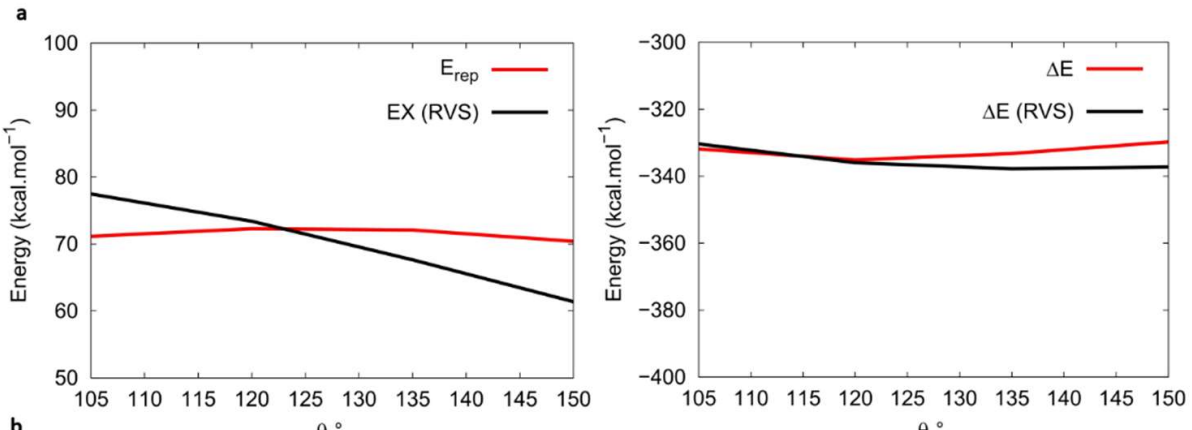
$\theta^{\circ}$
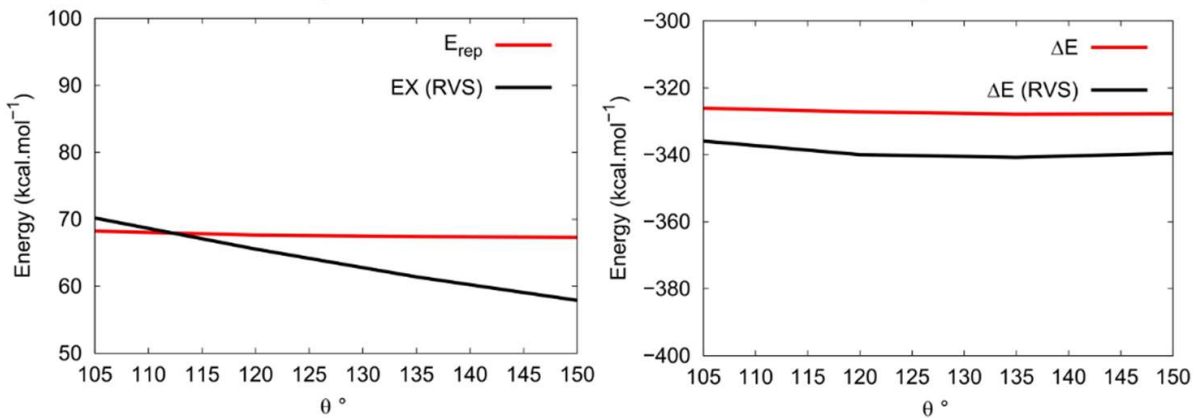

Figure 4. $\mathrm{Zn}^{2+}$-formate external complex. Compared evolution of $\triangle E$ (RVS) and $\triangle E$ (SIBFA) and of the repulsion contribution on variation of the $\mathrm{Zn}^{2+}-\mathrm{O} \theta$ angle; $\mathbf{a}:\left(\phi=0^{\circ}\right)$ and $\mathbf{b}:\left(\phi=90^{\circ}\right) . \mathrm{Zn}^{2+}-\mathrm{O}$ distance is $1.80 \dot{A}$. RVS: Reduced Variational Space (RVS) analysis. All energy values are represented in Supp. Info. (Table SIII a-d). 

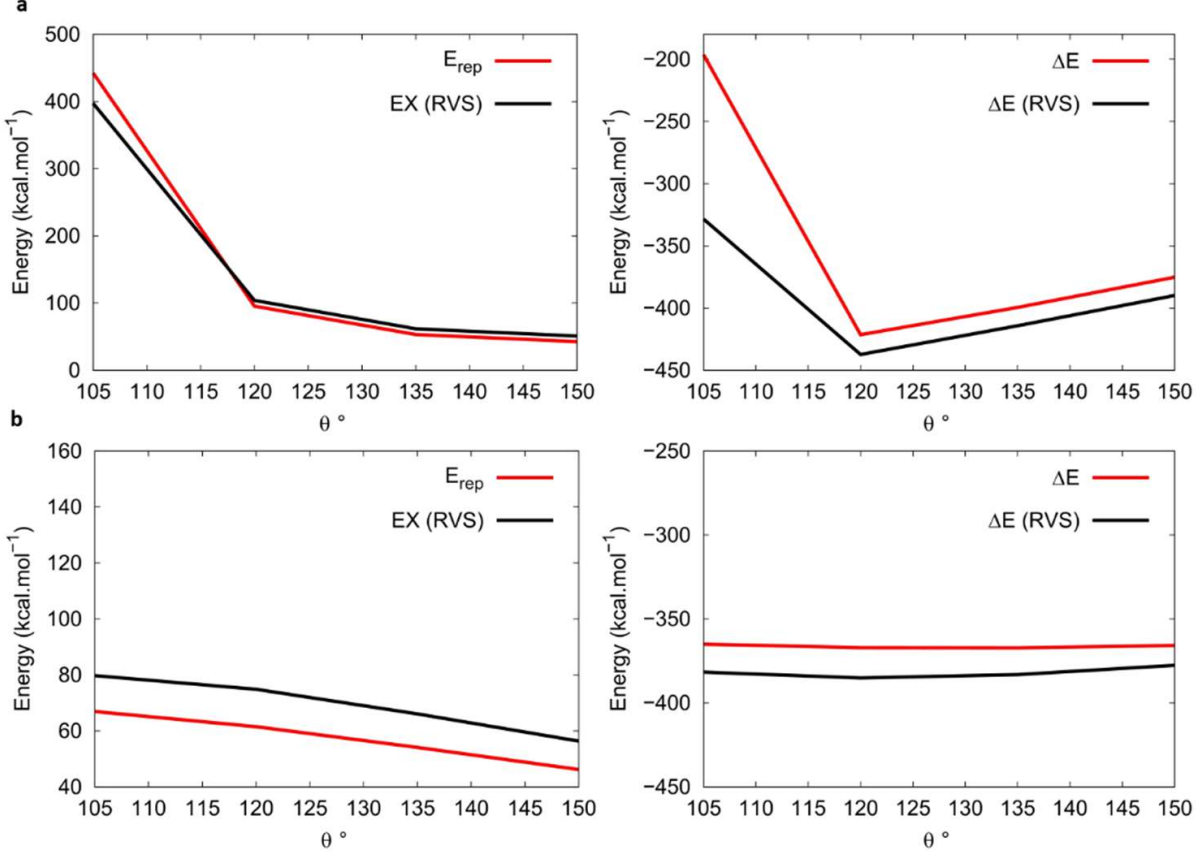

Figure 5. $\mathrm{Zn}^{2+}$ - hydroxamate complex. Compared evolution of $\triangle E$ (RVS) and $\triangle E$ (SIBFA) and of the repulsion contribution on variation of the $\mathrm{Zn}^{2+}-05 \theta$ angle; a: $\left(\phi=0^{\circ}\right)$ and $\mathbf{b}:\left(\phi=90^{\circ}\right)$. $\mathrm{Zn}^{2+}-\mathrm{O}$ distance is $1.80 \dot{\mathrm{A}}$. RVS: Reduced Variational Space (RVS) analysis. All energy values are represented in Supp. Info. (Table SVI a-d).
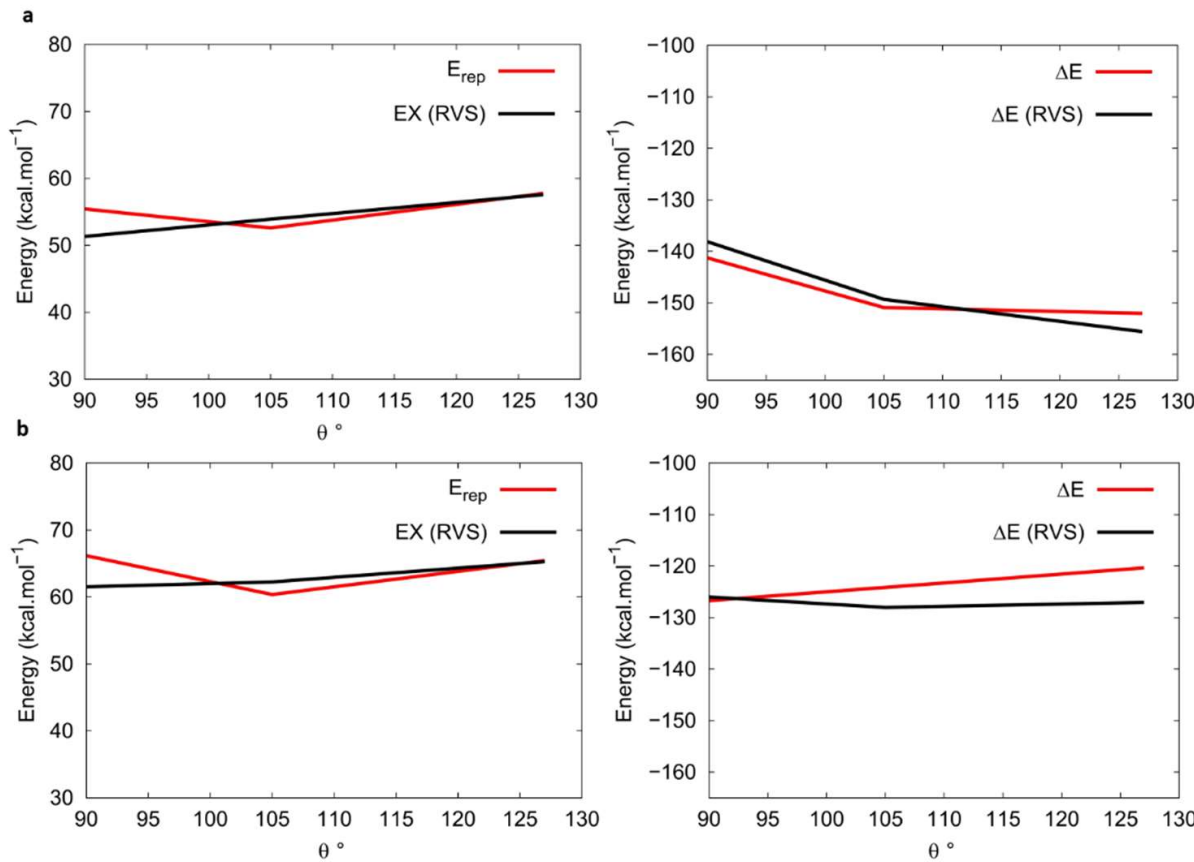

Figure 6. $\mathrm{Zn}^{2+}$ - imidazole complex. Compared evolution of $\triangle \mathrm{E}$ (RVS) and $\triangle \mathrm{E}$ (SIBFA) and of the repulsion contribution on variation of te $\mathrm{Zn}^{2+}-\mathrm{O} \theta$ angle; a: $\left(\phi=0^{\circ}\right)$ and $\mathbf{b}$ : $\left(\phi=90^{\circ}\right)$. $\mathrm{Zn}^{2+}-\mathrm{O}$ distance is $1.90 \dot{\mathrm{A}}$. RVS: Reduced Variational Space (RVS) analysis. All energy values are represented in Supp. Info. (Table SV a-d). 
a

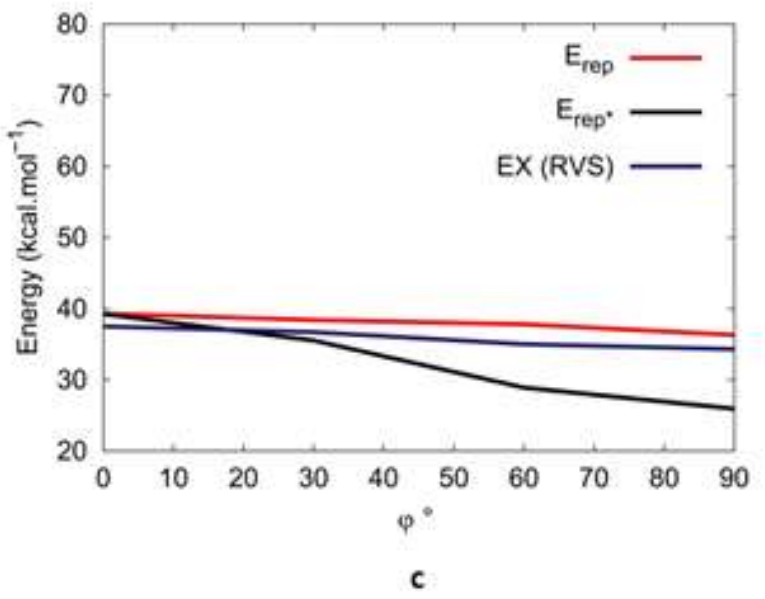

b

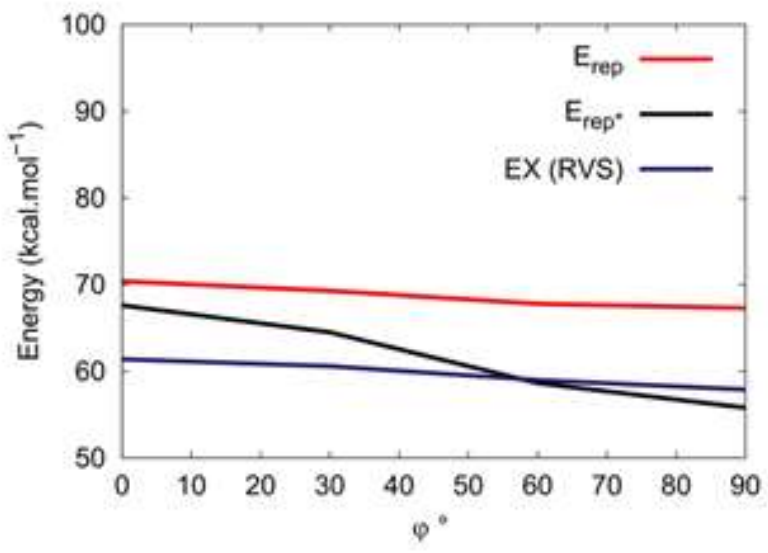

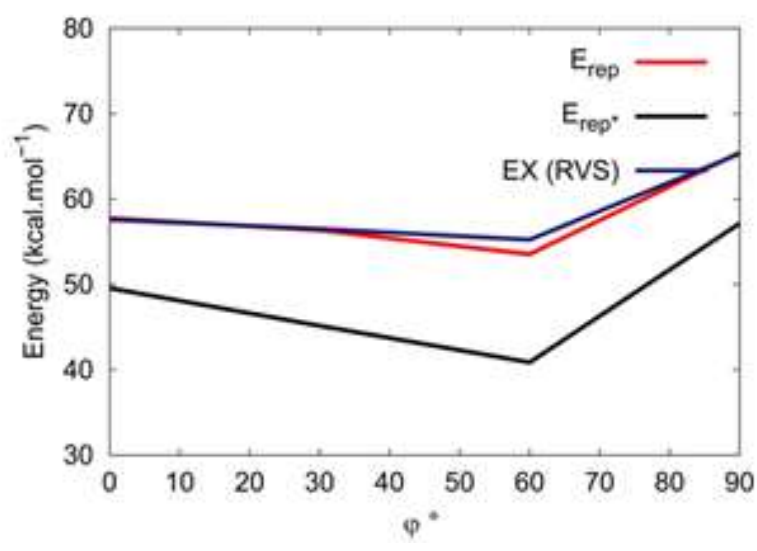

Figure 7. a. $\mathrm{Zn}^{2+}$-formamide complex. Compared evolution of the repulsion contribution on variation of the $\mathrm{Zn}{ }^{2+}-\mathrm{O} \phi$ angle with $\left(\theta=135^{\circ}\right) ; \mathrm{Zn}^{2+}-\mathrm{O}$ distance is $1.90 \dot{\mathrm{A}}$. b. $\mathrm{Zn}^{2+}{ }_{-}$formate external complex. Compared evolution of the repulsion contribution on variation of the $\mathrm{Zn}^{2+}-\mathrm{O} \phi$ angle with $\left(\theta=150^{\circ}\right)$; $\mathrm{Zn}^{2+}-\mathrm{O}$ distance is $1.80 \dot{A}$. c. $\mathrm{Zn}^{2+}$-imidazole complex. Compared evolution of the repulsion contribution on variation of the $\mathrm{Zn}^{2+}-\mathrm{O} \phi$ angle with $\left(\theta=127^{\circ}\right)$; $\mathrm{Zn}^{2+}-\mathrm{O}$ distance is 1.90 Aं. RVS: Reduced Variational Space (RVS) analysis. $\left(^{*}\right)$ Energy values when lone-pairs are not smeared. 


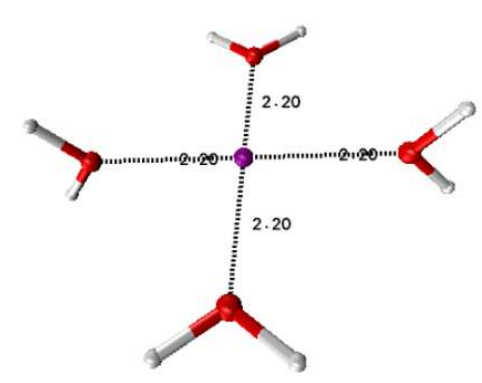

a

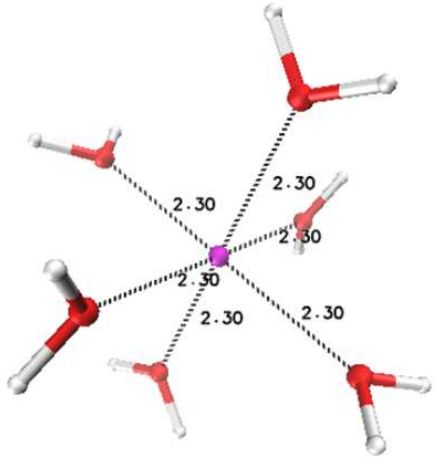

c

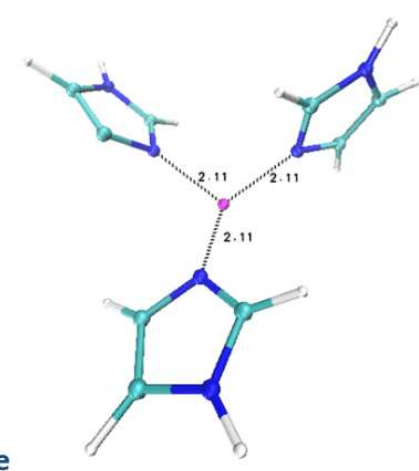

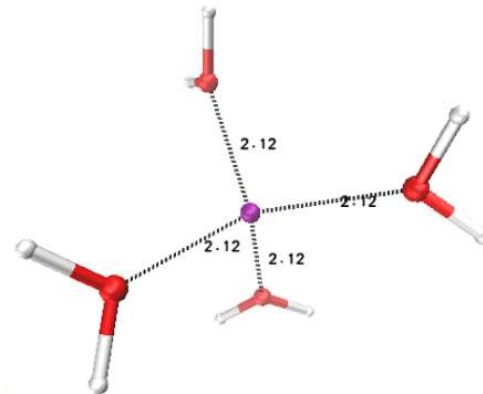

b
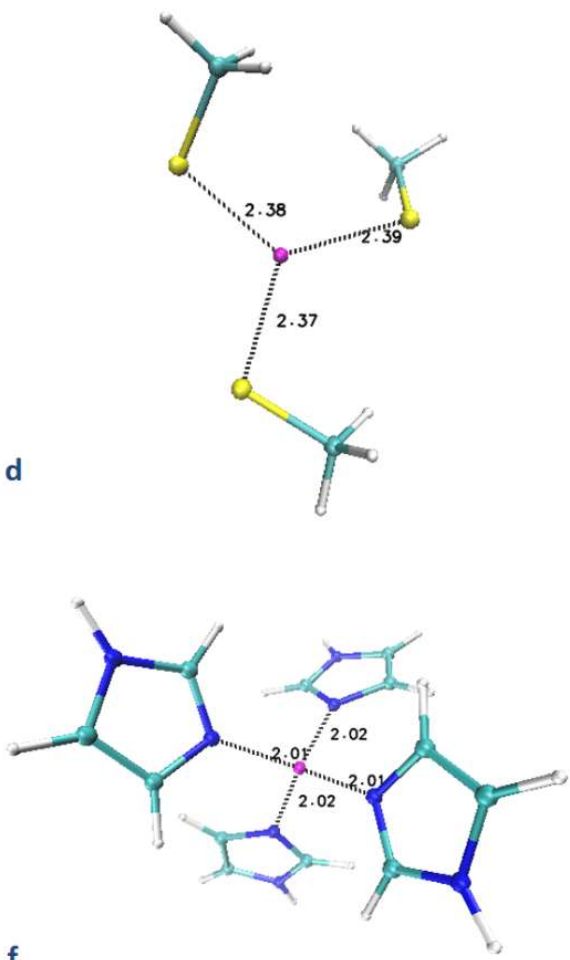

Figure 8. Polycoordinated complex of $\mathrm{Zn}$ (II) with: a) four planar water molecules, b) four pyramidal water molecules, c) six octahedral water molecules, d) three methanethiolate, e) three imidazoles and f) four imidazoles.

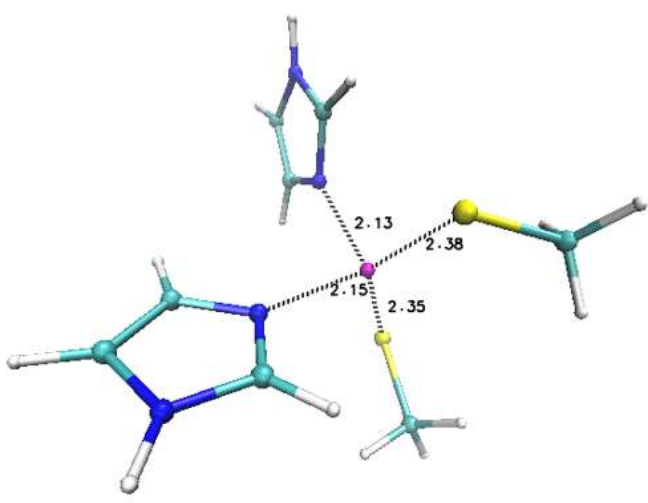

a

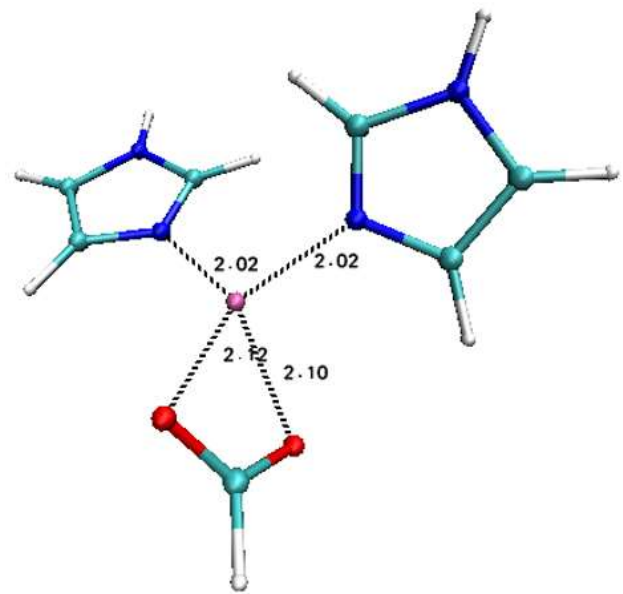

b 
Figure 9. Polycoordinated complex of $\mathrm{Zn}$ (II) with: a) two imidazoles and two methanethiolates [HHCC] and b) two imidazoles and one formate (Anthrax letal factor active site [HHE]).

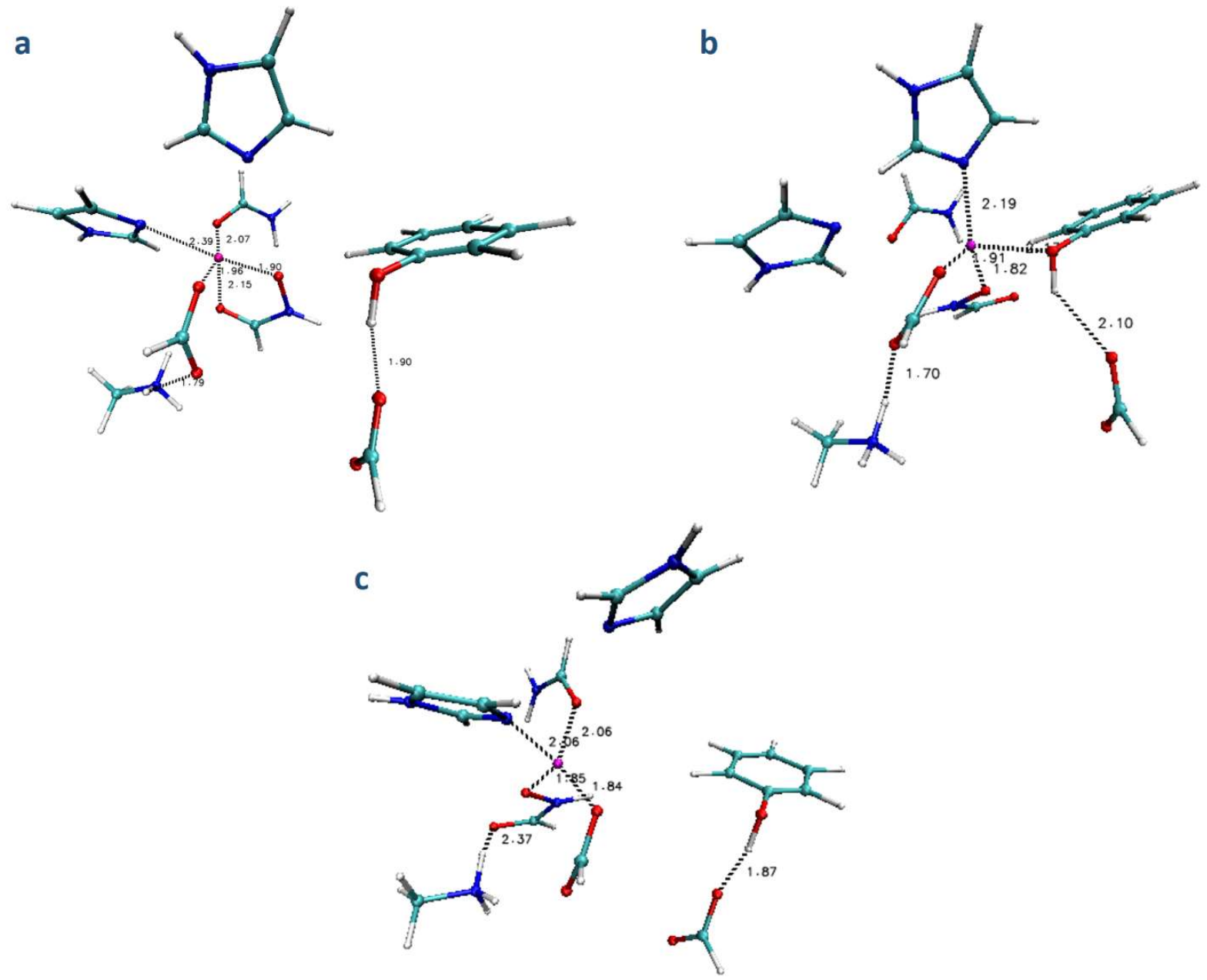

Figure 10. Polycoordinated complex of $\mathrm{Zn}(\mathrm{II})$ with phosphomannoseisomerase (PMI). Three structures provided by SIBFA MD are represented in $a, b$ and $c$.

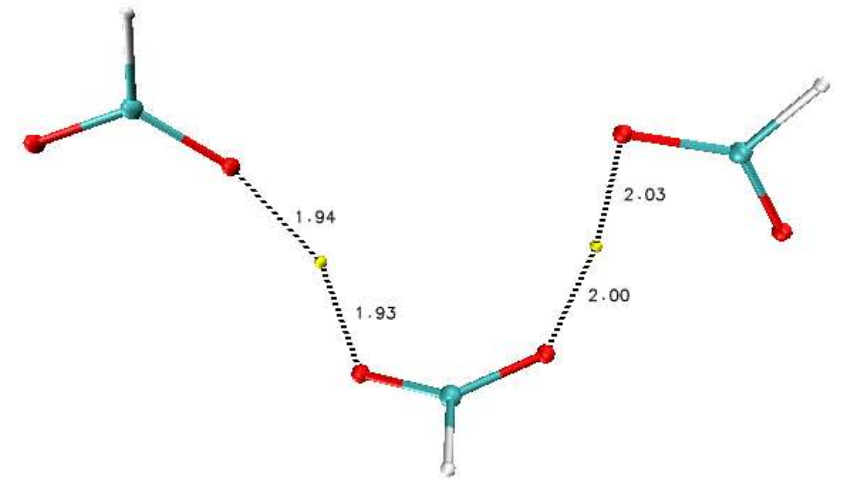

Figure 11. Polylicoordinated complex of $\mathrm{Mg}(\mathrm{II})$ with three formate in the integrase catalytic site (Catalytic triad [DDE]). 


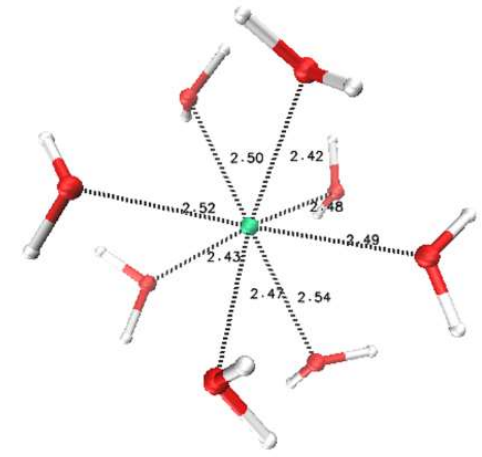

a

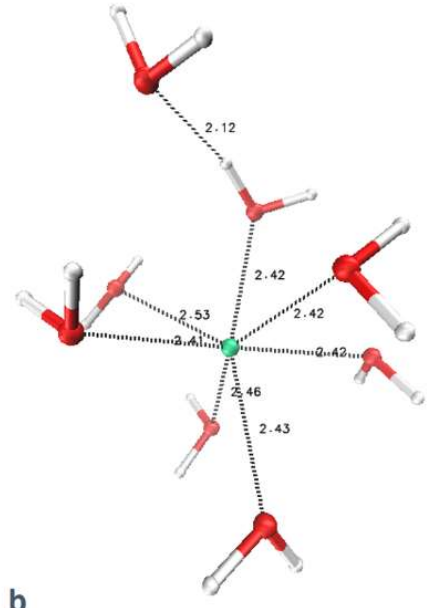

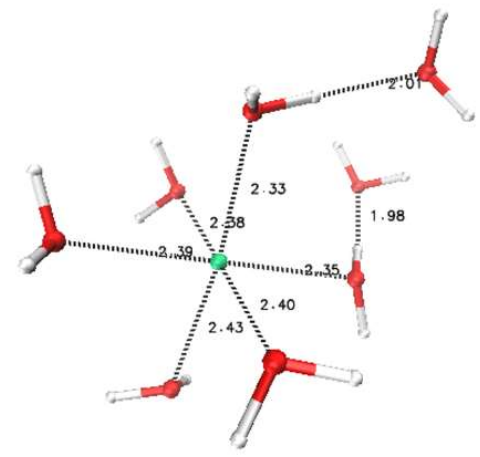

Figure 12. Polylicoordinated complex of $\mathrm{Ca}(\mathrm{II})$ with 8 water molecules. a) $\left[\mathrm{Ca}(\mathrm{H} 2 \mathrm{O})_{8}\right]^{2+}$, b) $\left[\mathrm{Ca}(\mathrm{H} 2 \mathrm{O})_{7+1}\right]^{2+}$ and c) $\left[\mathrm{Ca}(\mathrm{H} 2 \mathrm{O})_{6+2}\right]^{2+}$.

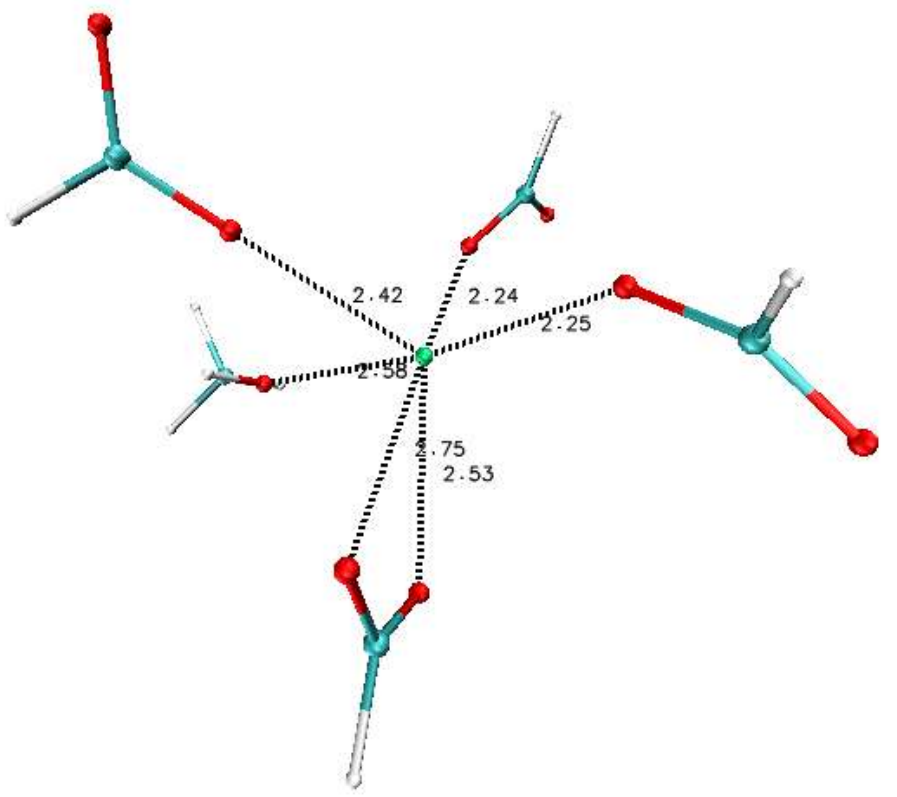

Figure 13. Polylicoordinated complex of $\mathrm{Ca}(\mathrm{II})$ with four formate and one methanol in the calmoduline active site [DDDTE]. 


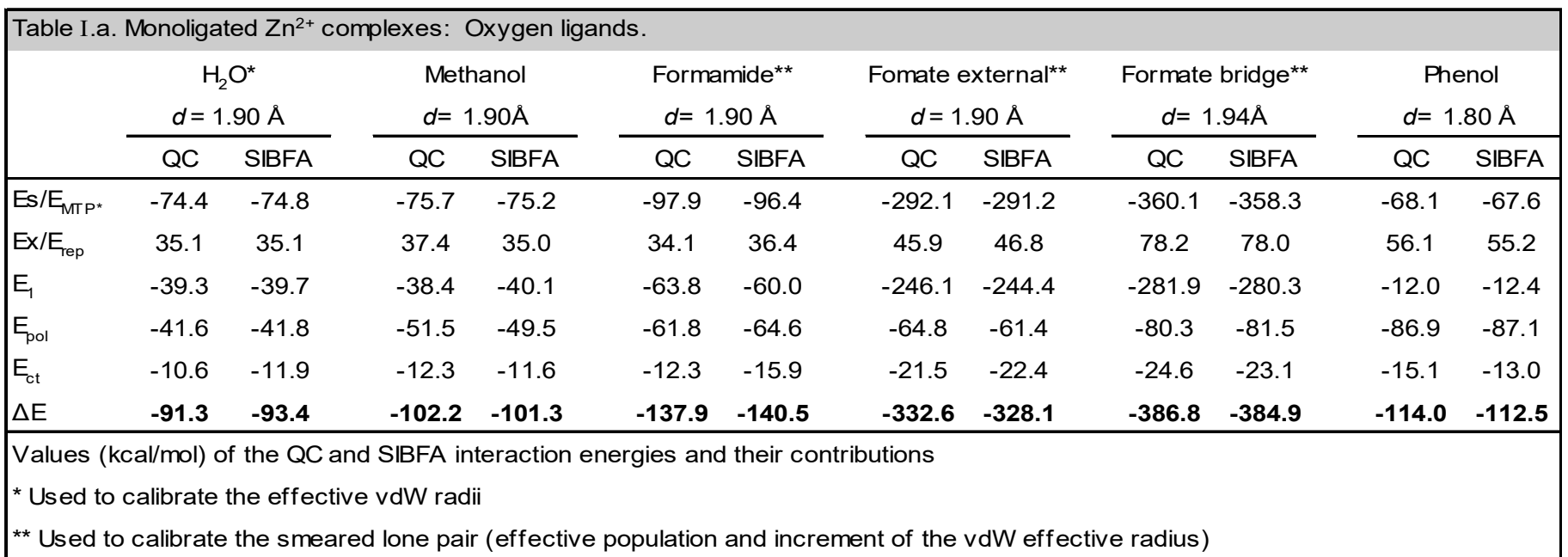

\begin{tabular}{|c|c|c|c|c|c|c|c|c|}
\hline & \multicolumn{2}{|c|}{$\begin{array}{l}\text { Imidazole }^{* *} \\
d=1.90 \AA\end{array}$} & \multicolumn{2}{|c|}{$\begin{array}{l}\text { Pyridine } \\
d=1.90 \AA\end{array}$} & \multicolumn{2}{|c|}{$\begin{array}{c}\text { Trimethylamine } \\
d=1.90 \AA\end{array}$} & \multicolumn{2}{|c|}{$\begin{array}{c}\text { Methanethiolate } \\
d=2.20 \AA\end{array}$} \\
\hline & QC & SIBFA & QC & SIBFA & QC & SIBFA & QC & SIBFA \\
\hline $\mathrm{Es} / \mathrm{E}_{\mathrm{MT} \mathrm{P}^{*}}$ & -112.9 & -112.4 & -98.9 & -98.3 & -104.3 & -110.2 & -323.8 & -323.2 \\
\hline $\mathrm{Ex} / \mathrm{E}_{\mathrm{rep}}$ & 57.6 & 53.8 & 59.7 & 59.6 & 69.0 & 66.6 & 69.9 & 71.0 \\
\hline $\mathrm{E}_{1}$ & -55.3 & -58.5 & -39.2 & -38.7 & -35.3 & -43.6 & -254.0 & -252.2 \\
\hline$E_{\text {pol }}$ & -78.3 & -80.1 & -84.6 & -88.3 & -82.5 & -82.3 & -91.6 & -92.7 \\
\hline$E_{c t}$ & -22.1 & -22.6 & -23.6 & -21.1 & -25.9 & -15.6 & -50.9 & -51.4 \\
\hline$\Delta \mathrm{E}$ & -155.6 & -161.2 & -147.3 & -148.1 & -143.7 & -141.5 & -396.4 & -396.3 \\
\hline
\end{tabular}

Values $(\mathrm{kcal} / \mathrm{mol})$ of the QC and SIBFA interaction energies and their contributions

** Used to calibrate the smeared lone-pairs (effective population and increment of the vdW effective radius)

\begin{tabular}{|c|c|c|c|c|c|c|c|c|c|c|}
\hline \multicolumn{11}{|c|}{ Table II.a. Monoligated Z Zn ${ }^{2+}$ complexes: Imidazole ${ }^{\star *}$. } \\
\hline & \multirow{2}{*}{\multicolumn{2}{|c|}{$\begin{array}{c}C 2 \\
d=1.90 \AA\end{array}$}} & \multirow{2}{*}{\multicolumn{2}{|c|}{$\begin{array}{c}\mathrm{N} 3 \\
d=1.90 \AA\end{array}$}} & \multirow{2}{*}{\multicolumn{2}{|c|}{$\begin{array}{c}C 4 \\
d=1.90 \AA\end{array}$}} & \multirow{2}{*}{\multicolumn{2}{|c|}{$\begin{array}{c}\text { N5 } \\
d=1.90 \AA\end{array}$}} & \multirow{2}{*}{\multicolumn{2}{|c|}{$\begin{array}{c}C 6 \\
d=1.90 \AA\end{array}$}} \\
\hline & & & & & & & & & & \\
\hline & QC & SIBFA & QC & SIBFA & QC & SIBFA & QC & SIBFA & QC & SIBFA \\
\hline $\mathrm{Es} / \mathrm{E}_{\mathrm{MT} \mathrm{P}^{*}}$ & -49.7 & -61.4 & -61.2 & -66.6 & -25.3 & -29.8 & -20.2 & -25.0 & -36.3 & -46.5 \\
\hline $\mathrm{Ex} / \mathrm{E}_{\mathrm{rep}}$ & 48.0 & 66.4 & 42.9 & 63.2 & 40.1 & 60.3 & 40.9 & 66.1 & 49.3 & 69.9 \\
\hline $\mathrm{E}_{1}$ & -1.6 & 5.0 & -18.4 & -3.4 & 14.8 & 30.5 & 20.6 & 41.1 & 13.0 & 23.4 \\
\hline $\mathrm{E}_{\mathrm{pol}}$ & -94.0 & -105.6 & -88.9 & -104.7 & -92.4 & -106.0 & -87.8 & -96.2 & -94.2 & -98.7 \\
\hline $\mathrm{E}_{\mathrm{ct}}$ & -25.4 & -20.6 & -18.6 & -20.5 & -22.0 & -21.9 & -15.3 & -22.9 & -27.0 & -22.6 \\
\hline$\Delta \mathrm{E}$ & -121.0 & -121.2 & -125.9 & -128.6 & -99.6 & -97.4 & -82.4 & -78.0 & -108.2 & -97.9 \\
\hline \multicolumn{11}{|c|}{ Values (kcal/mol) of the QC and SIBFA interaction energies and their contributions } \\
\hline \multicolumn{11}{|c|}{${ }^{* *}$ Used to calibrate the smeared lone-pairs (effective population and increment of the vdW effective radius) } \\
\hline
\end{tabular}




\begin{tabular}{|c|c|c|c|c|c|c|c|c|c|c|}
\hline & \multicolumn{2}{|c|}{$\begin{array}{c}\text { Formamide- } \mathrm{N} \\
d=1.90 \AA\end{array}$} & \multicolumn{2}{|c|}{$\begin{array}{c}\text { Formamide-C } \\
d=1.90 \AA\end{array}$} & \multicolumn{2}{|c|}{$\begin{array}{l}\text { Phenol-C2 } \\
d=2.10 \AA\end{array}$} & \multicolumn{2}{|c|}{$\begin{array}{l}\text { Phenol-C3 } \\
d=2.10 \AA\end{array}$} & \multicolumn{2}{|c|}{$\begin{array}{c}\text { Phenol-O30 } \\
d=1.90 \AA\end{array}$} \\
\hline & QC & SIBFA & QC & SIBFA & QC & SIBFA & QC & SIBFA & $\mathrm{QC}$ & SIBFA \\
\hline $\mathrm{Es} / \mathrm{E}_{\mathrm{MT} \mathrm{P}^{*}}$ & -11.2 & -21.9 & -2.3 & -10.2 & -38.8 & -42.5 & -35.0 & -39.2 & -45.9 & -50.8 \\
\hline $\mathrm{Ex} / \mathrm{E}_{\mathrm{rep}}$ & 41.3 & 50.3 & 29.3 & 61.6 & 36.3 & 34.1 & 34.7 & 37.0 & 45.0 & 51.9 \\
\hline $\mathrm{E}_{1}$ & 30.2 & 28.3 & 27.0 & 51.4 & -2.5 & -8.4 & -0.2 & -2.2 & -0.9 & 1.1 \\
\hline $\mathrm{E}_{\mathrm{pol}}$ & -64.9 & -69.6 & -69.0 & -88.4 & -103.6 & -93.6 & -103.6 & -98.3 & -106.3 & -76.9 \\
\hline$E_{c t}$ & -17.4 & -13.3 & -13.1 & -24.5 & -26.0 & -17.7 & -24.4 & -19.0 & 0.5 & -15.9 \\
\hline$\Delta \mathrm{E}$ & -52.1 & -54.6 & -55.1 & -61.5 & -132.2 & -119.7 & -128.3 & -119.5 & -106.8 & -91.6 \\
\hline
\end{tabular}

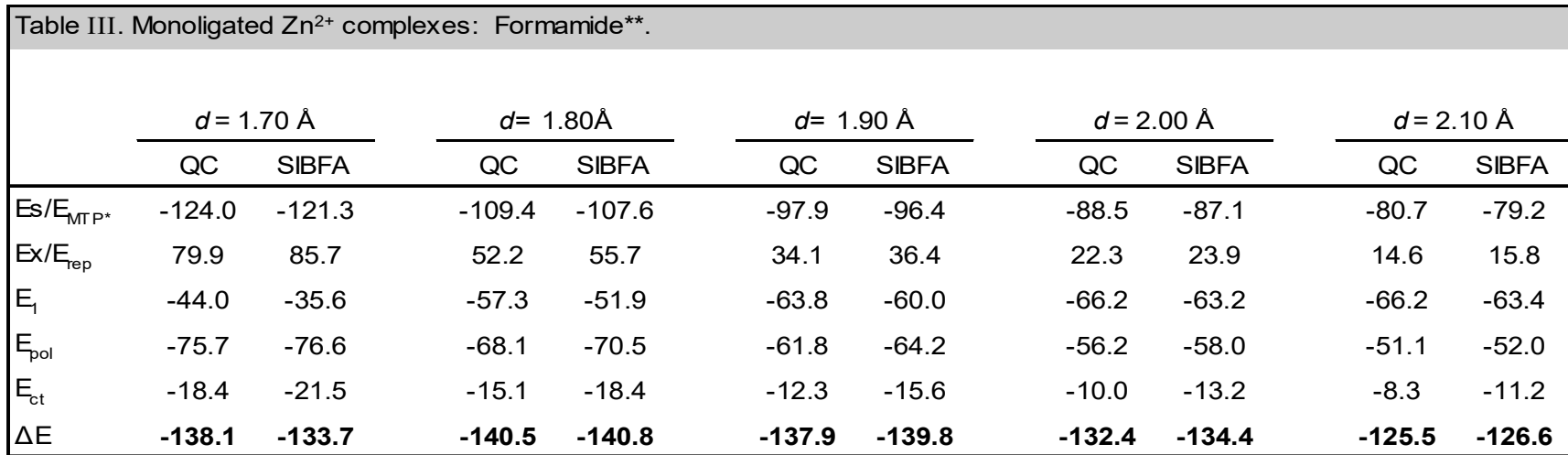

Values (kcal/mol) of the QC and SIBFA interaction energies and their contributions

** Used to calibrate the smeared lone-pairs (effective population and increment of the vdW effective radius)

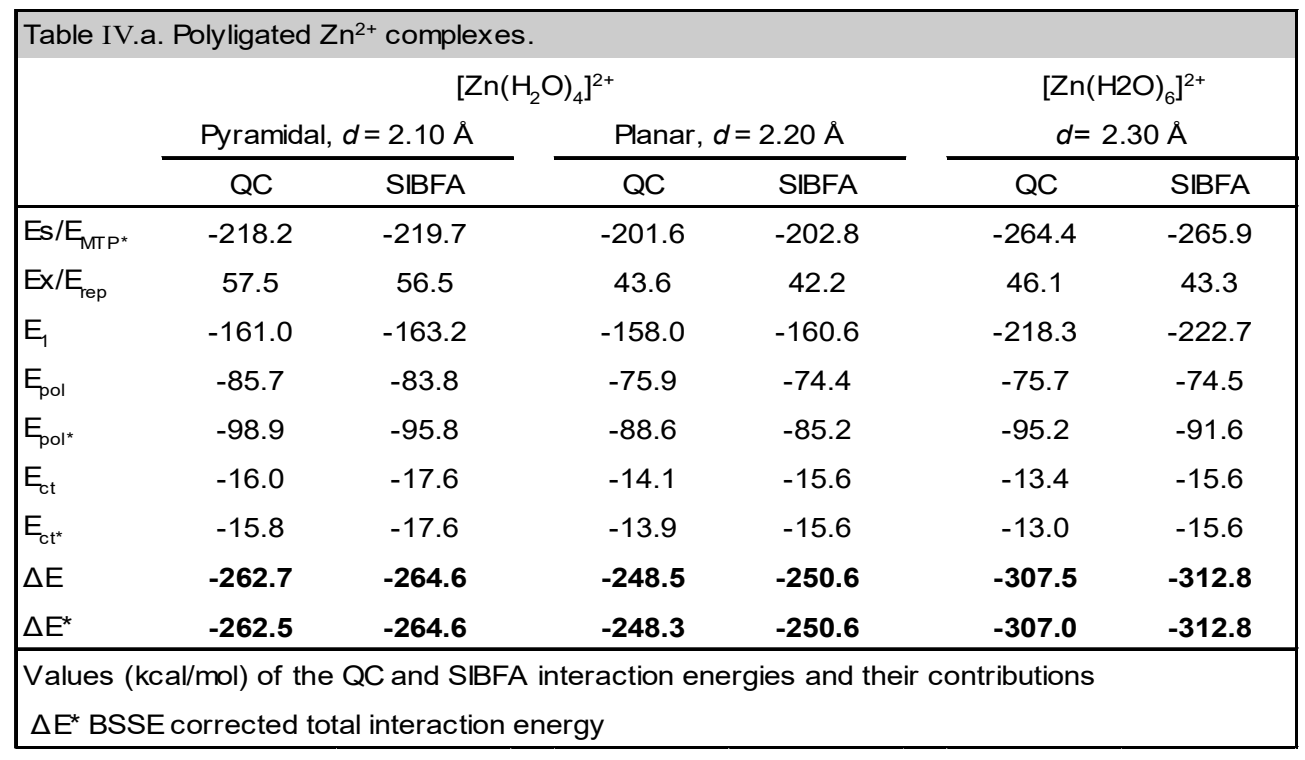




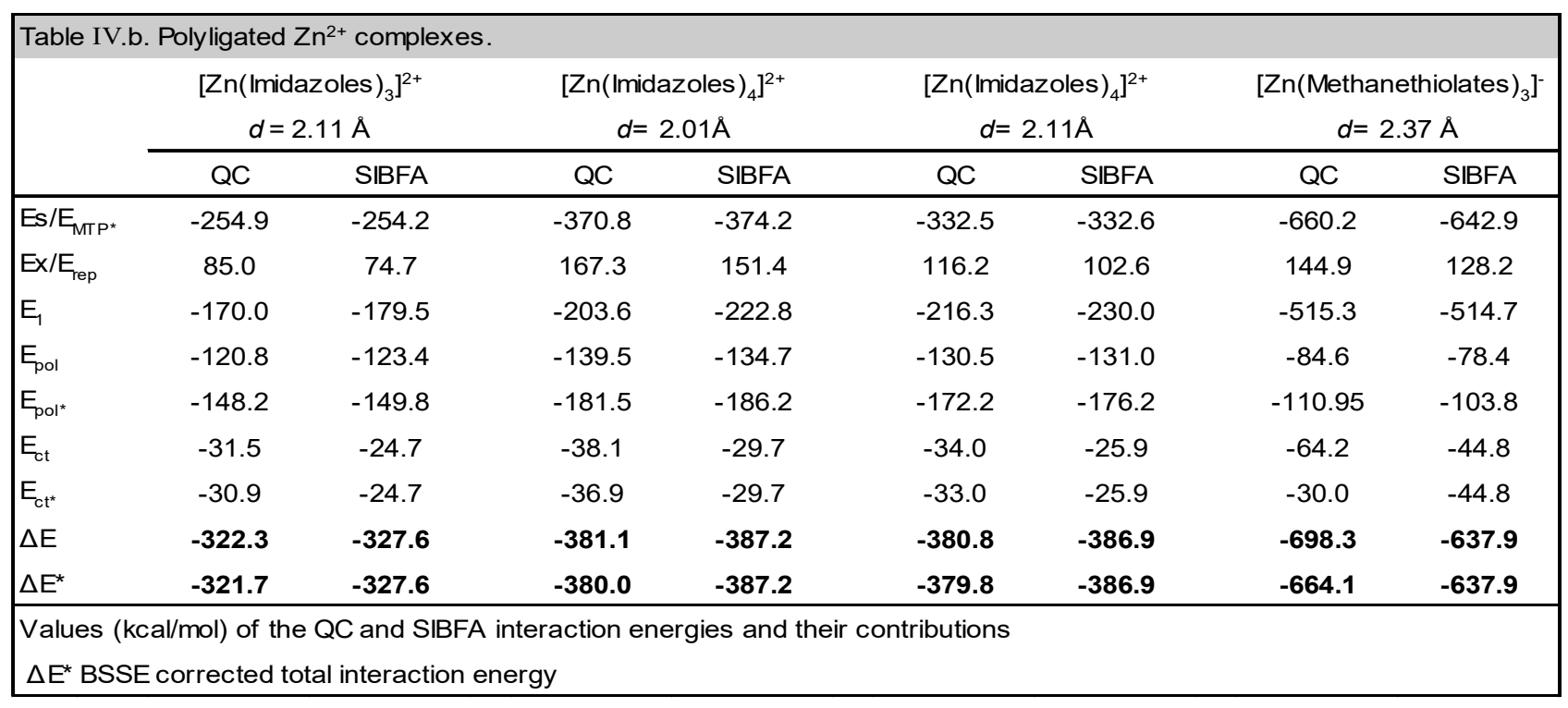

\begin{tabular}{|c|c|c|c|c|}
\hline & \multicolumn{2}{|c|}{$[\mathrm{Zn}(\mathrm{HHCC})]$} & \multicolumn{2}{|c|}{$[\mathrm{Zn}(\mathrm{HHE})]^{+}$} \\
\hline & QC & SIBFA & QC & SIBFA \\
\hline$E_{s} / E_{\mathrm{MTP}^{*}}$ & -656.6 & -640.1 & -498.2 & -493.1 \\
\hline $\mathrm{Ex} / \mathrm{E}_{\mathrm{rep}}$ & 172.1 & 149.1 & 127.7 & 113.7 \\
\hline $\mathrm{Ex} / \mathrm{E}_{\text {rep }} \mathrm{p}^{\star \star}$ & 172.1 & 137.5 & 127.7 & 102.1 \\
\hline $\mathrm{E}_{1}$ & -484.5 & -491.0 & -370.5 & -379.3 \\
\hline $\mathrm{E}_{\mathrm{pol}}$ & -110.2 & -88.9 & -108.4 & -109.8 \\
\hline $\mathrm{E}_{\mathrm{pol}^{*}}$ & -130.7 & -123.9 & -128.8 & -136.4 \\
\hline $\mathrm{E}_{\mathrm{ct}}$ & -35.7 & -38.6 & -33.6 & -26.2 \\
\hline $\mathrm{E}_{\mathrm{ct}^{*}}$ & -34.4 & -38.6 & -32.9 & -26.2 \\
\hline$\Delta \mathrm{E}$ & -630.4 & -618.4 & -512.5 & -515.3 \\
\hline$\Delta \mathrm{E}^{*}$ & -629.1 & -618.4 & -511.8 & -515.3 \\
\hline$\Delta \mathrm{E}^{\star *}$ & -629.1 & -630.6 & -511.8 & -528.6 \\
\hline \multicolumn{5}{|c|}{$\begin{array}{l}\text { Values ( } \mathrm{kcal} / \mathrm{mol} \text { ) of the } \mathrm{QC} \text { and SIBFA interaction energies and their contributions } \\
\Delta \mathrm{E}^{*} \mathrm{BSSE} \text { corrected total interaction energy }\end{array}$} \\
\hline \multicolumn{5}{|c|}{${ }^{\star *}$ Calculated $w$ ith no smeared lone-pairs } \\
\hline
\end{tabular}




\begin{tabular}{|c|c|c|c|c|c|c|}
\hline \multicolumn{7}{|c|}{ Table VI. PMI-Zn'+ complexes. } \\
\hline & \multicolumn{2}{|c|}{ A } & \multicolumn{2}{|c|}{ B } & \multicolumn{2}{|c|}{ C } \\
\hline & QC & SIBFA & QC & SIBFA & QC & SIBFA \\
\hline $\mathrm{Es}_{\mathrm{S}} \mathrm{E}_{\mathrm{MTP}} \mathrm{P}$ & -770.5 & -785.0 & -789.3 & -818.0 & -790.3 & -818.1 \\
\hline $\mathrm{Ex} / \mathrm{E}_{\mathrm{rep}}$ & 177.6 & 201.5 & 219.0 & 242.9 & 209.9 & 239.8 \\
\hline$E_{1}$ & -592.2 & -583.6 & -570.3 & -575.1 & -580.5 & -578.4 \\
\hline$E_{p o l(V R)} E_{p o l}$ & -102.9 & -99.6 & -100.6 & -98.7 & -110.3 & -102.5 \\
\hline $\mathrm{E}_{\mathrm{ct}}$ & -39.1 & -37.3 & -51.2 & -41.0 & -47.0 & -40.8 \\
\hline$E_{c t}{ }^{*}$ & -27.3 & -37.3 & -39.2 & -41.0 & -36.2 & -40.8 \\
\hline$\Delta \mathrm{E}$ & -734.2 & -720.5 & -722.1 & -714.8 & -737.8 & -721.6 \\
\hline$\Delta \mathrm{E}^{*}$ & -723.1 & -720.5 & -710.1 & -714.8 & -727.1 & -721.6 \\
\hline
\end{tabular}

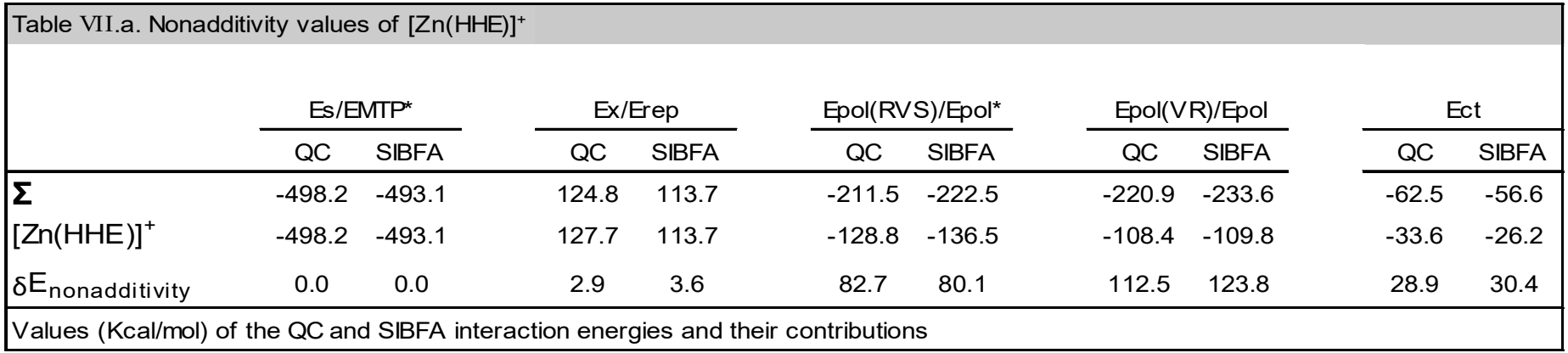

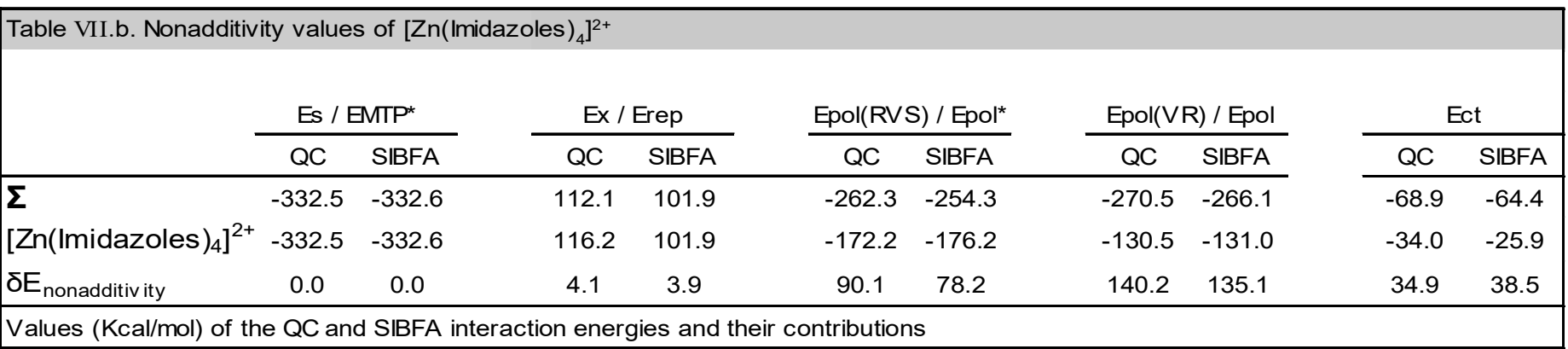

\begin{tabular}{|c|c|c|c|c|c|c|c|c|c|c|}
\hline \multicolumn{11}{|c|}{ Table VII.c. Nonadditivity values of $[\mathrm{Zn}(\mathrm{HHCC})]^{-}$} \\
\hline & \multicolumn{2}{|c|}{ Es / EMTP* } & \multicolumn{2}{|c|}{ Ex / Erep } & \multicolumn{2}{|c|}{ Epol(RVS) / Epol* } & \multicolumn{2}{|c|}{ Epol(VR) / Epol } & \multicolumn{2}{|c|}{ Ect } \\
\hline & QC & SIBFA & QC & SIBFA & QC & SIBFA & QC & SIBFA & QC & SIBFA \\
\hline $\boldsymbol{\Sigma}$ & -656.6 & -640.1 & 164.5 & 149.1 & -315.6 & -308.8 & -325.0 & -324.4 & -135.7 & -125.5 \\
\hline$[\mathrm{Zn}(\mathrm{HHCC})]^{-}$ & -656.6 & -640.1 & 172.1 & 149.1 & -130.7 & -123.9 & -97.9 & -88.9 & -48.0 & -38.6 \\
\hline$\delta E_{\text {nonadditivity }}$ & 0.0 & 0.0 & 7.6 & 6.4 & 184.8 & 185.0 & 227.1 & 235.5 & 87.7 & 86.9 \\
\hline
\end{tabular}




\begin{tabular}{|c|c|c|c|c|c|c|c|c|c|c|c|c|}
\hline & \multicolumn{2}{|c|}{$\begin{array}{c}\mathrm{H}_{2} \mathrm{O} \\
d=1.90 \AA\end{array}$} & \multicolumn{2}{|c|}{$\begin{array}{l}\text { Methanol } \\
d=1.90 \AA\end{array}$} & \multicolumn{2}{|c|}{$\begin{array}{l}\text { Formamide } \\
d=1.80 \AA\end{array}$} & \multicolumn{2}{|c|}{$\begin{array}{l}\text { Fomate external } \\
\qquad d=1.80 \AA\end{array}$} & \multicolumn{2}{|c|}{$\begin{array}{c}\text { Formate bridge } \\
\qquad d=1.94 \AA \\
\end{array}$} & \multicolumn{2}{|c|}{$\begin{array}{c}\text { Phenol } \\
d=190 \AA\end{array}$} \\
\hline & QC & SIBFA & QC & SIBFA & QC & SIBFA & QC & SIBFA & QC & SIBFA & QC & SIBFA \\
\hline $\mathrm{Es} / \mathrm{E}_{\mathrm{MT} \mathrm{P}^{*}}$ & -68.9 & -69.6 & -70.1 & -70.0 & -101.7 & -99.9 & -302.8 & -297.1 & -349.2 & -342.0 & -52.2 & -51.4 \\
\hline $\mathrm{Ex} / \mathrm{E}_{\mathrm{rep}}$ & 26.2 & 25.1 & 28.3 & 24.8 & 38.4 & 40.4 & 54.4 & 52.2 & 58.7 & 55.2 & 27.3 & 25.8 \\
\hline $\mathrm{E}_{1}$ & -42.7 & -44.5 & -41.8 & -45.2 & -63.3 & -59.5 & -248.4 & -244.8 & -290.6 & -286.7 & -24.9 & -25.6 \\
\hline $\mathrm{E}_{\mathrm{pol}}$ & -36.6 & -35.6 & -46.0 & -42.8 & -61.2 & -64.4 & -60.8 & -53.5 & -71.8 & -66.9 & -74.6 & -71.8 \\
\hline $\mathrm{E}_{\mathrm{ct}}$ & -1.4 & -2.2 & -1.5 & -2.1 & -2.2 & -3.3 & -3.6 & -4.0 & -4.2 & -4.9 & -1.8 & -2.0 \\
\hline$\Delta \mathrm{E}$ & -80.7 & -82.3 & -89.3 & -90.1 & -126.6 & -127.2 & -312.8 & -302.3 & -366.5 & -358.6 & -101.3 & -99.4 \\
\hline
\end{tabular}

\begin{tabular}{|c|c|c|c|c|c|c|c|c|}
\hline & \multicolumn{2}{|c|}{$\begin{array}{l}\text { Imidazole } \\
d=2.00 \AA\end{array}$} & \multicolumn{2}{|c|}{$\begin{array}{l}\text { Pyridine } \\
d=1.90 \AA\end{array}$} & \multicolumn{2}{|c|}{$\begin{array}{c}\text { Thrimethylamine } \\
d=1.90 \AA\end{array}$} & \multicolumn{2}{|c|}{$\begin{array}{c}\text { Methanethiolate } \\
d=2.20 \AA\end{array}$} \\
\hline & $\mathrm{QC}$ & SIBFA & QC & SIBFA & $\mathrm{QC}$ & SIBFA & $Q C$ & SIBFA \\
\hline $\mathrm{Es} / \mathrm{E}_{\mathrm{MT} \mathrm{P}^{*}}$ & -97.1 & -92.9 & -92.3 & -90.5 & -96.7 & -97.3 & -318.3 & -318.3 \\
\hline $\mathrm{Ex} / \mathrm{E}_{\mathrm{rep}}$ & 34.6 & 31.2 & 51.5 & 52.2 & 60.3 & 58.6 & 67.6 & 69.9 \\
\hline $\mathrm{E}_{1}$ & -62.5 & -61.7 & -40.8 & -38.4 & -36.4 & -38.7 & -250.7 & -248.4 \\
\hline $\mathrm{E}_{\mathrm{pol}}$ & -63.6 & -64.1 & -75.9 & -77.8 & -70.3 & -72.1 & -83.7 & -77.1 \\
\hline $\mathrm{E}_{\mathrm{ct}}$ & -2.2 & -3.0 & -2.4 & -3.1 & -3.9 & -2.2 & -11.7 & -6.6 \\
\hline$\Delta \mathrm{E}$ & -128.3 & -128.8 & -119.1 & -119.3 & -110.7 & -112.9 & -346.0 & -332.1 \\
\hline
\end{tabular}

\begin{tabular}{|c|c|c|c|c|c|c|c|c|c|c|}
\hline & \multicolumn{2}{|c|}{$d=1.60 \AA$} & \multicolumn{2}{|c|}{$d=1.70 \AA$} & \multicolumn{2}{|c|}{$d=1.80 \AA$} & \multicolumn{2}{|c|}{$d=1.90 \AA$} & \multicolumn{2}{|c|}{$d=2.00 \AA$} \\
\hline & QC & SIBFA & QC & SIBFA & QC & SIBFA & QC & SIBFA & QC & SIBFA \\
\hline $\mathrm{Es} / \mathrm{E}_{\mathrm{MT} \mathrm{P}^{*}}$ & -125.7 & -122.5 & -112.5 & -110.4 & -101.7 & -99.9 & -92.7 & -90.9 & -85.0 & -83.2 \\
\hline$E x / E_{\text {rep }}$ & 89.5 & 98.6 & 58.6 & 62.9 & 38.4 & 40.4 & 25.2 & 26.1 & 16.6 & 16.9 \\
\hline$E_{1}$ & -36.2 & -23.9 & -53.9 & -47.4 & -63.3 & -59.5 & -67.4 & -64.8 & -68.4 & -66.2 \\
\hline $\mathrm{E}_{\mathrm{pol}}$ & -73.3 & -65.6 & -66.8 & -62.6 & -61.2 & -58.9 & -56.0 & -54.8 & -51.0 & -50.4 \\
\hline $\mathrm{E}_{\mathrm{ct}}$ & -2.7 & -3.4 & -2.5 & -3.4 & -2.2 & -3.3 & -1.9 & -3.1 & -1.8 & -2.9 \\
\hline$\Delta \mathrm{E}$ & -112.2 & -92.9 & -123.2 & -113.4 & -126.6 & -121.7 & -125.4 & -122.7 & -121.2 & -119.6 \\
\hline
\end{tabular}




\begin{tabular}{|c|c|c|c|c|c|c|c|c|c|c|c|c|}
\hline & \multicolumn{2}{|c|}{$\begin{array}{c}\mathrm{H}_{2} \mathrm{O} \\
d=2.30 \AA\end{array}$} & \multicolumn{2}{|c|}{$\begin{array}{l}\text { Methanol } \\
d=2.30 \AA\end{array}$} & \multicolumn{2}{|c|}{$\begin{array}{l}\text { Formamide } \\
d=2.10 \AA\end{array}$} & \multicolumn{2}{|c|}{$\begin{array}{l}\text { Fomate external } \\
\qquad d=2.30 \AA\end{array}$} & \multicolumn{2}{|c|}{$\begin{array}{l}\text { Formate bridge } \\
\qquad d=2.50 \AA\end{array}$} & \multicolumn{2}{|c|}{$\begin{array}{c}\text { Phenol } \\
d=2.20 \AA\end{array}$} \\
\hline & QC & SIBFA & QC & SIBFA & QC & SIBFA & QC & SIBFA & QC & SIBFA & QC & SIBFA \\
\hline $\mathrm{Es} / \mathrm{E}_{\mathrm{MTP}} \mathrm{P}^{*}$ & -51.0 & -50.6 & -48.7 & -49.9 & -84.0 & -83.2 & -237.0 & -230.9 & -279.5 & -265.7 & -41.6 & -39.9 \\
\hline $\mathrm{Ex} / \mathrm{E}_{\mathrm{rep}}$ & 18.1 & 19.8 & 18.9 & 19.5 & 40.4 & 46.4 & 23.2 & 26.4 & 22.6 & 22.6 & 31.4 & 34.1 \\
\hline$E_{1}$ & -33.0 & -30.8 & -29.9 & -30.4 & -43.6 & -36.8 & -213.8 & -204.5 & -256.9 & -243.1 & -10.2 & -5.8 \\
\hline $\mathrm{E}_{\mathrm{pol}}$ & -17.3 & -20.0 & -23.3 & -25.4 & -35.2 & -40.7 & -30.6 & -33.2 & -30.5 & -37.2 & -47.9 & -50.3 \\
\hline$E_{c t}$ & -4.6 & -3.8 & -6.1 & -3.7 & -11.7 & -10.2 & -13.3 & -8.5 & -13.2 & -8.0 & -8.8 & -4.5 \\
\hline $\mathrm{E}_{\mathrm{ct}^{*}}$ & -3.5 & -3.8 & -5.5 & -3.7 & -10.9 & -10.2 & -11.1 & -8.5 & -10.7 & -8.0 & -8.8 & -4.5 \\
\hline$\Delta \mathrm{E}$ & -54.9 & -54.6 & -59.3 & -59.5 & -91.3 & -87.7 & -257.7 & -246.2 & -300.6 & -288.3 & -66.9 & -60.7 \\
\hline$\Delta \mathrm{E}^{*}$ & -53.8 & -54.6 & -58.6 & -59.5 & -90.5 & -87.7 & -255.5 & -246.2 & -298.0 & -288.3 & -66.9 & -60.7 \\
\hline
\end{tabular}

\begin{tabular}{|c|c|c|c|c|c|c|c|c|}
\hline & \multicolumn{2}{|c|}{$\begin{array}{l}\text { Imidazole } \\
d=2.30 \AA\end{array}$} & \multicolumn{2}{|c|}{$\begin{array}{c}\text { Pyridine } \\
d=2.30 \AA\end{array}$} & \multicolumn{2}{|c|}{$\begin{array}{c}\text { Trimethylamine } \\
d=2.50 \AA\end{array}$} & \multicolumn{2}{|c|}{$\begin{array}{l}\text { Methanethiolate } \\
\qquad d=2.50 \AA\end{array}$} \\
\hline & QC & SIBFA & QC & SIBFA & QC & SIBFA & QC & SIBFA \\
\hline $\mathrm{Es} / \mathrm{E}_{\mathrm{MT} \mathrm{P}^{*}}$ & -76.4 & -72.5 & -63.4 & -60.9 & -47.5 & -50.4 & -295.3 & -274.8 \\
\hline $\mathrm{Ex}_{\mathrm{fep}}$ & 37.2 & 34.4 & 38.1 & 35.8 & 20.0 & 22.4 & 79.4 & 76.2 \\
\hline$E_{1}$ & -39.2 & -38.2 & -25.3 & -25.1 & -27.5 & -28.0 & -215.9 & -198.7 \\
\hline $\mathrm{E}_{\mathrm{pol}}$ & -38.2 & -45.2 & -42.3 & -48.6 & -34.7 & -43.9 & -44.3 & -68.2 \\
\hline$E_{c t}$ & -10.3 & -5.0 & -10.8 & -5.0 & -7.9 & -2.0 & -25.5 & -18.8 \\
\hline $\mathrm{E}_{\mathrm{ct}^{\star}}$ & -9.9 & -5.0 & -10.5 & -5.0 & -7.7 & -2.0 & -22.5 & -18.8 \\
\hline$\Delta \mathrm{E}$ & -87.7 & -88.4 & -78.4 & -78.7 & -70.1 & -73.9 & -285.6 & -285.6 \\
\hline$\Delta \mathrm{E}^{*}$ & -87.3 & -88.4 & -78.1 & -78.7 & -69.9 & -73.9 & -282.7 & -285.6 \\
\hline
\end{tabular}

Values $(\mathrm{kcal} / \mathrm{mol})$ of the $\mathrm{QC}$ and SIBFA interaction energies and their contributions

$\triangle E^{*}$ BSSE corrected total interaction energy

\begin{tabular}{|c|c|c|c|c|c|c|c|c|c|c|}
\hline & \multicolumn{2}{|c|}{$d=2.10 \AA$} & \multicolumn{2}{|c|}{$d=2.20 \AA$} & \multicolumn{2}{|c|}{$d=2.30 \AA$} & \multicolumn{2}{|c|}{$d=2.40 \AA$} & \multicolumn{2}{|c|}{$d=2.50 \AA$} \\
\hline & QC & SIBFA & QC & SIBFA & QC & SIBFA & $\mathrm{QC}$ & SIBFA & QC & SIBFA \\
\hline $\mathrm{Es} / \mathrm{E}_{\mathrm{MTP}}$ & -264.5 & -258.0 & -249.6 & -243.5 & -237.0 & -230.9 & -226.3 & -219.8 & -216.9 & -209.9 \\
\hline Ex/E & 52.2 & 59.2 & 35.0 & 39.5 & 23.2 & 26.4 & 15.3 & 17.8 & 10.0 & 12.0 \\
\hline $\mathrm{E}_{1}$ & -212.3 & -198.8 & -214.6 & -204.0 & -213.8 & -204.5 & -211.0 & -202.0 & -206.9 & -197.9 \\
\hline $\mathrm{E}_{\mathrm{pol}}$ & -36.9 & -39.0 & -33.6 & -36.1 & -32.8 & -33.2 & -27.9 & -30.5 & -25.4 & -27.9 \\
\hline $\mathrm{E}_{\mathrm{ct}}$ & -18.3 & -12.5 & -15.3 & -10.3 & -13.3 & -8.5 & -12.1 & -6.9 & -11.4 & -5.7 \\
\hline $\mathrm{E}_{\mathrm{ct}^{*}}$ & -16.0 & -12.5 & -13.0 & -10.3 & -11.1 & -8.5 & -9.9 & -6.9 & -9.3 & -5.7 \\
\hline$\Delta \mathrm{E}$ & -265.2 & -250.3 & -261.2 & -250.4 & -257.7 & -246.2 & -248.8 & -239.4 & -241.5 & -231.5 \\
\hline
\end{tabular}

Values $(\mathrm{kcal} / \mathrm{mol})$ of the QC and SIBFA interaction energies and their contributions

$\triangle \mathrm{E}^{*} \mathrm{BSSE}$ corrected total interaction energy 
Table XI.b. Monoligated $\mathrm{Ca}^{2+}$ complexes: Formate bridge.

\begin{tabular}{|c|c|c|c|c|c|c|c|c|c|c|}
\hline & \multicolumn{2}{|c|}{$d=2.30 \AA$} & \multicolumn{2}{|c|}{$d=2.40 \AA$} & \multicolumn{2}{|c|}{$d=2.50 \AA$} & \multicolumn{2}{|c|}{$d=2.60 \AA$} & \multicolumn{2}{|c|}{$d=2.70 \AA$} \\
\hline & QC & SIBFA & QC & SIBFA & QC & SIBFA & QC & SIBFA & QC & SIBFA \\
\hline $\mathrm{Es} / \mathrm{E}_{\mathrm{MTP}} \mathrm{P}^{*}$ & -309.1 & -293.3 & -293.3 & -278.8 & -279.5 & -265.7 & -268.7 & -256.3 & -257.3 & -243.9 \\
\hline$E x / E_{\text {rep }}$ & 50.5 & 50.7 & 34.0 & 33.9 & 22.6 & 22.6 & 15.7 & 16.5 & 10.1 & 10.4 \\
\hline$E_{1}$ & -258.6 & -242.5 & -259.3 & -244.9 & -256.9 & -243.1 & -253.0 & -239.8 & -247.2 & -233.5 \\
\hline$E_{\text {pol }}$ & -37.3 & -43.7 & -33.7 & -40.4 & -27.9 & -37.2 & -27.9 & -34.6 & -25.1 & -31.2 \\
\hline$E_{c t}$ & -16.1 & -11.9 & -14.3 & -9.8 & -13.2 & -8.0 & -12.7 & -6.8 & -12.4 & -5.4 \\
\hline $\mathrm{E}_{\mathrm{ct}^{*}}$ & -13.2 & -11.9 & -11.6 & -9.8 & -10.7 & -8.0 & -10.3 & -6.8 & -10.2 & -5.4 \\
\hline$\Delta \mathrm{E}^{*}$ & -309.1 & -298.2 & -304.6 & -295.2 & -298.0 & -288.3 & -291.2 & -281.2 & -282.5 & -270.1 \\
\hline
\end{tabular}

Values $(\mathrm{kcal} / \mathrm{mol})$ of the QC and SIBFA interaction energies and their contributions

$\Delta \mathrm{E}^{*} \mathrm{BSSE}$ corrected total interaction energy

\begin{tabular}{|c|c|c|c|c|c|c|}
\hline & \multicolumn{4}{|c|}{$\left[\mathrm{Mg}\left(\mathrm{H}_{2} \mathrm{O}\right)_{4}\right]^{2+}$} & \multirow{2}{*}{\multicolumn{2}{|c|}{$\begin{array}{c}{[\mathrm{Mg}(\mathrm{H} 2 \mathrm{O}) 6]^{2+}} \\
d=2.30 \AA\end{array}$}} \\
\hline & Pyramid & $=2.10 \AA$ & Planar & $2.20 \AA$ & & \\
\hline & QC & SIBFA & QC & SIBFA & QC & SIBFA \\
\hline $\mathrm{Es} / \mathrm{E}_{\mathrm{MTP}} \mathrm{P}^{*}$ & -209.0 & -210.0 & -195.0 & -195.4 & -257.9 & -258.1 \\
\hline$E_{x} / E_{\text {rep }}$ & 42.2 & 38.9 & 32.8 & 29.4 & 35.0 & 31.0 \\
\hline$E_{1}$ & -166.8 & -171.1 & -162.2 & -166.0 & -222.9 & -227.1 \\
\hline$E_{p o l}$ & -81.2 & -76.5 & -72.7 & -68.6 & -73.6 & -69.1 \\
\hline $\mathrm{E}_{\mathrm{pol}^{*}}$ & -93.0 & -97.8 & -83.4 & -78.6 & -90.7 & -85.1 \\
\hline $\mathrm{E}_{\mathrm{ct}}$ & -3.6 & -3.0 & -3.6 & -3.2 & -4.2 & -3.4 \\
\hline $\mathrm{E}_{\mathrm{ct}^{*}}$ & -3.5 & -3.0 & -3.4 & -3.2 & -3.9 & -3.4 \\
\hline$\Delta \mathrm{E}$ & -251.8 & -250.7 & -238.7 & -237.9 & -301.0 & -299.6 \\
\hline$\Delta \mathrm{E}^{\star}$ & -251.6 & -250.7 & -238.5 & -237.9 & -300.7 & -299.6 \\
\hline
\end{tabular}

\begin{tabular}{|c|c|c|c|c|c|c|}
\hline \multicolumn{7}{|c|}{ Table XII.b. Polyligated $\mathrm{Mg}^{2+}$ complexes. } \\
\hline & \multicolumn{2}{|c|}{$\begin{array}{c}{\left[\mathrm{Mg}(\text { Imidazoles })_{3}\right]^{2+}} \\
d=2.11 \AA\end{array}$} & \multicolumn{2}{|c|}{$\begin{array}{c}{\left[\mathrm{Mg}(\text { Imidazoles })_{4}\right]^{2+}} \\
d=2.11 \AA\end{array}$} & \multicolumn{2}{|c|}{$[2 \mathrm{Mg}(\mathrm{DDE})]^{+}$} \\
\hline & QC & SIBFA & QC & SIBFA & QC & SIBFA \\
\hline $\mathrm{Es} / \mathrm{E}_{\mathrm{MT} \mathrm{P}^{*}}$ & -244.7 & -241.5 & -318.9 & -315.7 & -849.4 & -847.2 \\
\hline $\mathrm{Ex} / \mathrm{E}_{\mathrm{rep}}$ & 73.5 & 65.2 & 99.8 & 89.9 & 119.0 & 110.2 \\
\hline $\mathrm{E}_{1}$ & -171.2 & -176.3 & -219.0 & -225.8 & -730.3 & -736.9 \\
\hline $\mathrm{E}_{\mathrm{pol}}$ & -117.8 & -112.9 & -127.9 & -121.2 & -159.9 & -137.2 \\
\hline $\mathrm{E}_{\mathrm{pol}^{*}}$ & -140.6 & -138.7 & -163.5 & -162.8 & -175.6 & -137.2 \\
\hline $\mathrm{E}_{\mathrm{ct}}$ & -5.1 & -3.0 & -6.6 & -2.5 & -13.6 & -9.4 \\
\hline $\mathrm{E}_{\mathrm{ct}^{*}}$ & -4.4 & -3.0 & -5.5 & -2.5 & -13.1 & -9.4 \\
\hline$\Delta \mathrm{E}$ & -293.4 & -292.2 & -352.5 & -349.5 & -903.3 & -883.6 \\
\hline$\Delta \mathrm{E}^{*}$ & -292.8 & -292.2 & -351.4 & -349.5 & -902.8 & -883.6 \\
\hline
\end{tabular}




\begin{tabular}{|c|c|c|c|c|c|c|c|c|}
\hline & \multicolumn{2}{|c|}{$\left[\mathrm{Ca}(\mathrm{H} 2 \mathrm{O})_{6+2}\right]^{2+}$} & \multicolumn{2}{|c|}{$\left[\mathrm{Ca}(\mathrm{H} 2 \mathrm{O})_{7+1}\right]^{2+}$} & \multicolumn{2}{|c|}{$\left[\mathrm{Ca}(\mathrm{H} 2 \mathrm{O})_{8}\right]^{2+}$} & \multicolumn{2}{|c|}{$[\mathrm{Ca}(\mathrm{DDDTE})]^{2-}$} \\
\hline & QC & SIBFA & QC & SIBFA & QC & SIBFA & QC & SIBFA \\
\hline $\mathrm{Es} / \mathrm{E}_{\mathrm{MTP}}$ & -262.4 & -263.2 & -278.1 & -282.3 & -275.0 & -281.6 & -558.6 & -566.9 \\
\hline $\mathrm{Ex} / \mathrm{E}_{\mathrm{rep}}$ & 103.0 & 118.2 & 95.1 & 109.1 & 94.6 & 109.1 & 87.0 & 113.5 \\
\hline $\mathrm{E}_{1}$ & -159.3 & -145.0 & -183.0 & -173.2 & -180.4 & -172.5 & -471.6 & -453.4 \\
\hline$E_{\text {pol }}$ & -59.6 & -69.9 & -53.1 & -58.5 & -50.1 & -54.4 & -35.4 & -21.0 \\
\hline $\mathrm{E}_{\mathrm{pol}^{*}}$ & -62.3 & -84.7 & -56.0 & -75.4 & -53.8 & -72.9 & -29.8 & -24.6 \\
\hline$E_{c t}$ & -20.0 & -14.4 & -15.4 & -13.2 & -14.3 & -12.5 & -15.3 & -19.2 \\
\hline $\mathrm{E}_{\mathrm{ct}^{*}}$ & -11.0 & -14.4 & -6.2 & -13.2 & -5.1 & -12.5 & -3.2 & -19.2 \\
\hline$\Delta \mathrm{E}$ & -238.9 & -229.3 & -251.4 & -244.9 & -244.8 & -239.4 & -522.3 & -493.5 \\
\hline$\Delta \mathrm{E}^{*}$ & -230.0 & -229.3 & -242.2 & -244.9 & -235.6 & -239.4 & -510.2 & -493.5 \\
\hline
\end{tabular}

